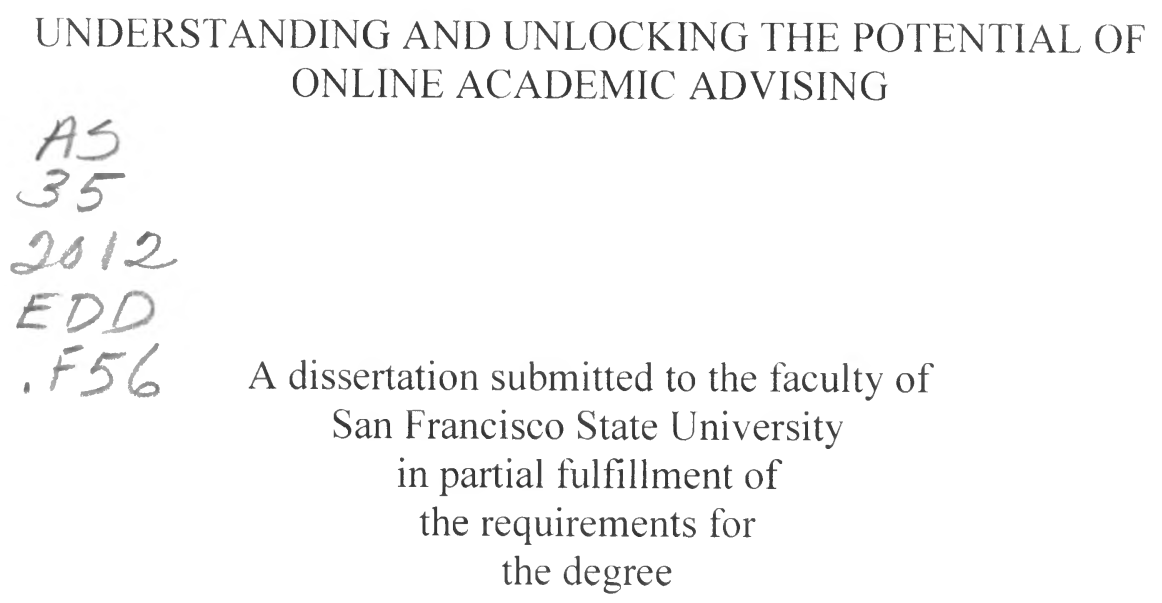

Doctor of Education

In

Educational Leadership

by

Jefferson Lee Flowers

San Francisco, California

August 2012 
Copyright by

Jefferson Lee Flowers

2012 


\section{CERTIFICATION OF APPROVAL}

I certify that I have read Understanding and Unlocking the Potential of Online Academic Advising by Jefferson Lee Flowers, and that in my opinion this work meets the criteria for approving a dissertation submitted in partial fulfillment of the requirements for the degree: Doctor of Education in Educational Leadership at San Francisco State University.
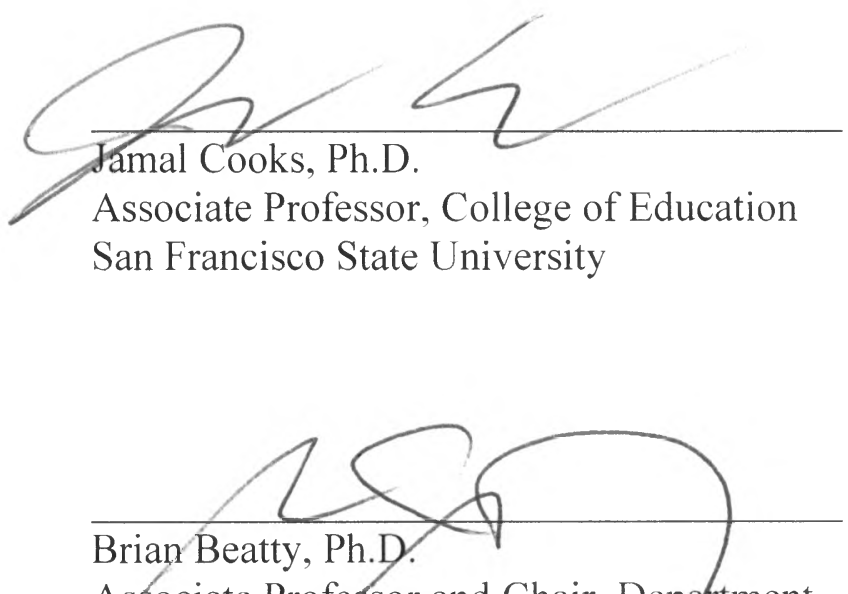

Associate Professor and Chair, Depzrtment

of Instructional Technologies

Graduate College of Education

San Francisco State University

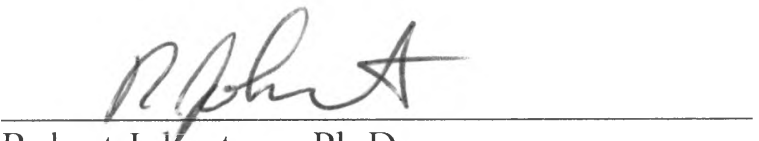

Robert Joknstone, Ph.D.

Dean of Planning, Research, and Institutional Effectiveness

Skyline College 


\title{
UNDERSTANDING AND UNLOCKING THE POTENTIAL OF ONLINE ACADEMIC ADVISING
}

\author{
Jefferson Lee Flowers \\ San Francisco State University \\ 2012
}

Student support services, such as academic advising, promote college student retention and increased graduation rates. As educational institutions continue to face budgetary uncertainties, academic advising services are facing cuts that threaten their ability to provide student support. Online solutions are being advanced at many institutions, as they offer potential amplification of dwindling resources. Although online education has been heavily researched, online academic advising is not as well studied. This study sought to understand the core components of academic advising and applied these findings to the creation of an online academic advising website, a virtual intelligent counselor (VIC). VIC was then used to probe student perceptions of online academic advising. A mixed-methods multiphase research design, using both a pre-validated survey instrument and student interviews, permitted comparison of student perceptions of this academic advising website to perceptions of an actual advising system at a local area community college. Student perceptions of the website demonstrated support for peer-generated educational roadmaps and other design elements incorporated into VIC. Additionally, the usefulness and potential of this website as a planning tool was seen in student interviews. Online tools hold the promise of delivering advising services in financially difficult times. and the importance of proper design has been shown to be a key to unlocking this great challenge.

I certify that the Abstract is a correct representation of the content of this dissertation.
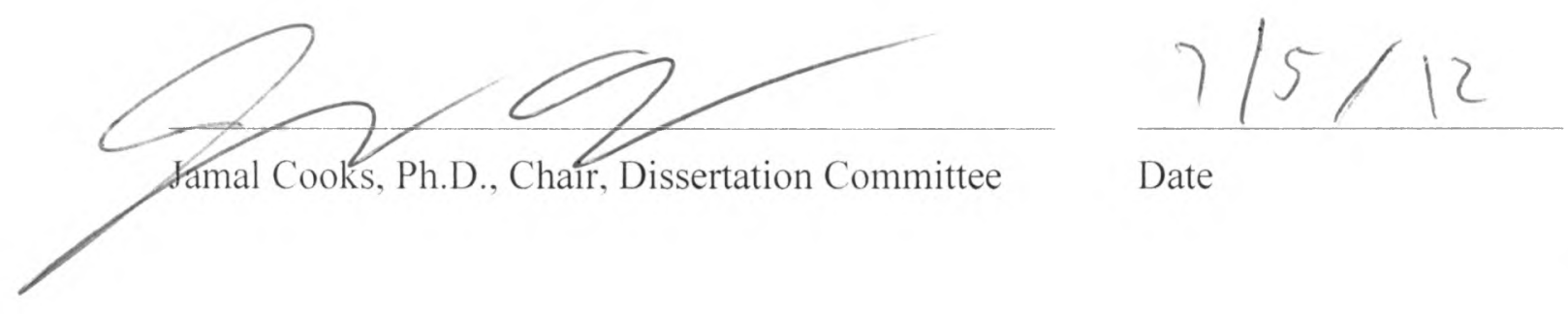

Date 


\section{ACKNOWLEDGEMENTS}

I owe a great deal of thanks to the people who made this work possible.

Jamal Cooks, Ph.D.

Brian Beatty, Ph.D.

Robert Johnstone, Ph.D.

Robert Gabriner, Ed.D.

Dayo Diggs, Ed.D.

Yvonne Tang

Ed and Sue Kroll

Sue Flowers

John Flowers

Jason Flowers

Terra Flowers

Ana Flowers

Ralegh Flowers

Marlowe Flowers 


\section{TABLE OF CONTENTS}

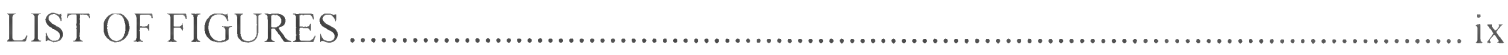

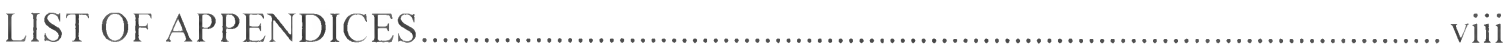

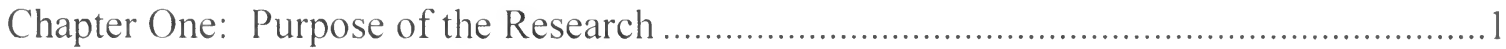

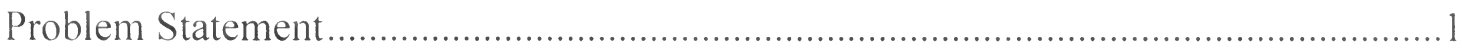

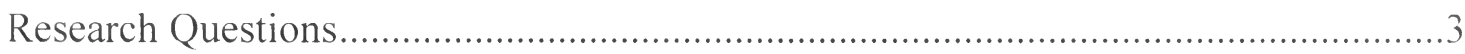

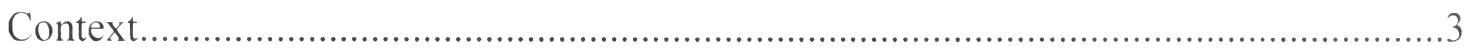

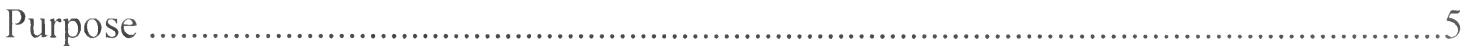

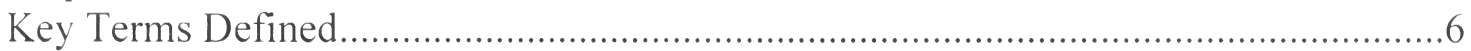

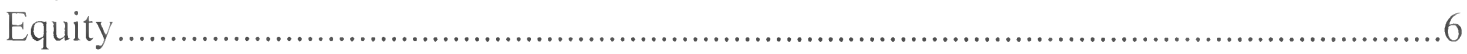

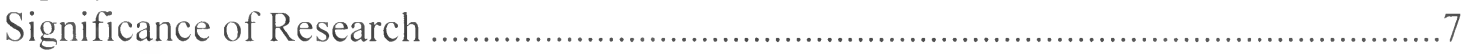

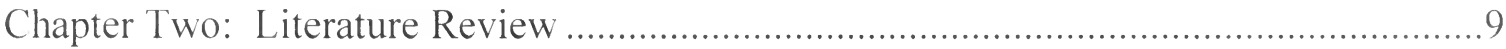

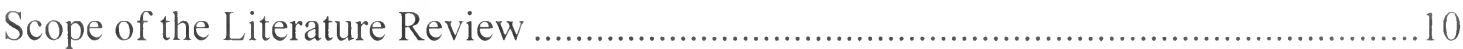

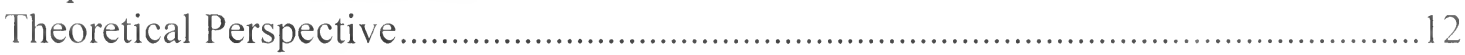

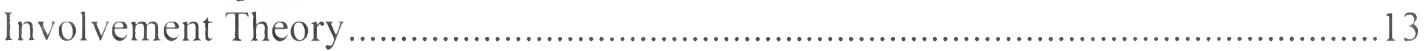

Persistence-Withdrawal Model ......................................................................... 16

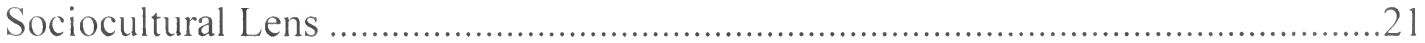

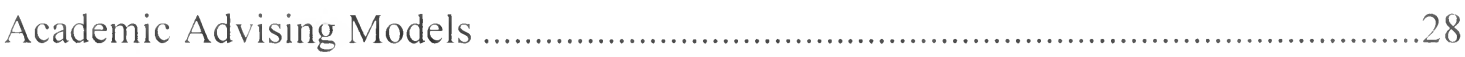

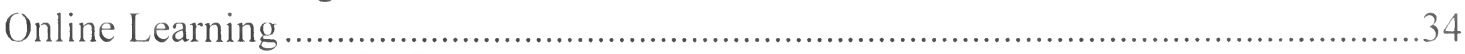

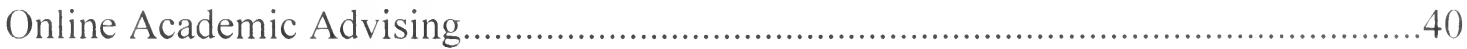

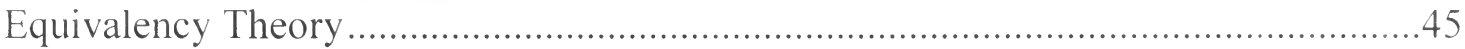

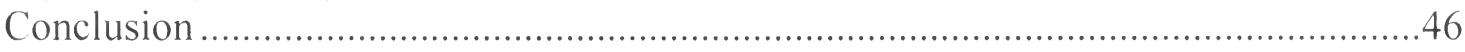

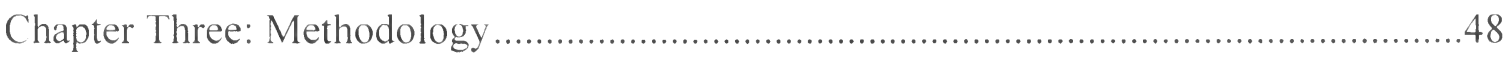

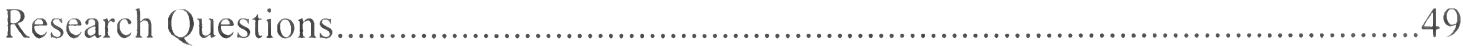

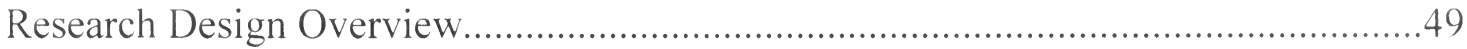

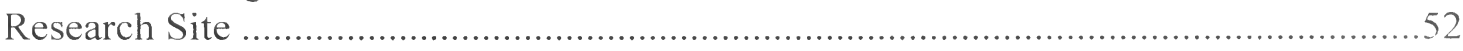

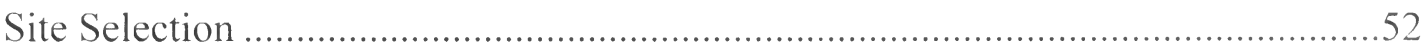

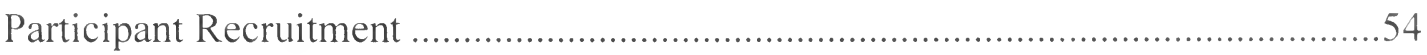

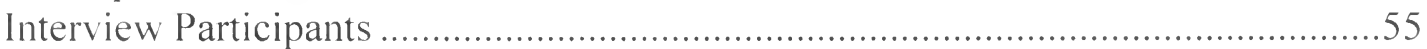

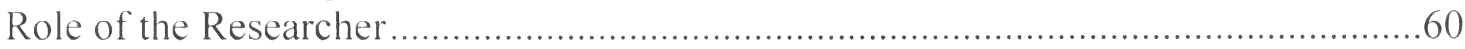

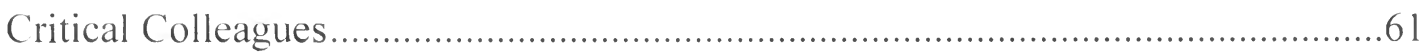

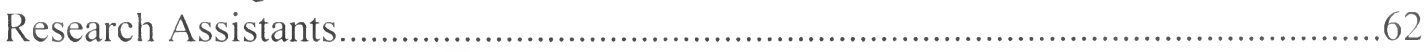

Ethics and the Protection of the Human Subjects........................................................65

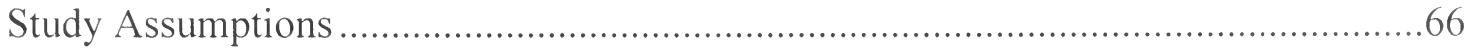




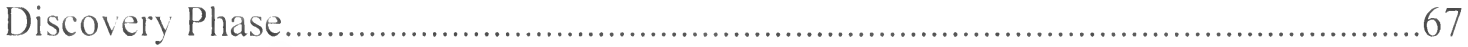

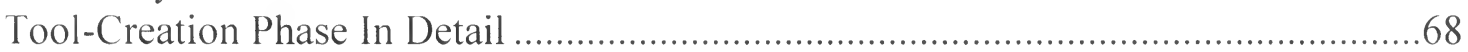

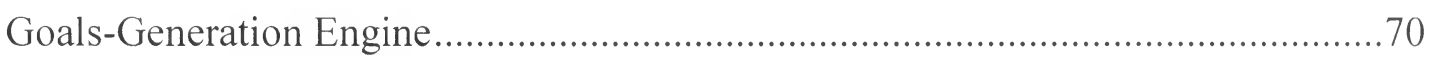

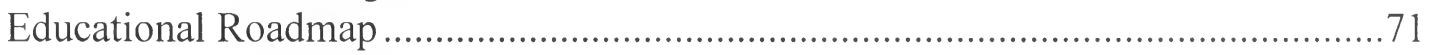

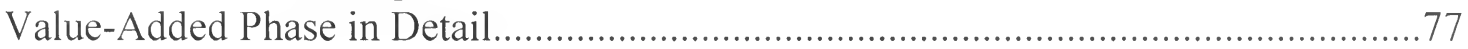

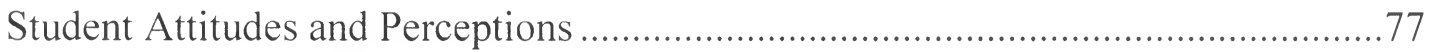

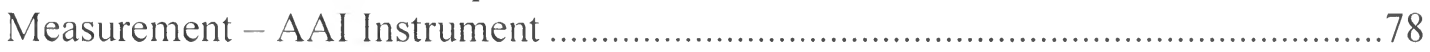

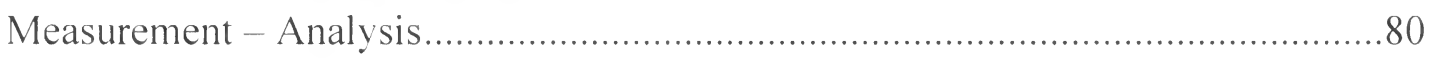

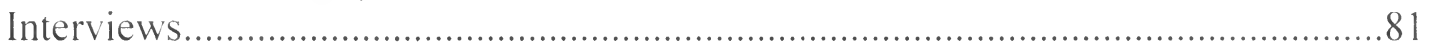

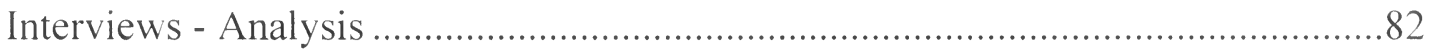

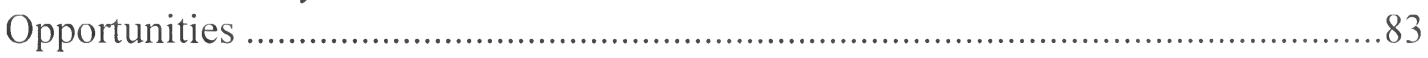

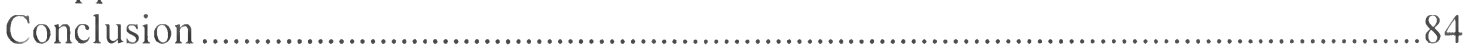

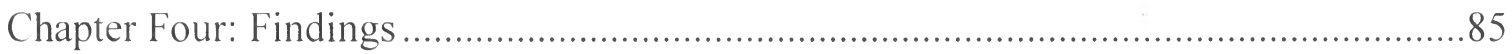

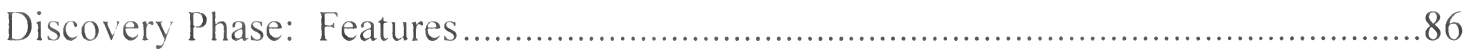

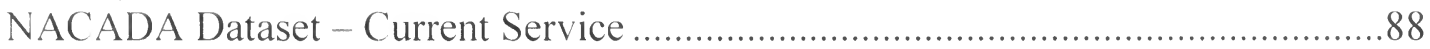

Custom Survey - Service Needs........................................................................

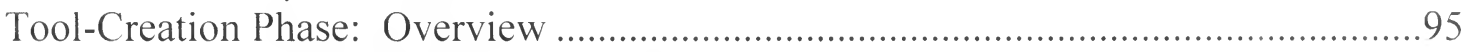

Value-Added Phase: Quantitative Findings..............................................................95

AAI Part 1 - Developmental-Prescriptive Advising (DPA) ....................................100

AAI Part 1 - Personalizing Education (PE) ……………....................................... 103

AAI Part 1 - Academic Decision Making (ADM) ………….................................107

AAI Part 1 - Selecting Courses (SC).................................................................. 110

Influence of Goals on the AA Experience ...........................................................113

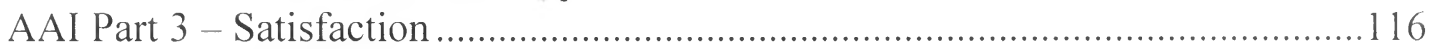

Value-Added Phase: Interview Findings ................................................................117

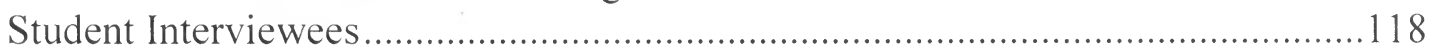

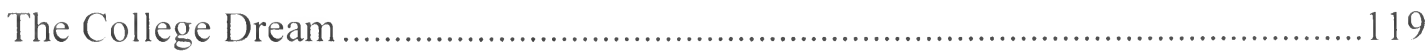

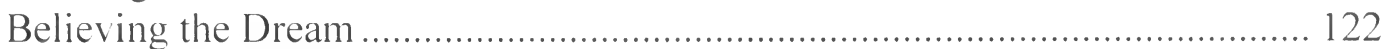

Personal Goals - Personal Reasons ............................................................. 123

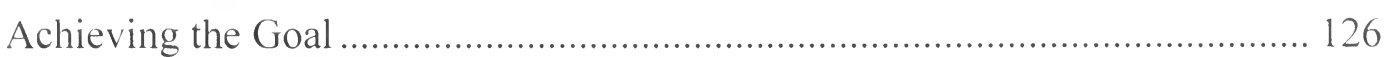

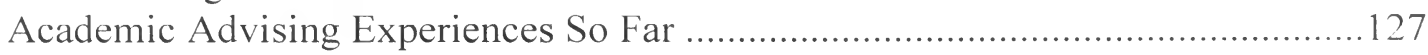

Seeking Academic Advising Help .............................................................. 129

Belief in the Help Provided ........................................................................ 132

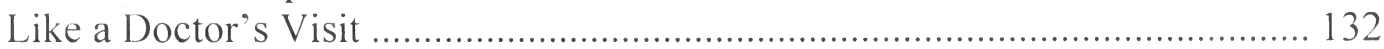

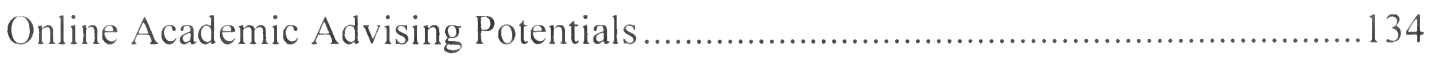

Using Current Online Systems …………………………………………..... 135

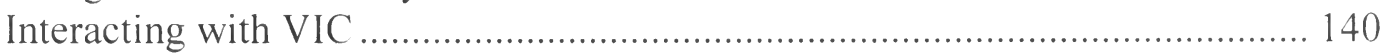

Thoughts Around Roadmaps ....................................................................... 141

Potentials - Efficiency and Effectiveness................................................................142 


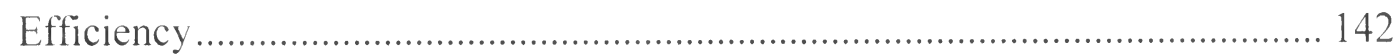

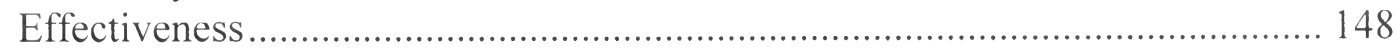

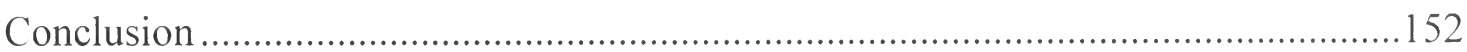

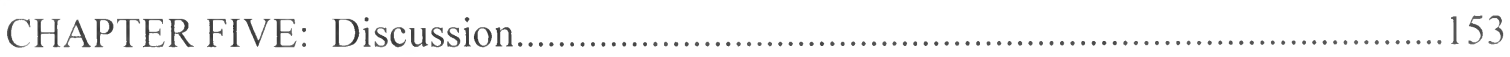

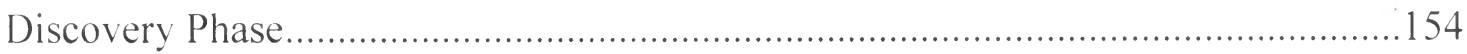

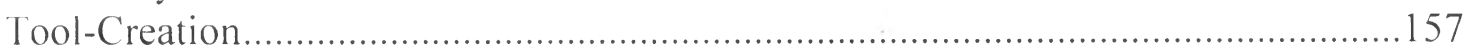

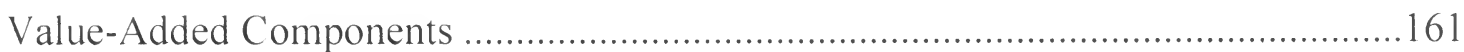

Aspects of Academic Advising: Comparing The Two Systems..............................162

Influence of Goals on the AA Experience .............................................................. 165

Satisfaction With The Two Advising Systems ……………………….................167

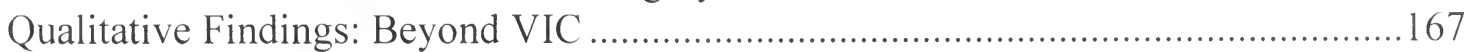

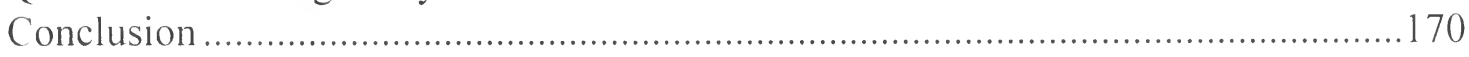

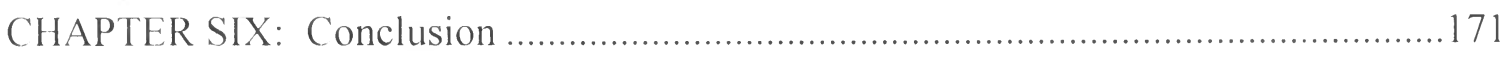

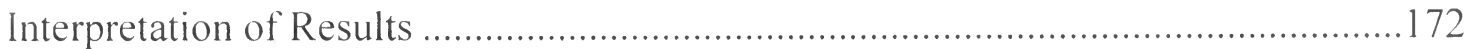

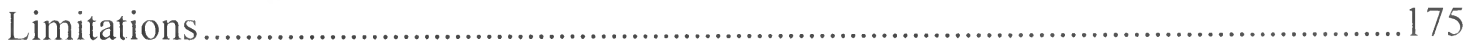

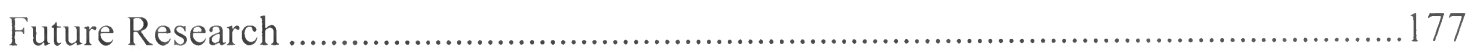

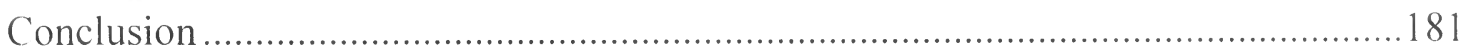

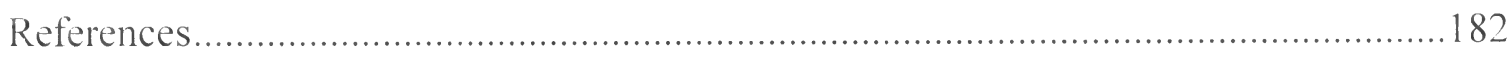

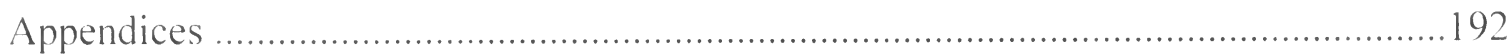




\section{LIST OF FIGURES}

Figure Page

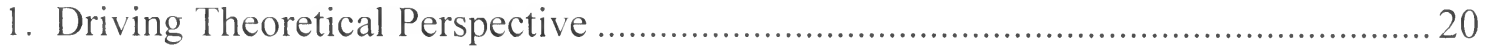

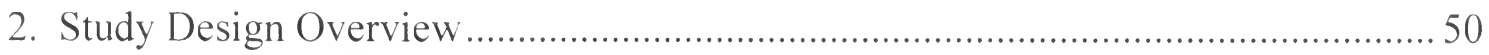

3. Student Ethnicity Statewide and at Peninsula College .............................................53

4. Student Age Statewide and at Peninsula College (PC) ........................................ 54

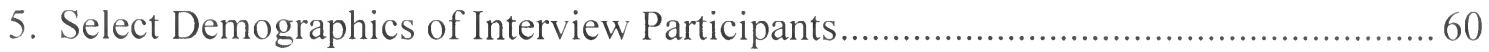

6. Questions Asked of the Goals-Generation Engine ............................................ 71

7. Majors Considered for Roadmaps with Institutional Titles by Institution ................ 74

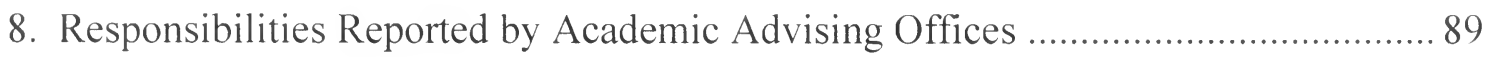

9. Demographics of Peninsula College student participants in a custom survey instrument to probe features necessary for an online academic advising experience,

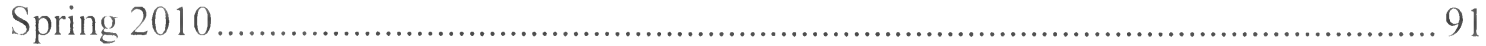

10. Relative Priority of Online Academic Advising Components ........................... 93

11. Demographics of Peninsula College Student Participants in the AAI to Probe

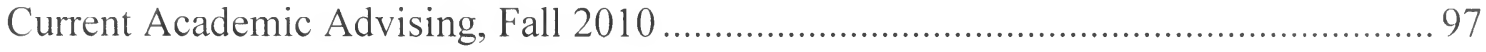

12. Demographics of Peninsula College Student Participants in the AAI to Probe Online Academic advising Experiences using VIC, Fall 2011 ................................... 99

13. Developmental-Prescriptive Advising (DPA) Experiences Currently at Peninsula College.

14. Developmental-Prescriptive Advising (DPA) Experiences using the Online

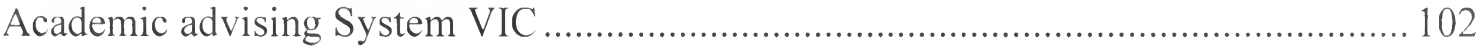

15. Personalizing Education (PE) Experiences Currently at Peninsula College ......... 104

16. Personalizing Education (PE) From the Online Academic Advising Experience. 105

17. Academic Decision-making (ADM) Experience at Peninsula College ................. 108

18. Academic Decision-making (ADM) From the Online Academic Advising

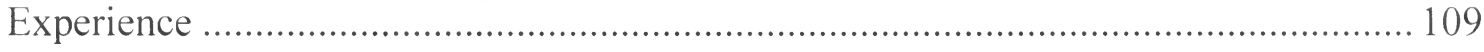

19. Selecting Courses (SC) Experience of Students Rating Services at Peninsula College. 
Figure

20. Selecting Courses (SC) Experiences of Students Rating the Online Academic Advising Experience of VIC 112

21. Association of Having a Goal With Perceptions of Academic Advising (AAI Part 1 Scores) for Peninsula College and VIC Participants 114

22. Comparisons of Peninsula College (PC) and VIC Satisfaction Scores ................ 117

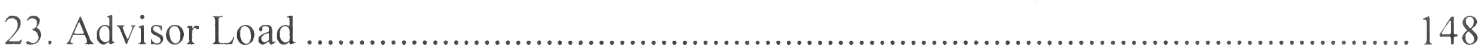

24. Districts Spending More Than One Standard Deviation from the Mean ............. 151 


\section{LIST OF APPENDICES}

Appendix

Page

1: Custom Survey Instrument of Student Services .................................................... 193

2: Unmodified Academic Advising Inventory (AAI) Instrument …………….......... 199

3: Modified Academic Advising Inventory (AAI) Instrument ..................................... 203

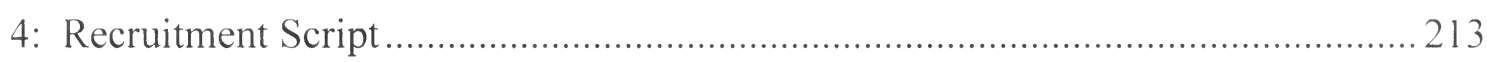

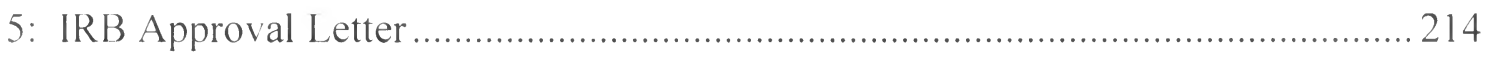

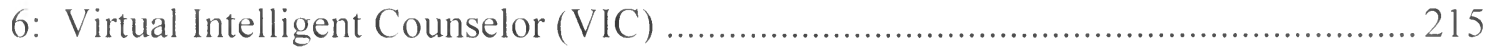

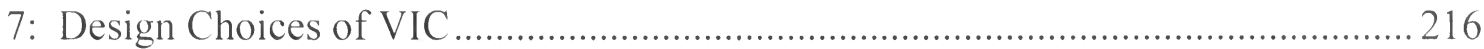

8: Detailed Explanation of Design Choices for VIC ……………………………......2217

9: Select Demographics of Student Research Assistants........................................... 218

10: Document Control and Worksheets Used to Generate Roadmaps .........................219

11: Protocol Used for Roadmap Generation.............................................................. 220

12: Rapid Scanning System to Encode Peninsula College Course Catalogue ............ 221

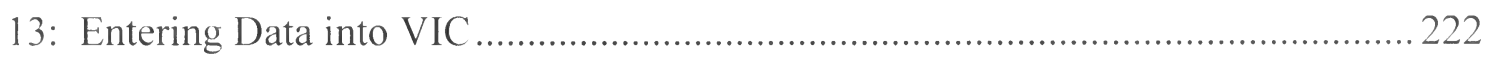

14: Flowchart of Intended Use of VIC Roadmaps Towards a SEP ..............................223

15: Example Structure of a User Initiated Roadmap .................................................. 224

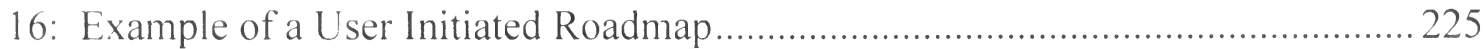

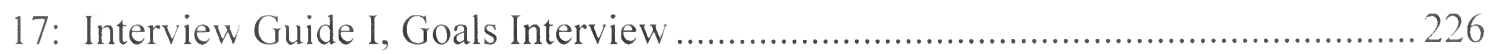

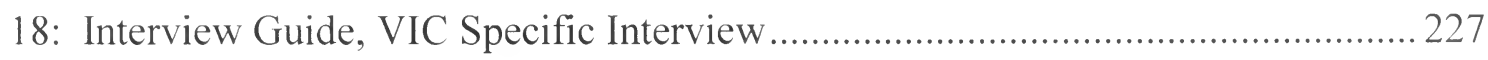

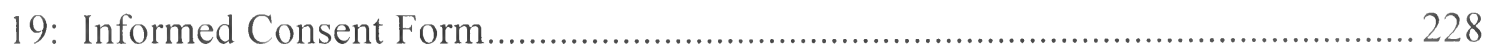


Chapter One: Purpose of the Research

Funding for California's community college (CCC) full-time equivalent students (FTES) is well below national averages (Hayward, Jones, McGuinness Jr., Timar, \& Shulock, 2004; Mortenson, 2009) and drastically below that of California's other educational institutions (Sengupta \& Jepsen. 2006). Along with this lack of proper funding, a weakening state economy (Ellwood, 2009; Schlisserman, 2009) further threatens massive budget reductions (O'Connell, 2009). These reductions to college budgets threaten the ability of institutions to provide student support services, such as academic advising.

\section{Problem Statement}

Academic advising services have been shown to increase the rates of college student retention and graduation (Eisen, 2009; Webber \& Ehrenberg, 2010). Changes in academic advising can also directly affect students" success in college (Tinto, 1975). The dwindling of advising services are of particular concern to those individuals that may lack the necessary social capital (Coleman, 1988; Portes, 1998) with which to successfully navigate the college experience, as they are now having to traverse this unfamiliar terrain without structures to provide external support (Croninger \& Lee, 2001).

The goal of the present study is to determine how online forms of academic advising can be developed and integrated within a community-college environment. With decreasing levels of academic services available, is it possible that this service can 
be delivered in online formats and still provide necessary supports to which students are accustomed? This study will seek first to identify the components of existing advising programs and then to determine the feasibility of providing these to students through a web experience.

Although there is a great amount of research on variables contributing to student success and persistence (Tinto, 1998), there is a lack of research into the dynamics that diminished academic advising can have on student success and persistence. It will be necessary to determine what constitutes an exemplar of this service in order to develop an initial understanding as to what other forms advising might take. In turn, understanding the nature of the coupling between these service components and student outcomes will allow for a more nuanced understanding of how these service elements can be provided in alternative delivery formats. In addition, this study can help in understanding how these elements can be further refined to respond to the needs of all students, including non-traditional students (Bean, 1985). 


\section{Research Questions}

During the course of the present research, the following questions emerged.

1. How can an academic advising website be created with features that incorporate current theories in order to foster an experience that is equivalent to modern praxis?

2. What are student perceptions of an academic advising website that assists in the co-creation of academic goals and the generation of education-planning instruments?

In order to address these two research questions, a multi-phase mixed methods design was employed. The first of these questions was addressed with an exhaustive research of current theory and praxis of academic advising. This informed the creation of an online website to act as a test platform. The second question was then probed using this proto-academic advising website.

\section{Context}

Academic advising services at CCC are inadequate, and this inadequacy arises from a multitude of failures inherent in how this service is currently provided. The total level of counseling services provided has been steadily declining at CCC. This is a direct result of these institutions" attempting to grapple with shrinking budgets, due in large part to the weakening economy and lack of state support. 
It is very possible that students are being given incorrect or incomplete advice. This can partly be explained by advising professionals' receiving decreased professional development due to shrinking budgets. This phenomenon may also be a consequence of institutions' moving towards ever-greater reliance on adjuncts to provide these services (L. del Mundo, personal communication, February 23, 2010). Adjuncts have few resources (Grubb, 2001) to impart to students and with which to assist in their development (Astin, 1999).

Additionally, students in California face a uniquely complex articulation system, in which each individual college must negotiate the specifics as to how classes will be transferred between institutions. The lack of a centralized statewide office or standard protocols has made overly-complicated advising necessary for these students. This can have a compounding negative effect should an error arise within a student education plan (SEP). While other systems have model plans for advisors and students to follow, California's articulation agreements are between individual schools. Recent legislation from the California senate, SB1440, seeks to recalibrate these articulation agreements by introducing increased uniformity across campuses.

Finally, students themselves may not have the social capital with which to properly gain access to or navigate the present system (Coleman, 1988), and may lack the ability properly to judge the advice provided to them. This is particularly true of those students who may not have a reference point with which to judge the merit or quality of these efforts. In all of these scenarios, the result is the same: sub-optimal 
student performance. The positive effects of these programs on students' academic success has been established (Kulik, Kulik, \& Shwalb, 1983), yet these programs and the support they offer are diminishing.

\section{Purpose}

This study used a mixed methods approach to determine what practices form the core components of academic counseling at $\mathrm{CCC}$, and whether these are readily transferable into online formats. This research first used a meta-study to determine what academic counseling variables influence student success and persistence. Once the major variables that go into academic advising were isolated, these were encoded in a dynamically-driven computer interface and presented to select students for their use.

The study then used both statistical and qualitative methods to ask about the effectiveness of this form of guidance for students, especially for those who were the first in their family to attend college or were non-traditional students. An analysis of grades and other traditional metrics of student performance was used to assess effectiveness. Surveys were also used to ask how students view this method of service delivery. It is vitally important to give weight to student voices, detailing the challenges they face as well as how these tools affect them as they pursue their educational goals. Personal interviews with students were conducted in order fully to understand how online academic advising instruments can be refined. Individual interviewing also probed how these students saw themselves and how these services influenced their perceptions. 


\section{Key Terms Defined}

The following are terms that will be employed within this study.

Academic advising: Services that help a student develop a goal (e.g., developing a specific major or concentration of study at college) and that allow for the creation of educational planning instruments.

Developmental academic advising: A teaching activity in which the advisee and advisor co-create an educational goal and pathway to achieve this outcome.

Equivalent online experience: An online educational or learning experience that has been perceived as similar to more traditional delivery mechanisms (Simonson, 1999; Simonson, Schlosser, \& Hanson, 1999), based on studies using pre-validated survey instruments and student interview data.

Prescriptive academic advising: Advising that follows a rigidly structured format with little collaboration between advisee and advisor.

Student success: Community college persistence and graduation towards the goal of transfer into an intended program of study at either a four-year institution or a certificate program.

\section{Equity}

The present research seeks to determine a means of helping the large numbers of students that do not persist in order to help them to matriculate through college. This research seeks to understand: 1) how academic advising is connected to students' overall involvement and development, as well as 2) how best to use the amplifying 
effects of the online space to assist students. Providing online forms of academic advising services permits fresh mechanisms for transmitting key information and could help provide students with the necessary tools for their educational planning and ultimate success.

\section{Significance of Research}

California community college budgets are facing tremendous pressures due to dwindling state support. These gaps are being addressed through significant reductions at many colleges, including decreases to student support services, such as academic advising. This may result in disproportionately adverse effects upon students who may lack the necessary social capital fully to participate in the planning of their education. In order to provide these and all other students with quality advice, the present study sought to determine how new online formats of academic advising services can be deployed. The goal was to learn how properly to design these systems so as to help create a perceived student experience that is as similar to existing structures as possible.

There have been prior attempts to provide electronic counseling services at both the college and state levels. These projects include degree-audit algorithms and databases containing articulation agreements between schools (ASSIST, 2011; EUREKA. CCIS, 2012; SFSU. 2012). The one thing that these attempts share is their limited appeal and usefulness as effective instruments from the standpoint of either students or professional counselors. Educators are now actively designing a new crop of tools in the hope of spanning individual courses and degrees; however, these tools 
may show the same structural faults of prior attempts as they also rely heavily upon static problem thinking (Moore, 1998).

This study sought to evaluate the potential development of a virtual intelligent counselor (VIC), one capable of learning and adapting to changing conditions, and based upon neural-network techniques that are apt at handling the essentially nondeterministic process of course selection needed for student success. The literature review in Chapter Two describes the need for such a system and some of the issues that would be relevant in designing it. 


\section{Chapter Two: Literature Review}

State support of higher education in California needs to be recalibrated and realigned to provide both adequate funding levels as well as funding targeted towards student success. This will greatly help to lift California out of its current fiscal crisis. "(...) Education drives incomes" (Mortenson, 2009, p. 12), and the linkage between personal prosperity and the overall state economic outlook has been well established. California's ranks $49^{\text {th }}$ among all states in total funding per student (Moore \& Shulock, 2006), which places both the state and its citizens at a great disadvantage. These levels of support are not sustainable given the future needs of California and a "human capital economy" (Mortenson, 2009) that needs an educated workforce to drive this economic engine forward (H. Johnson, 2009). Without these necessary reforms, California's educational systems will continue to decline.

"The economic collapse of 2008 significantly impacted the financial situation of many universities" (Rovai \& Downey, 2010, p. 143). Colleges have responded to decreased budgets by cutting or reducing course offerings, whole departments, and critical student support services (SSS). This has occurred at the same time that enrollment pressures are increasing, due in large part to individuals seeking to enhance their marketability in the work force. These programs have successfully provided a number of critical supports, such as academic advising (Kulik et al., 1983), but are now being lost. 
As a cost-saving strategy, institutions are now attempting to replace student support services, such as academic advising, using online models. Although a great deal of research has been conducted on best practices in online learning, little research has focused on how academic advising services can be transferred to this exciting new arena.

The purpose of this literature review is first to explain the theoretical perspective used by the researcher throughout the current study. Next, academic advising models that are currently implemented will be explored. These models will be considered using the lens of trends and efforts that are emerging to bring academic advising services into the online domain. Understanding how these systems have been constructed will demonstrate a gap in the literature: understanding why online academic advising systems have not been able fully to meet the needs of students. The current research sought to create an online solution that utilized developmental and sociocultural theories to create an experience equivalent to current praxis.

\section{Scope of the Literature Review}

The researcher used the SFSU Google Scholar portal as the primary search database for both peer-reviewed and trade journal articles. The portal was selected due to the high levels of integration possible with the citations engine used by the researcher, Zotero', as well as being an aggregator to databases that the SFSU library

\footnotetext{
' http://www.zotero.org/
} 
has licensed. Books were procured directly through the SFSU InvestiGator Catalog 2 system that is coupled directly with Illiad, an automated system for interlibrary loan. Finally, the ProQuest Dissertations and Theses database was employed for those searches requiring these types of work.

Searches were conducted around the general concepts behind: i) academic advising, ii) student educational plans, and iii) online teaching strategies. Literature that fell outside of peer review, such as trade journals or books, was subject to additional scrutiny. Materials had to come from industry-recognized associations. Literature was not confined to studies of college-based students, although these were highly preferred articles from the $\mathrm{K}-12$ arena were also used when possible.

Academic advising encompassed an array of theoretical perspectives and working models, with prescriptive and developmental theories dominating the searches conducted; the researcher also conducted subsequent probing into models that have been attempted in the field and studies comparing the effectiveness of particular models.

Student educational planning was also a key theme of this literature review. Student educational planning holds an ever-increasing role as a support that is believed to be important for student success. Both the form and how this service presently is provided to students were searched, to isolate best practices.

\footnotetext{
http://opac.sfsu.edu
} 
Academic advising encompassed an array of theoretical perspectives and working models, with prescriptive and developmental theories dominating the searches conducted; the researcher also probed models attempted in the field and studies comparing the effectiveness of particular models. Student educational planning also has an increasingly important role as a support that is believed to be essential for student success. Thus, student educational planning was also a key theme of this literature review - specifically, to isolate best practices, both the form of these plans and how they are presently provided to students were searched.

Another search criterion, online teaching strategies, evolved from earlier efforts in distance education. The role of online teaching in education is a quickly evolving field of study and one must first understand the challenges of this new domain. Concepts that were explored in this review included equivalency theory, nonverbal communication, immediacy, the negotiation of social interactions and tool creation.

\section{Theoretical Perspective}

A developmental approach to understanding the act of academic advising as a learning experience was used for the present work. Involvement theory seeks to explain how the efforts expended by students during their college experience result in

developmental outcomes. In addition, a persistence-withdrawal model was employed as it attempts to understand the dynamics of integration between the individuals and their educational activities. Understanding how academic advising and student behaviors are 
coupled informed this work. Additionally, a sociocultural perspective was used further to elucidate the interactions of the advisee and the larger advising system.

Involvement Theory

Astin (1999) developed student involvement theory in order to understand the link between the finite physical and psychological energies that students are able to devote to their academic experience. The term involvement is rooted deeply in behavior as well as in how individuals express themselves through actions. Students must take an active role in their education and in their involvement. The theory has five basic postulates:

1. "Involvement refers to the investment of physical and psychological energy in various objects." (p.519)

2. Involvement is thought to reside upon a continuum, which differs not only between students but also within the same student at different times in their life.

3. There are both quantitative and qualitative aspects to this quality.

4. Educational programs are a function of both student learning and their personal development, directly influencing a student's perceived quality, quantity and level of involvement they spend towards their development.

5. The effectiveness of any educational program is directly related to its ability to foster involvement.

Involvement, as defined, can also be seen through an individual's behaviors, permitting direct observation and measurement

Involvement theory was selected due to its helpfulness in the "design of more effective learning environments" (Astin, 1999, p. 518). In this study, academic advising was viewed as a developmental activity; therefore, having a working understanding of 
how involvement makes for an effective program was necessary when designing the study website.

Involvement theory focuses on the "how" of student development rather than on the "what:" that is, this theory focuses on understanding what behaviors students express through how are they are spending the finite resources of involvement. In this theory, the college experience is not viewed as a socially-constructed phenomenon; nor does the theory account for institutional structures or collective values that may influence these behaviors. The theory fails to take into consideration any external pressures that could alter a student's educational trajectory. These external pressures and social construction have been addressed by other theoretical frameworks.

In order to verify that student involvement influenced student development, Astin and Sax (1998) performed an analysis of five consecutive administrations of the Cooperative Institutional Research Program (CIRP) from 1990-1994 and a follow-up survey from the 1995 College Student Survey. The follow-up survey was mailed out, netting 3,450 students (2,287 females and 1,163 males). Additional data used in this study included Scholastic Aptitude Test scores, American College Testing Program scores, enrollment information from the U.S. Department of Education, and information collected from the RAND Corporation.

Multivariate analyses of the data were performed using an input-environmentoutcome model (Astin \& Sax, 1998). This model allows for flexibility as well as the decoupling of individual student characteristics with regard to the effects attributable to 
service participation. This analysis allowed for a determination of the effects that student involvement had on development of individuals with regard to their academic performance, life skills, and civic growth.

Some limitations of this study were the absolute effect sizes (Cohen, 1992) seen were small for some of the variables considered (Astin \& Sax, 1998). Single- item scales with limited response choices may also have resulted in additional measurement uncertainly. Although 3,450 students took part in the follow-up survey, this number was a small fraction of those asked, leading to possible survey bias.

Considering these possible sources of error, one finding of note was: the more time spent involved in a service activity, the greater the personal development observed (Astin \& Sax, 1998). This finding demonstrates how involvement enhances personal growth. Individuals who become involved and spend their finite resources of physical or psychological energy will experience development, which can be seen in the behaviors they exhibit.

The researcher believes that providing an online academic advising service may increase students" levels of involvement as they will have the tools at hand more easily to participate in their educational planning. These increases in involvement should result in greater personal growth that can be seen using matriculation as a target behavior. 
Persistence-Withdrawal Model

Tinto's $(1975,2000)$ persistence-withdrawal model seeks to address how integration of individuals into their institutions results in student development. This model recognizes the highly social nature of the college experience and that the way individuals interact with both institutional structures and values determines their potential for growth. This model goes beyond involvement theory, in that development must take social processes into account.

Although individuals' original expectations of the educational experience are seen initially as strong predictors of how they will view the college experience and goals, this model is iterative. The concept of a feedback loop can be utilized, one in which continual interactions between the individual and institution redefine this relationship. This refinement has an effect upon the academic and social spheres as seen by students, influencing the ability to achieve their original goals.

As individuals progress through college, their integration into academic and social structures results in new levels of commitment. "Other things being equal, the higher the degree of integration of the individual into the college systems, the greater will be his commitment to the specific institution and to the goal of college completion" (Tinto, 1975, p. 96). Therefore, one is able to link student commitment (to both the goal and institution) to the specific behavior, as defined by completion.

Under this model, commitment is treated as a finite resource that an individual possesses. An individual's commitment is not static, and is constantly being re- 
evaluated due to external pressures. Using the concept of a cost-benefit analysis, the model claims that the perceived value of any one activity over alternatives can used to explain the observed actions of a student. Hence, the model explicitly recognizes the importance of student perceptions in the decision to remain in college.

This perception is also influenced by the experiences that a student has while engaging with both the academic and social systems of the college. These perceived experiences result in new normative and structural integration that may cause individuals to re-evaluate their commitment to the goal of college completion. Academic integration can be thought of as encompassing both grade performance and intellectual development, both acting as measures of persistence behavior. Social integration. primarily through friendship, does not necessarily require congruency of the institution with the individual. This form of integration can both assist and detract from the more important academic integration and can affect continuation in college.

Under Tinto's model $(1975,2000)$, commitment is also seen as being influenced by institutional characteristics that affect college persistence. An institution "may be unwilling or unable to meet the needs of its most creative and challenging students" (Tinto, 1975, p. 117), resulting in students' being unable to achieve their educational goals. It is important to consider the critical role of the institution in the way that students' commitment affects their college-going behavior.

Commitment as a predictor of college persistence was utilized in this study. In the researcher's view, providing academic advising services online should make 
educational planning more accessible to students. The link between this form of educational planning activities and goal commitment has been observed. Tinto (1975) has seen "in terms of educational plans the more likely is the individual to remain in college" (p. 102). An online academic advising experience may result in greater educational planning, possibly raising student levels of commitment and persistence.

Although the model notes the importance of institutional support for overall student persistence and goal completion (Engstrom \& Tinto, 2008), the model does not specifically state what institutional characteristics affect these decisions. The present study sought to link academic advising activities, an institutional support service, to an individual's college-going behavior. The support offered by using online tools was viewed in terms of increasing both academic and social integration.

Berger and Milem (1999) studied the relationship of involvement behaviors (Astin, 1999) and perceived integration (Tinto, 1975, 1987) to an integrated model of persistence. This study of the freshmen experience at a private research university utilized a longitudinal panel consisting of surveys conducted at three points in time: after orientation, midway through the first semester, and at the end of the first year.

Responses $(\mathrm{N}=1,547)$ from these survey instruments were correlated to determine relationships between student persistence and the seven independent variables considered. Path analysis demonstrated that academic and social integration were positive predictors of institutional commitment. In addition, early perceptions of involvement positively carried through the first-year experience. 
Berger and Milem (1999) used Tinto’s model and constructs from Astin’s theory of involvement, and showed both direct and indirect effects on student persistence. The study established the relationship between "behavioral involvement and perceptual integration in the college persistence process" (Berger \& Milem, 1999, p. 642). This study relied upon select behavioral measures of involvement in order to determine student interactions with college prior to integration activities. It was shown that these processes are coupled. Furthermore,

The findings from this study suggest important implications for the study and practice of higher education. First, the results of the path analysis provide support for use of Astin's (1999) Theory of Involvement as a helper theory to more explicitly specify Tinto's $(1975,1993)$ conceptual description of the persistence process. (Berger \& Milem, 1999, p. 661)

This study lent support to the use of these two developmental frameworks for the study of online academic advising services. Tinto's $(1975,1993,2000)$ model talks about various forms of integration without pinning down exactly what these look like, instead it relies upon student perceptions. Astin (1999) uses a strictly behaviorist approach. and defines student involvement as a precondition to persistence. The current study sought to determine how sources of academic and social integration could be infused into an online advising experience through the lens of student involvement.

This study lent support for the use of these two developmental frameworks for the study of online academic advising service. Tinto's model talks about various forms of integration without pinning down exactly what these look like, instead it relies upon student perceptions. Astin, using a strictly behaviorist approach, defines student 
involvement as a precondition to persistence. The current study seeks to determine, how sources of academic and social integration can be infused into an online advising experience through the lens of student involvement.

Figure 1. Driving Theoretical Perspective

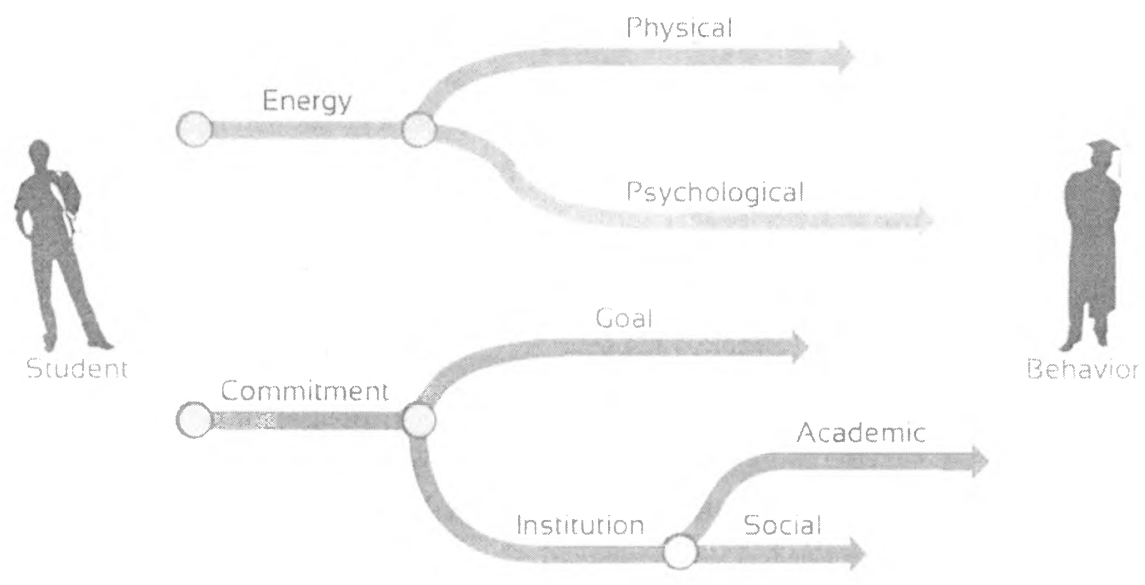

Figure 1 provides an overview of the main constructs that informed the current work. Involvement theory and the persistence-withdrawal model are both developmental approaches and employ the concept of finite resources. In the former model, that resource is the personal energy that a student is able to spend for activities that enhance development. The latter model emphasizes that commitment to either a goal or institution affects students as they progress through the educational experience. An online academic advising tool would require proper utilization of these resources in order to yield the targeted behavior of student success, defined previously as transfer to a four-year institution. 
Sociocultural Lens

Involvement theory makes the claim that students develop by becoming involved, which can support student success (Astin, 1999), whereas Tinto's (1975, 2000) model of student persistence-withdrawal focuses on the mediating role of the social environment in higher education in affecting the individual. The ability to accept the socialization process of the college experience predisposes a student towards persistence behaviors. In order to situate these developmental issues confronting students during the act of online academic advising, a sociocultural lens was applied.

Culture is a fundamental dimension in the analysis of personal psychological development and one of the finite resources mentioned in involvement theory. The term "culture" represents the individual's personally identified community(ies) of practice (Schwen \& Hara, 2003; Wenger, 2000, n.d.). The community of practice that the student identifies will provide the necessary social sharing and artifacts to permit cognitive development. It will be useful to understand how one is able to create such change in order to advance certain behaviors.

A concept advanced by Vygotsky (1978) - the zone of proximal development (ZPD)- explains how a learner can be made receptive to a cognitive change. Vygotsky stated that the ZPD represents:

[the] distance between the actual developmental level as determined by independent problem solving and the level of potential development as determined through problem solving under adult guidance or in collaboration with more capable peers. (Vygotsky, 1978, p. 86) 
An individual in the ZPD is able to interact with a more capable other, allowing the individual to build a scaffold upon his or her pre-existing knowledge base in order to expand overall development. Applied to an educational setting, such as academic advising, this idea requires the learner to be ready to take on new knowledge and the necessary educational infrastructure to be in place to facilitate growth. This idea of the ZPD shows the way social interactions play into an individual's cognitive development. This component of sociocultural theory will be utilized in order to understand how the social activity of academic advising is coupled with the growth of the individual.

In contrast to views of human cognitive development as being affected by passive stimuli from the physical world, "The most fundamental concept of sociocultural theory is that the human mind is mediated" (Lantolf, 2000, p. 1). The goal is to explain how an individual can become empowered towards higher psychological functioning through internalization processes that take place during communication and learning.

Lantolf (2006) approaches the question of empowerment through noting the application of societal pressures conducive towards development. In a discussion of "social artifacts" (p. 69), he mentions the social tools available to the individual in his or her internal quest for cognitive growth. Cultural factors include activities, artifacts (physical), and concepts, and these are all interrelated such that "[they] generally function as an integrated organic system" (Lantolf, 2006, p. 69). These are the 
necessary contexts to Vygotsky's proposal as they empower individuals towards intentionally controlling their mental capacities (Lantolf, 2000).

Additionally, Lantolf (2000) has made significant contributions towards introducing a sociocultural framework to elucidate the process of learning. His ideas have included a detailed analysis of the internalization process(es) that members of a specific community of practice utilize during learning. Through the process of individual growth, symbolic artifacts "lose their exclusive unidirectional quality and take on bidirectional functions" (Lantolf, 2006, p. 90). This abstraction from both the physical world and actions can now be viewed as how the mind makes new connections and undertakes reorganization within the context of social artifacts: hence, a socially mediated process.

Tappan (1997) further elaborates upon this idea through a discussion of the act of making the necessary internalized connections between the individual and external activities. This act of internalizing the external physical world requires that we look at the social context of this transformation.

A sociocultural perspective is necessary to understand the act of learning that academic advising represents. This activity represents the development of individuals and requires that they be in a ZPD to be able effectively to scaffold upon their preexisting understandings. Advising is a socially mediated act, which necessitates an appreciation of how the individual is able effectively to learn through internalization 
processes. A working understanding of these sociocultural considerations will benefit the design of online tools for academic advising.

An act of learning requires that the learner be able effectively to access the ZPD. In a study on the effectiveness of online courses (Rovai \& Barnum, 2003), researchers reported wide variation in student perceptions of quality. The Rovai and Barnum (2003) study surveyed students $(\mathrm{N}=328)$ in 19 out of 28 fully online graduate level courses at a southern university, and sought to determine perceived course quality using a survey instrument with follow-up interviews. The study sought to assess the perceived quality of online versus more traditional formats of coursework in terms of three cognitive measures, and demonstrated significant differences in perceived learning on each of the three measures. The researchers observed large variations in student perceptions of the amount of learning that took place in online classes, although actual measurement of levels of learning in the online courses corresponded with that reported for traditional counterparts.

Additionally, 10 students were selected for in-depth interviews in order to isolate possible causes of these findings. Based on these interviews, Rovai and Barnum (2003) suggested that student perceptions were affected by design constraints imposed by the online environment. The researchers thought socially constructed knowledge and corresponding discourse were not readily accessible, with students' considering the online process to be tedious and inefficient. There was a need for a more complete process of "negotiating a common understanding" (Rovai \& Barnum, 2003, p. 69) to 
allow all students to be able effectively to access a ZPD online. The researchers believed that active monitoring of variations in user perceptions would be one mechanism to yield a stable user experience. The Rovai and Barnum study benefited the present research into an online advising system in so far as designs were implemented to ensure that students were able to perceive some common benefit, so that students would continually contribute to their educational planning activities.

The concept of negotiating a common understanding was further studied by Ahern et al. (2006) in their work on the interconnectedness between formal socially constructed structures and individuals to "sustain instructional interaction" (p. 45) online. The ability to maintain high levels of instructional interaction within the online domain requires access to what Ahern et al. referred to as a common ground. This construct represents the mechanism used by an individual to map prior skills and understandings of how to negotiate shared meanings with others to have successful collaborative discourse online.

Ahern et al. (2006) demonstrated the need to be sensitive to the constraints that an online tool imposes upon individual interactions with others. Individuals may not be able to access common ground easily online due to the longer intervals needed to regenerate context between participants. It was suggested that the initial mapping of and design of these online tools can be used to assuage inherent constraints of the medium. One recommendation was for the instructor, a more capable other, to engage 
in active monitoring of student interactions to encourage students to continue their coexploration within this online zone of learning.

Student-centered learning focuses upon co-creation between participants and lends itself well to the arena of computer-mediated communication (CMC). CMC allows for discourse between peers that is "unrestricted in time or place" (Ahern \& ElHindi, 2000, p. 386). This permits a virtual ZPD, relying upon on co-creation between interested students; the challenge is how such an environment can be formed to allow "each member of the group [to] be able to establish common ground in the discussion" (Ahern \& El-Hindi, 2000, p. 387).

Ahern and El-Hindi (2000) recognized that "network-based communication has the reputation for being cold and impersonal" (p. 391) and sought to determine how to use this vehicle in order to establish collaborative discourse. Nearly 20 students participated in a nine-week online discussion around learning and teaching. The data were analyzed from an ecological perspective, and also in terms of the effect of tool design upon the usage patterns observed. These patterns included numbers of linked messages, comments between collaborators, and the use of multiple links between collaborators. The principle finding was that these tools can create discourse communities, provided the online components are appropriate to the task. In the present work on the creation of an online advising system, each component's design and precise intent were critical to the overall mission. 
In order that design and intent could be properly assessed during the creation process in this work, reflective praxis was utilized after the design had been shown to be useful in improving teaching and learning techniques. Although reflective practice has become a widely accepted benchmarking tool, it is not clear why it works or what best practices are. Reiman (1999) has addressed the lack of theory by applying some sociocultural tenants from Vygotsky and Piaget to a developmental framework. The work seeks to understand "the sociological/cultural perspective and the psychological perspective (to understand) cognitive-development level as a predictor of behavior" (Reiman, 1999, p. 602).

The present study used a developmental lens, based both on involvement theory (which is itself a behavioral theory) and Tinto's model, which can be seen in terms of predicting behavior. Reiman (1999) also attempted to integrate these models in order to answer the question, how "can educators promote development" (p.602). Since the present study sought to determine whether an online academic advising experience can promote development, it asked: what factors are key towards achieving this development? Additionally, this analysis showed that development takes different forms depending upon the prior cognitive structures an individual is able to access and use.

The process of creating this new learning and advising experience necessarily requires trial and error. Reflective praxis may minimize the number of cycles of refinement while the researcher constructs this new space. Also, through mindful 
construction within this new domain, reflective practices can be reinforced for program participants as they progress through their own personal development. Hence, in this study, conscious reflective practices were of direct benefit to both the researcher and the intended audience.

Reiman (1999) uses two lenses for analysis_-Piagetian and Vygotskian-which makes for some difficulty in understanding how this technique can be properly deconstructed. This is also a purely theoretical treatment of an actual practice, with little stated as to best practices in the field. Even with these limitations regarding implementation, the theoretical treatment does allow for a more complete understanding of reflective praxis as it relates to improving each of the advising components during design activities.

\section{Academic Advising Models}

The present work seeks to understand current models of academic advising and to determine how these can be transferred to the online domain. Prevailing practices and models used in the field of academic advising follow from developmental, prescriptive, and integrative advising models. These forms of advising have different assumptions and requirements as they seek to understand how to influence student behaviors towards achievement of educational goals.

Crookston (1972) studied the linkages between student development and academic advising. Developmental advising under this model is understood as consisting of the opportunity for the individual to obtain a self-fulfilling life, inclusive 
of but not limited to only a professional one. Second, within a learning community, both advisor and student actively participate to create this growth. In this context, academic advising is seen as concerned "with facilitating the student's rational processes, environmental and interpersonal interactions, behavioral awareness, and problem-solving, decision-making, and evaluation skills" (Crookston, 1972, p. 5).

Using a behavioral lens, these advising skills overlap with those from the teaching domain. The relationship between the academic advisor and student is critical in the co-construction of this developmental space. Co-construction activities are diametrically opposite the traditional forms of academic advising, in which the relationship can be said to be primarily prescriptive: that is, the student has a concern, seeks help, obtains advice, and then executes said advice.

Crookston (1972) realized that there are a number of underlying assumptions that may actually work counter to the intended goal of supporting students' achievement of their goals during an advising session. Under a traditional advising paradigm, the faculty (advisor) providing advice may see himself or herself as having provided an answer the effectiveness of which is largely dependent upon how well the student is able to carry out the prescription; however, responsibility for the intended outcome has not been formally given to the student. If the student is unable to obtain a satisfactory outcome, he or she is not likely to feel personal responsibly, as the action taken originated from the advisor and not from within. In order to combat this potential pitfall. Crookston (1972) suggested the use of developmental advising techniques. 
Under a developmental framework, the relationship between advisor and advisee is fundamentally about engagement towards growth, or personal development, to achieve educational tasks. The developmental advisor uses a student's prior knowledge to formulate a plan of action for any given task, these include: "abilities, motivation, rewards, maturity, initiative, control, responsibility, learning output, evaluation, and the relationship itself" (p. 6). These characteristics can be thought of as encapsulating goals that add to a student's intrinsic desire to grow. Hence, the student is at all times a responsible party for the achievement of his or her goals.

O'Banion (1972) suggested a five-step approach to expand upon the role of academic advising as a mechanism to allow individuals to choose their programs of study in order to develop to their fullest potentials. The five steps have become dimensions of the academic advising experience and are: "(1) exploration of life goals, (2) exploration of vocational goals, (3) program choice, (4) course choice, and (5) scheduling courses" (O'Banion, 1972, p. 64). Under this model, an academic advising system would require activities relating to each of these five steps to be offered to students, ideally in the sequence presented. This model is holistic, and builds upon Crookston`s (1972) perspective that the personal development of the individual be considered, and not only intellectual development.

The act of academic advising therefore pertains to the growth of a student's personal as well as academic needs. An advising system must therefore be created around these goals, coordinating the processes of development. "[A college's advising 
system] should organize its resources to insure that it is sufficiently effective so that the student will have the greatest possible opportunity to discover her potential through the college experience" (O’Banion, 1972, p. 69)

The foundations of modern academic advising systems have come directly out of the work of Crookston (1972) and O'Bannion (1972) (Hagen \& Jordan, 2008; NACADA, 2006). The developmental and prescriptive paradigms advanced by these two researchers are extensively used in the academic advising literature (Gordon, Habley, \& Grites, 2008) and in traditional normative approaches employed by academic advising systems (NACADA, 2006). Some recent researchers in the field of academic advising have suggested that better results may come from a blending of these two approaches, referred to as comprehensive or integrative academic advising.

Fielstein (1994) found that when students were free to rate developmental and prescriptive activities separately, traditional or prescriptive advising activities were found to be essential. The passing of information, prescriptive advising activities, are "actually critical building blocks that enable developmental advising to evolve" (Fielstein, 1994, p. 77). A more comprehensive approach to academic advising may be required, one that takes the best of developmental and prescriptive advising, providing students with personally-generated content.

In a study to assess the ability of an advising model to enhance the quality of instruction at a college in the United Kingdom (UK), Broadbridge (1996) conducted focus groups of 40 undergraduates in 14 different majors. These focus groups began 
with a discussion exploring student perceptions of their advising relationships, planning, and thoughts surrounding advisors. Findings were consistent with an earlier study: students preferred developmental advising activities (Winston, Jr. \& Sandor, 1984a) but a change in preference was observed as students progressed in their academic careers.

Students initially sought activities that could be more correctly termed prescriptive advising. Students desired formally defined relationships and information regarding possible course pathways, and wanted to leave their advising sessions having been told about recommended educational pathways that in turn led to "greater involvement and motivation in their academic studies" (Broadbridge, 1996, p. 19). However, as students progressed through their college experience, the relationship between the advisee and advisor became more established and was regarded as an integral part of the student's educational experience. These exploratory findings also point towards the need for a modified academic advising system that focuses upon the relationship needs of the individual, such that the exact form of the relationship may evolve over time from one paradigm to another.

Heisserer and Parette (2002) have recognized that although there are "shortcomings of both prescriptive and developmental advising models, strengths have been noted in both approaches, suggesting that elements of the two be implemented in higher educational settings" (p. 71). They have used the term integrative advising to explain this mixed or comprehensive approach towards academic advising. The researchers suggested expanding training around this approach, stating that the most 
important function performed is direct institutional contact with students. Effective contact requires that student needs are being met by the advisor using communication, questioning, and referrals, so that accurate information can be provided even as the advisor demonstrates a caring presence. This model combines approaches from both developmental and prescriptive advising systems to give a coordinated and comprehensive academic advising experience. Heisserer and Parette (2002) also recommended that web-based technologies be devoted specifically to advising activities as a resource to support students.

The present research is based on interest in current praxis in the field of academic advising. These advising systems use theory to guide the formulation of their activities, and understanding prevailing theories permits the creation of any online advising system to be similarly grounded. The dominant model used in the field is developmental, in which the focus is upon co-creation of a relationship between the advisor and advisee to develop goals and planning. Although more traditional, or prescriptive, advising activities may be perceived by students as less desirable, these activities are still important and may build foundations that allow developmental advising to take place. More recent theorists believe that academic advising systems ought to take a more balanced or comprehensive approach, integrating, the best elements of either developmental and prescriptive advising to address individual needs. Integrative advising proceeds from the recognition that using only the best portions of a system may be the most effective mechanism for achieving a student's educational goal. 


\section{Online Learning}

There is a great deal of research on online learning as it connects to traditional subject matters, but few studies have asked how academic advising services can be provided online, in a way that could guide the creation of a proto-online academic advising system and its testing regarding how it would be received by students. It will be important to draw on the online learning literature to find online techniques that have been shown to be important in improving real and perceived learning activities, such as academic advising.

Academic advising is a co-creation between the individual and advisor, where development is possible within a ZPD. Paulus (2009) studied how small groups using computer-mediated communication (CMC) tools in an online environment were able to learn and to achieve common ground between members. Understanding how individuals use $\mathrm{CMC}$ tools online to arrive at common ground benefited the current research during its design stages. Paulus' study differed from earlier studies, as the focus was upon off-topic concepts that were not purely academic. Since academic advising models used in this work recognize the importance of both social and academic endeavors, understanding how individuals are able to arrive at a common ground online in either context was of interest.

Paulus (2009) studied small-group interactions in graduate-level courses at a single university site using an emergent qualitative study design in which transcripts of all communications were analyzed. The study was small $(N=21)$ but compensated for 
this by spanning all of the students' enrolled online courses. All forms of communication were coded along "four topics: conceptual (related to the course objectives), logistics (related to completion of the task), technical (related to the communication tools being used), or social (e.g. small talk)" (Paulus, 2009, p. 233). These topics allowed the researcher to understand what participants were talking about and how they negotiated common ground.

Students spent the majority (61\%) of their online interactions not discussing the concept to be learned in the course, but instead discussing technical (5\%), social (17\%) and logistic (39\%) topic units. The primary tools used in the CMC were forums, chat, and then e-mail, in that order. These behaviors allowed for an understanding of how students were able to achieve common ground. Common ground must be continually negotiated in each interaction, as was seen in Paulus' (2009) data, with the majority of online communication being spent on off-topic tasks. Through detailed analysis of the topics that were discussed and of how students utilized the CMC tools, the researchers concluded that, " the groups established common ground through being explicitly responsive, responsible, and relational" (Paulus, 2009, p. 241). Students demonstrated responsiveness in eliciting and accepting contributions from members, in being responsible to the group with respect to the coursework, and finally in acting as a single group by creating and maintaining relationships. These means of arriving at common ground differed from traditional interactions (in non-CMC environments), where nonverbal behaviors or immediacy cues established grounding between participants. 
An online academic advising tool can use CMC elements to permit students to co-create with peers and the site itself. In order for students to be successful in these interactions and to sustain these forms of communication, Paulus (2009) demonstrated a need also to focus on non-academically motivated work in order to allow students to negotiate common ground. Making tools that let students be responsive, responsible, and relational was one mechanism to achieve these attributes and further reinforced academic advising models that recognize the social and academic goals of a student.

The importance of non-verbal communication to convey feeling and emotion to build relationships in a learning environment has also been seen (Arbaugh, 2001; Gorham, 1988: Mehrabian, 2007; Witt, 2004). The ability effectively to communicate and listen has also been shown to be important during advising, as this behavior leads towards the creation of the relationship required under a developmental advising model.

Barnett et al. (2006) studied the effect of immediacy upon the quality of the relationship that forms between an advisor and advisee, and presented a number of specific and learnable non-verbal techniques. These techniques focused upon use of visual and auditory cues as well as on how to form questions to elicit active collaboration between the parties. Although online academic advising may not use facial and auditory cues, it can integrate active listening through encouragement, paraphrasing, and summarizing, which have been shown to lengthen interactions as well as improving the quality of a session (Barnett et al., 2006). 
Barnett et al. (2006) studied the effect of integrating such communication techniques on the perceived immediacy and efficacy of an academic advising session. The study consisted of randomly assigning 13 nursing students to one of two groups. One group was given advisors that been given training on best practices of immediacy during academic advising, the other group was provided non-trained advisors. After each individual had an advising session, he or she was asked to state perceptions of the relationship with the advisor. The researchers concluded that immediacy did result in perceived increases in efficiency and student satisfaction. This small-scale study sought to determine how non-verbal behaviors could be used "to reduce advisor's talk time while providing their advisees with an opportunity to tell their stories better and more fully" (Barnett et al., 2006, p. 11). This study provides further evidence of the importance of non-verbal, or immediacy, components to the perceived quality of an advising activity, including one that takes place online.

This study raised the question of how, during the design of an online instrument, student perceptions of different components of a learning activity could be measured on an individual basis. Studies of student perceptions of advising systems have been performed, but these studies typically have been unable to decouple individual elements. Yet in an online system, components of advising can be created completely separately from one another, so that in testing student perceptions, it is possible to validate any single component as it relates towards measures of student satisfaction. 
Paechter and Maier (2010) sought to determine variables that resulted in a successful online learning experience, and in so doing created a method to validate the individual components of an online experience. Their study sought to determine how the experience, course satisfaction, and preference of either online or traditional formats were influenced by 25 independent variables across five fields of instruction. These five fields included:

- course design

- interaction between students and instructor

- interaction with peers

- individual learning processes

- learning outcomes

The study used survey instruments to probe student attitudes and perceptions in 29 Austrian universities, with 2,196 students participating. All students selected were enrolled in online courses at the time of the study. Although student majors were permitted to vary, most (52\%) were in the social sciences. Females accounted for $62 \%$ of participants, with $80 \%$ of participants being between 18 and 25 years of age.

One of the main findings from this study was the importance of the design of an online course in order to achieve higher levels of satisfaction. "For the design of elearning, it is important to know which course characteristics are important for students' satisfaction" (Paechter \& Maier, 2010, p. 295). The concept of common ground and the sustaining of collaborative communication again arose in the need to use different CMC 
environments based upon the type of work to be accomplished. Interactions between learners again benefited from the presence of an instructor in order to facilitate and maintain collaborative peer interactions. Students did recognize the ability of online techniques to support highly individualized learning processes that may not be possible in traditional courses. For courses that required building up conceptual or methodical knowledge, students preferred more traditional forms of classes.

Based on these findings, the authors suggested the need for a blended approach that uses the best possible elements from online and traditional environments. The online academic advising system proposed in this study may do better in augmenting existing institutional structures, allowing students to perform particular tasks and generate work units that could then be further refined in personal interactions with a more capable other, such as an advisor.

The impact of the Paechter and Maier (2010) study rested upon the statistical methods used to determine components that students felt were needed to have a successful online learning experience, as well as in understanding preferences for a more traditional format. The tools used in their study were critical for the present study"s goal of determining those components of academic advising that students consider important, allowing for a more nuanced analysis of individual components as they related to overall student perceptions. The Paechter and Maier article provided both a method of analysis to make this type of determination as well as establishing 
how important each is towards a successful electronic-advising experience; it provided key methodological and statistical instruments for use in the present research.

\section{Online Academic Advising}

Online academic advising systems have been created using any number of combinations of expert systems (Waterman, 1986) and artificial intelligence (AI) methods (Goertzel \& Pennachin, 2007; Jennings, 2000; Russell, 2010). These two approaches are computational means towards decision management. Another way to describe these methods, "AI as uncertainty management — what to do when you don't know what to do" (Thrun \& Norvig, 2011). Modern techniques have been applied both to the generation of academic goals and optimized educational pathways.

One key responsibility of an academic advisor is in assisting students in choosing an educational goal, in the form of a major. This key function was included in the online tool created, and could stand to benefit from advancements in computeraided decision-management. Such an expert system could permit advising using forms of reasoning similar to those used by current practitioners. It would utilize the same set of rules and knowledge and apply heuristics to arrive at a solution that best fits a student's needs.

Grupe (2002) created and studied the use of one such system to develop a recommended major of study from a student's input. The system that was created sought to capture the "deep knowledge possessed by advisors" (Grupe, 2002, p. 336) in an effort to design a system that could provide guidance in situations that are not well- 
defined. The system was called MyMajors.com; based within the internet it required a 15-20 minute interview session with a student. The goal of the system was to emulate typical processes presently used in academic advising sessions that would then result in selecting appropriate majors.

The MyMajors.com tool requires the student to rate a series of attitudinal questions. The first questions asked are of a psychological nature or ask about aptitude; as the student continues, the questions focus upon grades and test scores. The system uses a neural-network structure with 300 nodes in the hidden layer, resulting in at least six possible majors. Background information accompanies these majors so the student can explore and learn more about each in detail.

The power of this tool is in the 300 rules that represent deep knowledge representation. Grupe (2002) interviewed college academic advisors who specialize in major selection at their institutions to arrive at one set of rules. Then using feedback from actual students, these rules could be modified in an iterative fashion. Rules were coupled to one another using probabilities, resulting in thousands of interconnected pathways that allowed the tool to arrive at a set of majors.

The encapsulation of pure information or statistics from advisors as a set of interconnected rules may not be an ideal method, since it is fraught with personal bias and error. A better technique may come from direct data-mining of an institution`s student-information management system. This would free up resources to capture heuristics that come from an advisor's personal experiences in the field. 
However, this tool represents an online-based expert system that assists students in generating educational goals based upon modern computing methods. Such a device reduces the time spent collecting information from a student, increasing "efficiency of time advisors spend with students" (Grupe, 2002, p. 343). These efficiency gains can then be applied towards more in-depth discussion or serving more students in their choice of major.

Hamdi (2006a, 2006b, 2007)has approached the problem of online academic advising through a tool called multi-agent system for academic advising (MASACAD). This online tool uses multiple instances of intelligent or expert systems to provide academic advising recommendations. The MASACAD tool uses machine learning and data-mining techniques in order to provide student-optimized educational roadmaps based on current information. This system has only been applied to students that already had a pre-defined educational goal or major.

The limitation placed on only educational paths instead of goal creation was intentional. "The goal of academic advising, as stated previously [i.e. creating an educational goal]. is too general because many experts are involved" (Hamdi, 2006a, p. 5). The singular focus on pathway optimization can use data procured from existing databases through automated data-mining techniques. These automated systems eliminate the need to consult with academic advisors during training of this system, in ways that could potentially introduce bias. 
A student first engages the system through creation of a mediation agent which can then converse with agents that are embedded in the computer environment. As this initial mediation agent interacts with subsequent agents, these other agents perform their tasks and modify the state of the mediation agent. Examples of these agents are a grades agent that is able to determine how a student's grades affect matriculation, and a course requirement agent, which would determine prerequisite needs for a particular pathway. As the initial mediation or searcher agent progresses through the system, it becomes aware of the best possible path and returns this to the user for review.

Each agent represents a complete neural network designed for a specialized task. This requires that these agents receive proper training. For the selection error rate sought, $<15 \%$, the use of model data showed "a [required] training period of $8,000.000$ cycles" (Hamdi, 2006a, p. 14). This "implementation and preliminary testing show that the multi-agent paradigm, combined with ideas from machine learning, user modeling, and Web [data] mining, would be a good approach for the problem of information customization" to solve problems around academic advising (Hamdi, 2006a, p. 18).

Hamdi (2007) evaluated the MASACAD academic advising system using 20 computer-science students in different stages of matriculation at a university. Each was instructed to obtain advising through the system and the nature of this advice was then studied to determine suitability and detect possible errors. No errors, such as those that would violate university rules, were seen in the advice given. A majority of students 
(75\%) took the courses recommended to them by the system, with only three students modifying the list of classes due to personal non-academic reasons.

The MASACAD academic advising system and the use of multiple agents suggests a possible mechanism to provide educational planning tools to students. The information that the student receives is up-to-date, reflecting any institutional policy changes as well as allowing customization of near real-time information for the educational roadmaps provided. The study was small and limited to a single major, computer science. These limitations may affect the ability of such a system to scale to a full university's course catalog, and may require new agents in order to handle the increase of information. Also the system "does not exploit any kind of feedback to refine its functionality" (Hamdi, 2007, p. 764).

Hamdi's (2007) work has shown the potential of a multi-agent approach in the creation of educational planning instruments, such as class roadmaps. These agents were artificial and used machine learning in order to produce the sought behavior, requiring model data to be at hand. The currently proposed system, VIC, does not have similar data but also uses a multi-agent approach in which artificial agents were replaced by real intelligence, in the form of students. The use of real individuals sidestepped the need for training back-propagation neural networks, in essence having these black boxes come pre-trained. The use of humans in similarly configured networks to produce work has been seen in efforts such as Amazon's mechanical turk and the fold-it projects (Cooper et al., 2010; Paolacci, Chandler, \& Ipeirotis, 2010). 
The benefits of using an expert system in developing human capital — as in the case of academic advising - was studied by Moore (1998), who created and studied an expert system capable of predicting admission into a MBA program and providing enrolled students a prognosis for degree completion. The system was entirely rulebased and used weightings to determine the exact form of its outputs. Evaluation of the system was performed by using it in parallel with and then comparing it to the preexisting admissions/advising systems at the institution. The system excelled in pointing out cases of students at risk of failing, as it was able to provide advising staff members with this list of students upon their entrance into the university. More than $80 \%$ of these at-risk students have been able successfully to complete their first year since this system has been implemented.

"The appropriateness of expert system technology" (Moore, 1998, p. 669) for academic advising activities was demonstrated in this work. A system could be used to provide objective, unbiased, and consistent academic advising tools. The ability to augment and complement existing institutional structures to allow for efforts elsewhere is a powerful tool in an environment of dwindling resources. In addition, students can use the tool to ensure that they are on the correct educational pathway at all times.

\section{Equivalency Theory}

The second research question in this study delves into student perceptions of an online academic advising service. In order properly to gauge and understand these perceptions, one must be able to use benchmarks. In other forms of distance education, 
such as online classrooms, one mechanism uses equivalency theory to make comparisons across differing delivery formats.

Equivalency theory is based upon the importance of instructional experiences in supporting learning, and states that one goal of new technologies and environments (such as online learning) is to provide learning experiences equivalent to those resulting from existing practices and systems (Simonson, 1999; Simonson et al., 1999). The similarity of the learning experience would then translate into similar learning outcomes and expectations of the student. Hence, designers of new online environments must consider ways to make their tools appropriately so that the learning experience of the student is one that is familiar regardless of the exact format (Simonson et al., 1999).

The constructs underlying equivalency theory provides a framework to study and understand student perceptions of online academic advising services. If proper attention is paid during the creation and design of appropriate tools and technologies, a learning experience can be created that ought to provide similar expectations and instructional experiences of the students. This theory allows for a comparison between systems through existing measures of outcomes.

\section{Conclusion}

As the financial situation affecting California's community colleges continues to have negative effects on the ability of these institutions to provide student support services, such as academic advising, technological solutions will be sought. These are thought to help maintain fiscal stability by reducing capital expenses. Although there is 
abundant research into online teaching at the college level, there does not appear to be much basic research into how academic advising services can be provided in this new medium. There have been some attempts at providing academic advising online, but these have focused upon the creation of either an educational goal, such as a major, or a model plan of coursework. The current research has sought to add to this growing body of literature on online academic advising and to join the two functions of goal creation and educational roadmaps into one complete advising system. 


\section{Chapter Three: Methodology}

This chapter is meant to elucidate methods used in this study. The work followed a multiphase mixed methods-design (Creswell \& Plano Clark, 2010) approach. The phases can be best understood as starting with a needs assessment, which informed the creation of a proto-online-advising service, and concluding with a study of attitudes and perceptions regarding this experience. An assessment of needs for online academic advising was performed in order to develop an online academic advising test platform-a virtual intelligent counselor (VIC). This test platform then acted as a means to probe prevailing student attitudes and perceptions of online academic advising services. Students were then asked the perceived value of this online tool using a pre-validated survey instrument, followed up with interviews to aid in explaining the results.

In performing any program evaluation, the goal is to test the effectiveness and efficiency of a treatment (McDavid \& Hawthorn, 2006). The present study seeks to understand how online academic advising compares to traditional service delivery treatments. The initial needs assessment included a component to determine "felt needs (what people say they need)" (Grant, 2002, p. 157) with regard to options for academic advising.

Information from this needs assessment was then used for the further development of a sample online academic advising website, VIC. A formative assessment was then performed to determine if VIC had achieved the intended outcome of parity with existing academic advising systems. Each of the multiple phases acted to 
inform subsequent stages and allowed each individual component to be analyzed more effectively as a whole, rather than piecemeal.

This chapter will introduce the design and aspects of the site that was selected. Site attributes including the recruitment of and characteristics of participants will be elaborated. The methods used in the initial needs assessment will be presented first. Next an account of design choices for VIC will be described. Finally, methods for comparing VIC to traditional academic advising systems will be described.

\section{Research Questions}

During the course of the present research, the following questions emerged.

1. How can an academic advising website be created with features that incorporate current theories in order to foster an experience that is equivalent to modern praxis?

2. What are student perceptions of an academic advising website that assists in the co-creation of academic goals and the generation of education-planning instruments?

\section{Research Design Overview}

This research was informed by prior work (Flowers, 2010a, 2010b), which suggested students would be amenable to novel forms of academic advising. Specifically, students had reported difficulty with the accessibility and utility of the preexisting forms of academic advising at Peninsula College (a pseudonym). Using this information, the researcher sought to test the feasibility of online academic advising 
delivery compared to a traditional system. This required that a testing platform first be created in order to conduct future experiments. The current research will be presented in three phases: discovery, tool creation, and value (Figure 2).

Figure 2. Study Design Overview

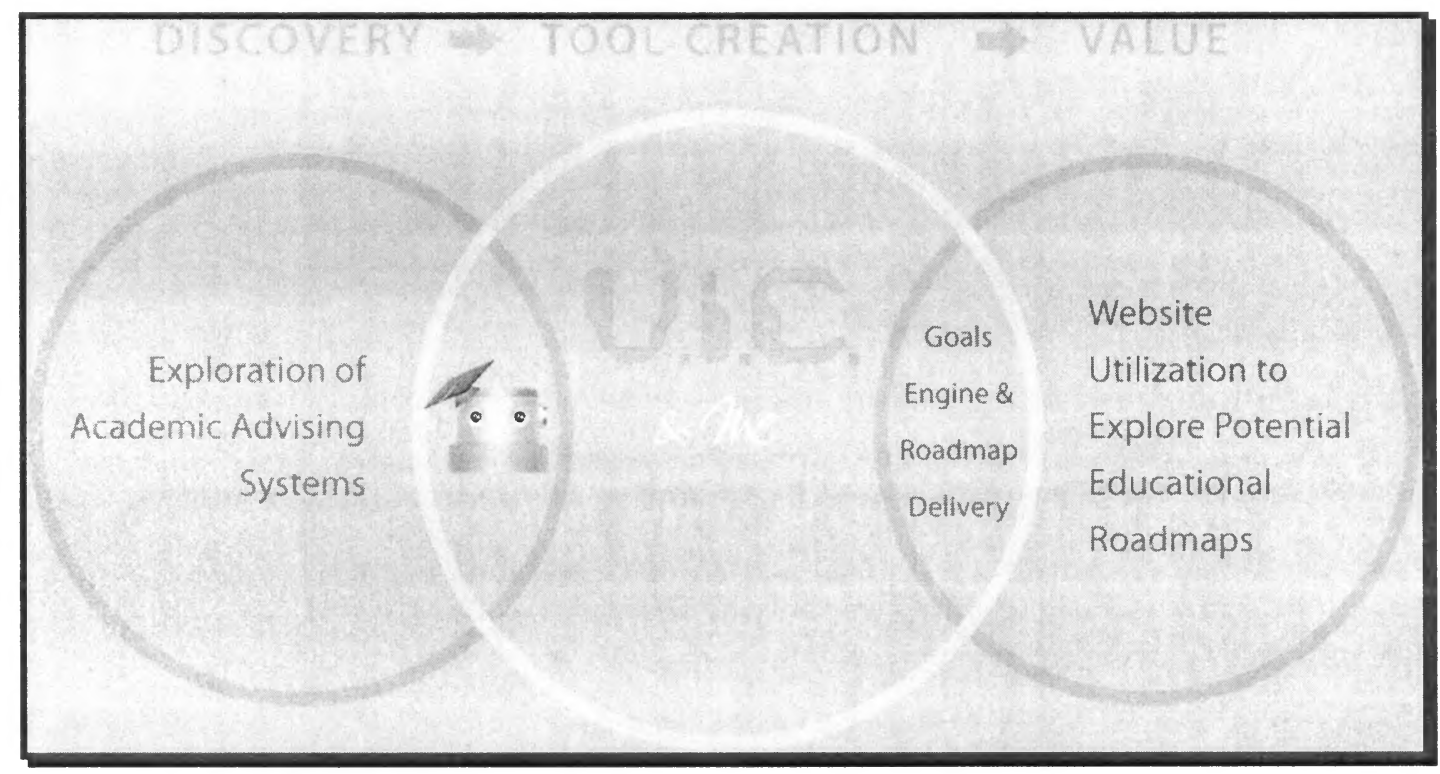

The first phase, labeled Discovery, can be understood as a needs assessment: it determined how academic advising was currently seen by students and investigated the critical components of this service. Interviews of students were conducted to create a custom survey instrument (Appendix 1) that also followed the use of critical colleagues, and national survey data of academic advisors (Habley, 2004a). Interviews and external data were used to further understand what features of an academic advising website would be needed to ensure an "equivalent learning experience" (Simonson, 1999, p. 7) to a face-to-face developmental academic advising session (Crookston, 1972; 
NACADA, 2006; O’Banion, 1972; Winston. Jr. \& Sandor, 1984a). Developmental academic advising was used as a benchmark due to its ubiquity in current practice. Insights from this investigation were then integrated into the consideration of ways that students could successfully interact with an online academic advising system.

Based on these data, the researcher came up with the concept of a virtual intelligent counselor (VIC) as an anchor for an academic advising portal. VIC was used for the design and creation of this website, http://www.vicandme.com (herein referred to as VIC). The website then acted as a test platform for later experiments to probe the effectiveness and efficiency of an online service delivery paradigm and determine its equivalency compared to current advising praxis.

After VIC was completed, students were recruited, asked to use this tool, and asked about their attitudes and perceptions. A combination of a pre-validated survey instrument and follow-up interviews of select individuals was used to probe attitudes and perceptions of academic advising systems and compare the two forms of academic advising systems. The survey instrument used was the Academic Advising Inventory (AAI) (Winston. Jr. \& Sandor, 1984b). This instrument needed some modifications for use online; Appendix 2 and Appendix 3 show the unmodified and modified instruments, respectively. Modifications were made to allow the AAI to work within an online survey management portal as well as using only those portions of the instrument that were relevant to the current study. Finally, in order to understand the survey results 
more fully a select group of students was asked to share their experience with advising services and VIC through in-depth interviews.

\section{Research Site}

The California Community College (CCC) represents the single largest system of higher education in the nation (California Community Colleges, 2012). This system has 112 colleges, with Peninsula College being one of these. Peninsula College (PC) is in the San Francisco Bay Area, an affluent portion of the nation, and the college benefits greatly from the generosity of the community. The college is a full service institution that offers numerous academic programs and transfer opportunities to fouryear universities.

\section{Site Selection}

The selection of Peninsula College can be attributed to its being the researcher's employer. This site was highly geographically accessible and enabled the researcher to gain entry into various institutional systems necessary to carry out this study. Furthermore, Peninsula College holds a diverse student body in terms of ethnicity and age distributions. Figure 3 shows distributions for ethnicity compared to statewide averages. These annual figures were procured from the California Community College Chancellor's Office (CCCCO) Data Mart project for the 2009-2010 year. 
Figure 3. Student Ethnicity Statewide and at Peninsula College

\begin{tabular}{lccc}
\hline & $\begin{array}{c}\text { Statewide } \\
(\%)\end{array}$ & $\begin{array}{c}\text { Peninsula College } \\
(\%)\end{array}$ & $p$ \\
\hline African-American & $7.22 \%$ & $3.36 \%$ & $<.05$ \\
American Indian & $0.66 \%$ & $0.35 \%$ & $<.05$ \\
Asian & $11.25 \%$ & $17.34 \%$ & $<.05$ \\
Filipino & $3.03 \%$ & $6.28 \%$ & $<.05$ \\
Hispanic & $30.42 \%$ & $20.93 \%$ & $<.05$ \\
Pacific Islander & $0.66 \%$ & $2.15 \%$ & $<.05$ \\
Two or More & $1.32 \%$ & $1.71 \%$ & $<.05$ \\
Unknown & $13.44 \%$ & $11.15 \%$ & $<.05$ \\
White & $32.00 \%$ & $36.72 \%$ & $<.05$ \\
\hline
\end{tabular}

NOTE: Retrieved from the CCCCO Data Mart Project, 2009-2010.

Statewide $(n=2,758,808)$; Peninsula College $(n=18,566)$

Figure 3 shows ethnicity as a percentage for statewide and PC student s. The descriptors used for ethnicities were a result of the CCCCO Data Mart Project naming conventions. No statistical differences were observed using a one-tailed significance of the difference between proportions (McNemar, 1947; Newcombe, 1998), $p<.05$. 
Figure 4. Student Age Statewide and at Peninsula College (PC)

\begin{tabular}{lccl}
\hline & $\begin{array}{c}\text { Statewide } \\
(\%)\end{array}$ & $\begin{array}{c}\text { Peninsula College } \\
(\%)\end{array}$ & $p$ \\
\hline 19 or Less & $25.62 \%$ & $28.30 \%$ & $<.05$ \\
20 to 24 & $27.64 \%$ & $25.26 \%$ & $<.05$ \\
25 to 29 & $13.08 \%$ & $12.96 \%$ & .31 \\
30 to 34 & $7.75 \%$ & $7.81 \%$ & .38 \\
35 to 39 & $5.84 \%$ & $5.62 \%$ & .10 \\
40 to 49 & $9.10 \%$ & $9.09 \%$ & .48 \\
$50+$ & $10.46 \%$ & $10.93 \%$ & $<.05$ \\
Unknown & $0.50 \%$ & $0.02 \%$ & $<.05$ \\
\hline
\end{tabular}

NOTE: Retrieved from the CCCCO Data Mart Project, 2009-2010.

Statewide $(n=2,758,808)$; Peninsula College $(n=18,566)$

Figure 4 shows age bins as percentages for statewide and PC students. Age bins were an artifact of the CCCCCO Data Mart reporting capabilities. A one-tailed test of the significance of the difference between proportions (McNemar, 1947; Newcombe, 1998 ) demonstrated some statistical differences between age bins, as shown. No differences between proportions were seen between these two sets, for the two largest age bins.

\section{Participant Recruitment}

Participants in this study were recruited through convenience sampling, with recruitment taking place exclusively within the Math Science Division, the same division in which the researcher works. Prior to any recruitment efforts, the researcher gave a short presentation of the study parameters during a divisional meeting to elicit the assistance and explicit permission of fellow instructors. The procurement of 
permission was a request of the divisional dean. After obtaining permission, participant recruitment was conducted via one of three direct methods. The researcher first emailed other instructors within the division, requesting that they tell their classes about a need for volunteers. In some cases, the researcher also visited classes for direct recruitment. Lastly, the researcher posted flyers throughout the Math Science building asking for volunteers. All three of these vectors of recruitment used a variant of the same script, Appendix 4. An incentive was provided and may have influencing factor for an individual to choose to participate. Finally, all participants were 18 years of age or older at the time of this study.

Interview Participants

Daniel, a male, age 25, self-identified as white. He was the first in his immediate family to go to college and had the goal of obtaining his B.A. and then proceeding on towards graduate education. Daniel wanted to pursue a medical path, and had been working as an emergency medical technician (EMT) prior to entering college. Daniel was a former student of the researcher and was asked to participate due to his experiences with academic advising at Peninsula College (PC). These advising experiences resulted in his having to extend his total time at $\mathrm{PC}$ by at least one year, as the educational plan provided to him contained an error that was not caught in time. Overall, Daniel took this setback as a chance to explore college and taught himself how to perform academic planning activities. 
Lisa, a female, age 45, and a self-identified African-American, was a returning college student. Lisa was a prior student of the researcher at the time of her interviews. She had already obtained a degree, but was pursuing another degree that would permit her to enter a nursing program and had been working towards this goal for four years at the time of this study. Lisa was an ideal candidate to ask to participate in an interview, as it was her shared personal insights that helped shape the trajectory of the present study. These efforts centered around her involvement in helping to provide student feedback on the custom survey instrument that sought to better understand student services at Peninsula College, Appendix 1. In addition to this work, Lisa was an outspoken individual who was able to provide candid insight into academic advising. John, a male, age 23 years, self-identified as Hispanic (specifically of South American roots) and was the first in his family to attend college. John was also a former student of the researcher who had maintained close ties. He viewed the college experience as a means to ensure future prosperity and prove his tenacity to himself and others. Although John worked, he could also regularly be seen in the Math Science building in the early morning until well into the late evening. When asked about the hours he kept, he would attribute his stamina to a heartfelt desire to prove to himself his belief in himself and a passion to achieve the goals he had set for himself. The need to prove himself was deep-rooted and independent of how others (including faculty members) looked at him. John was asked to participate due to experiences with 
academic advising services that had left him needing to seek other avenues of academic planning.

Karen, a female, age 43, and a self-identified Hispanic, was the first college student in her family; she was seeking her degree in order to have greater career mobility. Karen was also a current student of the researcher at the time of her interviews. She talked about her decision to go to college nearly 23 years after graduating high school, and the anxiety this transition caused. She talked about not having an individual she could confide in regarding the college experience. We talked about how her first meeting with an advisor at Peninsula College empowered her to pursue a college degree and provided tools to chart a path through this experience. This advisor made the difference in her college experience and gave her the needed confidence to believe in herself. Karen was asked to participate to investigate her thoughts as to how this type of knowledge can be effectively transferred between advisor and advisee.

Ian, a male, age 34, self-identified as Filipino and was the first in his family to attend college. Ian had initially entered college to pursue a career in engineering. Later he sustained an injury that left him unable to continue working in construction. Learning of the time needed to achieve his original educational goal, he decided to change his major to a field that captured his imagination, physical therapy. Ian was never a student of the researcher, although he was a member of a study group that included John and met regularly in the Math Science building at Peninsula College. Ian 
was asked to participate due to his experiences changing to another major and having successfully taught himself how to navigate the multiple academic advising systems between Peninsula College and the transfer institutions he was considering.

Mary, a female, age 23, self-identified as Asian and was pursuing transfer into a four-year university. Mary had entered the community college system as a senior in high school, haven taken classes at four separate local area community colleges. She took this route to save money and experiment with majors until she was able to find a course of study that suited her best. She talked about difficulties navigating between these separate institutions and taking classes that would not be useful for transfer. Mary was a prior student of the researcher at the time of her interviews.

Paul, a male, age 28, self-identified as African-American and was a returning college student, having previously earned a B.A. Paul sought to change careers and came back to community college in order to work towards a new major focused within the medical field. Paul was a prior student of the researcher's and revealed in class that his father was a faculty counselor at a nearby college, City College of San Francisco. Paul also told the researcher that he had many positive interactions with advisors while he earned his first degree, and had formed lasting personal bonds with his academic advisors. Paul was an ideal candidate to be interviewed due to his unique perspective on academic advising, resulting both from great prior experiences and having an immediate family member that worked in the profession. 
Andrew, male, age 20, was a self-identified white of Persian origin and was known to the researcher through a mutual acquaintance. He wanted to pursue a college education to obtain a more economically stable future. Andrew worked for two years after high school and then felt ready to dedicate the necessary time and energies to college. He was asked to participate in the current research due to having to teach himself academic planning skills and having "never [having] had an opportunity to get to know a counselor [academic advisor]." Despite these experiences, Andrew felt that the present system could be made better through the proper application of technology to amplify the efforts of advisors. This belief may be attributed his work within the technology sector.

Tammy, female, age 31, was a self-identified Asian and was introduced to the researcher through a mutual acquaintance. Although Tammy came from a family that had achieved college degrees and valued education greatly, she talked about having to rely upon external help to navigate her college experience. Her family members had obtained their degrees from institutions that were out of the country, and had different structures and protocols. In her early experiences with advisors, Tammy performed the tasks asked of her, out of a deeply rooted need to follow the advice of an expert. Gradually she came to learn enough about the system to provide her own pathway, and her relationships with advisors matured into two-way partnerships. 
Figure 5. Select Demographics of Interview Participants

\begin{tabular}{|l|l|l|l|}
\hline \multicolumn{1}{|c|}{ Name } & \multicolumn{1}{c|}{ Ethnicity } & Age & Gender \\
\hline Lisa & African-American & 45 & Female \\
\hline Karen & Hispanic & 43 & Female \\
\hline Mary & Asian & 23 & Female \\
\hline Tammy & Asian & 31 & Female \\
\hline Daniel & White & 25 & Male \\
\hline John & Hispanic & 23 & Male \\
\hline Ian & Filipino & 34 & Male \\
\hline Paul & African-American & 28 & Male \\
\hline Andrew & Persian & 20 & Male \\
\hline
\end{tabular}

Figure 5 represents a summary of interview participants and select demographics. The order presented does not represent the order that these individuals gave their interviews.

\section{Role of the Researcher}

The researcher was a chemistry instructor working at Peninsula College when all data were collected. At the time of this study, he had taught at Peninsula College for nearly five years, the first two as an adjunct and started a tenure track at the beginning of this research. Courses taught by the researcher spanned from general to organic chemistry series - classes that satisfied transfer requirements to both the California State University (CSU) and University of California (UC) systems.

The researcher is also an active member of the campus, participating on a number of committees and faculty advisor to the science club. During his courses 
taught and these extra-curricular activities, the researcher was able to better understand the needs of students and the challenges that they faced.

A number of students within the Math/Science division talked about the difficulties in transfer due to differing articulation agreements between institutions, requiring additional classes to be taken to ensure transfer. Additionally, making certain that prerequisites were fulfilled to allow student to leave Peninsula College with their Associates degree was also seen as a challenge. These and first hand experiences of the researcher pointed to a need to more fully understand academic advising in order to provide these students with the information necessary to transfer. This study is an attempt to address these concerns and provides further context to the research and site considered.

All study participants were recruited from either classes taught by the researcher or from within the Math/Science division - in which the researcher was a member. During all student interviews, measures were taken to minimize the possible influence of the researcher's academic position might have upon the student. Although steps were taken to minimize the influence of this power imbalance, some participants may have engaged in the research due to their prior relations with the researcher.

\section{Critical Colleagues}

This work benefited from the collaborations of critical colleagues (Males, Otten, \& Herbel-Eisenmann, 2010). These individuals came from both Peninsula College and from San Francisco State University (SFSU). The researcher reached out to members 
from the academic advising staff and worked with a number of these faculty members. One member in particular was extremely helpful, Laura, as she was able to most effectively communicate college protocols having recently transition from teaching within the Math/Science Division over to becoming a full time academic advisor.

The researcher also worked with a number of talented members from SFSU, including members from the dedicated staff of the University and fellow graduatestudents. The ability to speak with members from the SFSU technology department assisted in understanding of found results as well as ideas for exploration. The greatest help though, came from fellow cohort members.

My fellow graduate students not only provided invaluable assistance as proofreader`s, they also were a source of an external check of study ideas as the work emerged. They provided the researcher with a number of avenues for analysis and is seen in the integration of their work within this study. These individuals represented a wide array of backgrounds in terms of gender and ethnicity. The multitude of perspectives added to the design choices taken and the overall richness of the analysis. Research Assistants

During the development of the test website, three undergraduate research assistants were utilized. These assistants were former students of the researcher's, had recently finished their studies at Peninsula College, and were waiting to start the Fall 2012 semester at their individual transfer institutions. They were asked to participate due to their having successfully transferred into local four-year universities as well as 
understanding the nuances of articulation agreements between Peninsula College and these other institutions. Their insight into the creation of viable educational roadmaps was instrumental in the development of this critical component.

Fred was the first member asked to join in study. Fred had been a former student of the researcher and had recently graduated from Peninsula College the coming semester to continue his studies at his transfer institution, SFSU. Fred was first in his family to go to college, and was newly arrived. Fred shared with the researcher the challenge of putting himself through school while working full-time and having limited external supports to navigate college. The ability he showed in navigating PC's system to transfer within three years as well as having strong communication skills demonstrated to the researcher Fred's qualifications as a student research assistant.

Al was the next student asked to participate. Both he and Fred were students in the same course taught by the researcher earlier, organic chemistry. Al was a stronger student, grade wise, and had greater communication skills as evidenced in his written reports for his coursework. He too was first in his family to go to college, newly arrived, and spoke about his initial challenges in adjusting to college. Unlike Fred, he did not have to work a full-time. Al was asked to join, as he had been not only successful in selecting his courses in order to transfer, he earned his Associate degree in Chemistry - a first in recent history of Peninsula College (PC). The challenge in earning an Associate degree in the sciences at PC stems in part with having to balance the courses needed and those that will be accepted at the transfer institution without 
going over with regard to units. This demonstrates a high level of dexterity in course selection and it was believed by the researcher more than aptly qualified $\mathrm{Al}$ to be a student research assistant.

Although Liz was never a student of the researcher, she was well known to the researcher. Liz was both Al's longtime girlfriend and frequently would be found in the Math/Science Building studying at one of the study desks. The researcher and her would frequently talk in the hallway. She was newly arrived, and though she was not first in family to go to college, she was first to go to college in a foreign country. She talked about the anxiety of having to piece together the intricacies of college with little external support and having had a number of academic advising sessions that left her believing that she alone would need to select her own courses. Liz was also awaiting to continue her studies at her transfer institution. Her abilities at navigating Peninsula College towards transfer within a three-year window were the reason that the researcher felt that she was capable of being a student research assistant.

The three students asked to participate in the study were both known to the researcher and one another. They shared to varying degrees those characteristics that the researcher felt would be helpful during the study; such as proven abilities at selecting courses in order to successfully transfer and solid communication skills. It was believed by the researcher that their insight and their having successfully transferred from Peninsula College would add to study. The researcher relied upon the research assistants to answer some design choices such as the institutions, majors, and 
courses to be considered. Their understanding of issues, which would have otherwise eluded the researcher, during the creation of the educational roadmaps for VIC was additional evidence of their qualifications as student research assistances for this study.

\section{Ethics and the Protection of the Human Subjects}

Prior to beginning any work, the researcher completed NIH training in the protection of human research participants, as well as working with SFSU's Institutional Review Board (IRB) out of the Office of Research and Sponsored Programs (ORSP) to obtain all necessary permissions and approval to begin the collection of human volunteer data (Appendix 5). Although participation in this study involved minimal risk, there was still potential loss of privacy. This potential risk was minimized by taking all necessary steps to properly maintain control of all personally identifiable information collected. This process began by assigning all research participants pseudonyms (Bogdan \& Biklen, 2007) known only to the researcher; these were maintained within a password-protected Excel workbook. These pseudonyms were used in all transcripts, field notes, and written documents. Additionally, any identifying information was either changed or omitted. All other electronic files relating to this research were password-protected. Physical files, such as a field notebook and individual notes, were securely maintained in a locked desk to which only the researcher had access.

During the recruitment of interview participants, a script (Appendix 4) was developed in close conjunction with a highly experienced research advisor. This 
recruitment script clearly outlined the scope of the research as well as emphasizing the voluntary nature of participation and the fact that withdrawal from participation or the refusal to participate at any time would have no consequences whatsoever.

Interview locations were selected to minimize potential psychological pressures. Interviews were conducted either in the personal office of the researcher or on campus near the food court in private group study rooms. At the time of each interview, participants were asked to sign an individual consent form. They were provided a copy for their recorders. Prior to the start of an interview, the researcher asked if a recording device could be utilized as well as reaffirming their ability to leave at any time during the study.

After interviews were transcribed, recordings were deleted. All data collected from this research will be destroyed one year after the successful completion of all program requirements, per SFSU ORSP guidelines.

\section{Study Assumptions}

Study assumptions were required and would influence how data would be later analyzed. The first assumption being that data were assumed to have come from normally distributed groups. Unless otherwise noted, statistical significance was set at the $p=.05$ threshold. Lastly, sample populations studied were not sufficiently large to suggest generalized models that could be used to describe the intended target population, California Community College students. However, this study's results might be of benefit to other research efforts through a mechanism of transferability. 


\section{Discovery Phase}

This phase of the project sought to determine the critical components of an online academic advising experience. These components would then become the foundation used to create a proto-academic advising website that would then act as an experimental test platform. In this portion of the study, student participants were recruited during Fall 2010. This phase of the project can be understood as having followed an exploratory sequential design (Creswell \& Plano Clark, 2010, p. 86). Discovery began with a few individuals sharing their experiences and from this start, a larger sample of students were then gathered in order to generalize from these initial findings.

Five students known to the researcher were recruited for interviews in order to establish the language necessary to describe academic advising activities. Guiding questions (Weiss, 1995) were used for these interviews, with the researcher attempting to foster a naturalistic environment (Bogdan \& Biklen, 2007; Denzin \& Lincoln, 1994). These efforts were designed to both maximize the time available as well as to allow unforeseen ideas to emerge.

As students talked about their experiences and understanding of academic advising, the researcher typed up key points of these sessions in front of the student to permit rapid member checking. At the end of each of these sessions, the researcher would ask student participants for their assessments of the experience and ideas for improvement. These ideas were then integrated, in an iterative fashion, into future 
sessions. These activities helped develop the language necessary to describe the act of academic advising and assisted in the creation of a custom survey instrument.

A custom online survey (Appendix 1) was then used to determine the components that students at Peninsula College of an online academic advising experience that would be equivalent (Simonson, 1999) to the services they had received. This instrument was sent to 240 students whom the researcher taught or that were otherwise affiliated through the college, of which 153 students $(64 \%)$ completed the survey. The information from this instrument acted as a significant driver of design choices and influenced the development of the academic advising testing website, VIC.

\section{Tool-Creation Phase In Detail}

The present study sought to understand the potential of online academic advising, hence the need for an experimental test platform. This platform was modeled using academic advising components that students stated were important during the discovery phase. National data were also used to drive the creation of this test website. Operationally, the website needed to be both modular and flexible to permit rapid prototyping of advising modules.

The choice of the elements included the present online tool would be fundamentally different from other online academic advising services. Prior online advising systems used in California include: CSU Mentor (XAP Corporation, 2012), SFSU DARS (SFSU, 2012), Eureka Online (EUREKA, CCIS, 2012), and more recently efforts such as Degree Works (Sun Gard Corp, 2011). These prior and current 
academic advising attempts can best be understood as information management systems (Barreau, 1995; Bergman, Beyth-Marom, \& Nachmias, 2003; Falk, Avery, \& McGee, 1999). The primary goals of these systems can described as the storing of data, shuttling data between work units, and finally presenting data to the end user. Research has demonstrated the importance of aligning the context and design of these systems (Barreau, 1995) and may suggest reasons why currently available academic advising systems have had limited impact and adoption (Habley, 2004a, 2011). In contrast to these systems, advising system created for this study uses a combination of artificial and real intelligence to generate possible goals and educational roadmaps using available data.

Joomla (Open Source Matters, 2011) was selected as the content management system (CMS). This selection was based on its being open-source and modular. Opensource meant that there was supported by a community of developers, ensuring that software fixes and patches would be available if needed. The modularity allowed for greater control of customization and future scalability. The gantry platform (Rocket Theme, 2011) was mapped atop of the Joomla site for rapid applications deployment, full browser management, and the design framework of the actual website. These two complementary components- one being the platform for content management and the other the development environment-- permitted the creation of a test website that could act as the experimental platform. 


\section{Goals-Generation Engine}

In order for students to obtain an educational roadmap, students would either already have an educational goal in mind or develop such a goal. For those students that did not already have a goal, VIC included a goals generation engine. The goals generation engine was modeled using the cognitive-information-processing (CIP) approach (Perterson, Sampson Jr., Lenz, \& Reardon, 2002). CIP can be understood as an approach to service delivery. This approach allows a student to formulate a goal through a series of questions to arrive at a list of possible educational majors. Once the student has a list of possible majors, the website then is able to provide a set of appropriate educational roadmaps.

Operationally, the goals engine asks users a series of low-burden questions with the goal of helping students arrive at possible majors. Using the answers provided, additional information is then presented to assist students towards understanding their current selection of majors. In the absence of pre-validated questions, critical colleagues (Males et al., 2010) were used to assist in the formulation of the questions the engine uses. Questions were informed by practice (Perterson et al., 2002) and designed to help students think about how to view their strategies for selection purposes. Figure 6 lists the questions asked. 
Figure 6. Questions Asked of the Goals-Generation Engine

Question Asked

What is your life and work commitment (outside of school per week)?

What types of problems do you enjoy solving more?

Do you prefer working with people or systems?

What level of social interaction are you more comfortable with?

The answers from these questions helped yield custom considerations that could help in selection of a major pathway. These suggested pathways followed from the questions as well as from external assistance from critical colleagues with experience in the field of advising. After the student chose a major to explore, VIC then presented a series of educational roadmaps to guide the student in formulating student educational plans (SEP).

\section{Educational Roadmap}

Presenting students with educational roadmaps presented unique challenges in the final implementation. The selection of both majors and schools to be included in VIC would permit proper navigation of the different articulation agreements between institutions. The researcher had originally been led to believe from the advising staff of Peninsula College (PC) that a library of such roadmaps was being actively maintained. 
When it was discovered that the actual list of roadmaps was significantly less than initially reported, the researcher sought alternative means.

Educational roadmaps were to be one of the results a student would obtain via an academic advising session. Academic advising as a teaching event has been included in the definition used by NACADA (2003). This resulted in the researcher seeking to apply a mode of teaching that had been successfully used in prior courses taught, Supplemental Instruction (SI) (Arendale, 1994; Congos \& Schoeps, 1993; Etter, Burmeister, \& Elder, 2001; Maxwell, 1998; Ramirez, 1997).

Supplemental Instruction uses collaborative learning and the sharing of learning strategies in a peer environment. Under the SI model, the coordinator selects a peerleader, "usually [having] successfully completed the targeted course" (Etter et al., 2001, p. 357) as well as having strong communication skills. In the present study, the 'targeted course' was the academic advising session that would result in the transfer from Peninsula College to a four-year institution. The researcher called upon three students to act as 'model students' and be SI leaders, referred to as research assistances (see Appendix 9 for select demographics of the research assistants). In creating the educational roadmaps, the researcher allowed these assistances to develop the choice of institutions that would be considered as well as the exact nature of the recommended course work.

The research team met over the course of three days to develop a working plan for the creation of these educational roadmaps. The choices of majors to include were 
driven by classes offered at Peninsula College's Math Science Division, as this division would be the primary recruitment arena for the present study. An internet search using various Boolean operators arrived at those majors that were both popular and the highest paying to trim the list of potential majors. The use of pay as a discriminator was a direct result of collaboration among the research assistances. They reasoned that many of their peers, as well as themselves, used future employment opportunities, as measured in potential pay, in the calculus of major selection.

The researcher limited the number of majors that would be considered to one dozen. The choice of this number was a result of the researcher wanting to be assured that this portion of the study could be performed in the allotted timeframe. The task of selecting the one dozen majors that would be considered though was assigned to the research assistants. Delegation of these choices stemmed from the researcher believing that they would have a fuller understanding of the end users needs in this particular regard. With the majors selected (see Figure 7), the next task was to determine which four-year institutions to focus upon.

For purely pragmatic reasons, it was agreed that only three public universities would be considered. Geographic proximity to Peninsula College was a significant conditional variable in the choice of these institutions. After internal deliberations, the research assistances arrived at the final list of institutions: University of California (UC), Berkeley; UC Davis; and San Francisco State University (SFSU). This allowed 
for the mapping of majors to the selected universities using the articulation agreements between institutions (ASSIST, 2011).

Figure 7 lists the majors selected along with the exact title used by each of the institutions considered. Figure 7 also provides a mechanism for an end-user to understand what each of the target institutions call similar majors. A high level of specificity was required in order to have the correct prerequisites considered.

Figure 7. Majors Considered for Roadmaps with Institutional Titles by Institution

\begin{tabular}{llll}
\hline \multicolumn{2}{l}{ Educational Institutions } & & \\
Peninsula College & UC Berkeley & UC Davis & San Francisco \\
Biology & Chemical Biology & Biological Sciences & Cell Biology \\
$\begin{array}{l}\text { Chemistry } \\
\text { Physics }\end{array}$ & Chemistry & Chemistry & Chemistry \\
Nursing & Physics & Physics A. B. & Physics \\
Engineering & N/A & N/A & Nursing \\
& Engineering Physics & Mechanical Engineering & Mechanical \\
Mathematics & Applied Mathematics & Mathematics & Engineering \\
& & & Applied \\
Computer Science & Computer Science & Computer Science & Mathematics \\
& Business & Computer \\
Business & Administration & N/A & Engineering \\
Economics & Economics & Economics & Business \\
Psychology & Psychology & Psychology & Administration \\
Sociology & Sociology & Social Services & Psychology \\
Health & Public Health & Social Services & Sociology \\
\hline
\end{tabular}

NOTE: Not all institutions referred to each of these areas of concentration with the same terms.

The goal of creating these educational roadmaps was to provide a pseudostudent educational plan (SEP), modeled after those generated by Peninsula College. 
As roadmaps were created collaboratively, a document control system was needed to maintain the supporting paperwork. A production system paradigm was used in order to ensure that every member had the same data and that efforts were not duplicated. The system took the form of document packets disaggregated by major and included articulation agreements, institutional specific graduation requirements, and a custom worksheet, Appendix 10. A logic map detailing how these roadmaps were generated can be seen in Appendix 11.

During the creation of these roadmaps, the researcher observed non-linear amplification of effort measured in the speed with which complete roadmaps were generated with increased collaboration between assistances. The first research assistant to arrive on the day of creating complete educational roadmaps, Fred, took nearly one hour to complete only one major and institutional specific roadmap. When $\mathrm{Al}$ and Liz arrived, the researcher witnessed cross talk between assistances. This cross talk took the form of one person advancing a particular set of coursework with the others challenging said coursework, in a collegiate manner. Instead of this activity slowing down the process, the opposite was observed with subsequent roadmaps being generated in less time. This was an important observation and warrants future research.

The evaluation of quality of all the generated educational roadmaps used triangulation (Bogdan \& Biklen, 2007) techniques that included internal and external measures. Internally, roadmaps were only considered after agreement between all three research assistants. Externally, educational roadmaps developed by the staff of 
Peninsula College's advising services were used as a comparator. The process was highly iterative, and only after agreement between these measures was achieved, the roadmap was considered usable.

While the research assistants developed the educational roadmaps, the researcher created a mechanism for the rapid input of their finished data into VIC, based on the realization that the course schedule for Peninsula College had to be recreated within Microsoft Excel using the course ID reformatted as a barcode. These barcodes were then modified to have a header and footer that would be used later for final HTML encapsulation. These headers and footers also allowed for inclusion of additional course specific parameters. As completed data packets were developed by the research assistants, the researcher could then scan their data directly into VIC, please see Appendix 12 and Appendix 13.

The process of the research assistants generating data worksheets and the researcher inputting these into the computer continued for each of the twelve majors selected. This resulted in a total of 72 individual educational roadmaps (12 majors, three institutions, and two types of students either full- or part-time). The intended use of these roadmaps would act as a starting point to develop formal SEP. An additional flowchart, Appendix 14, was developed by Fred to tell future students how these roadmaps should be used. Final approval of this device was through agreement of the other two assistants. 
Appendix 15 shows both the university options as well as the type of student that best describes their status. Students are considered either full time or part time, with these two designations influencing the load per semester for the educational roadmap provided. A user-initiated roadmap is shown in Appendix 16, providing an example of the course work that would be required of a student.

\section{Value-Added Phase in Detail}

After the website had been created, it was then possible to ask student participants to interact with VIC. Individuals were directed to the front page of the website, which contained a brief description of the project and an immediate immersion into the interface. Visiting students were directed to begin their experience by accessing the goals generation engine to determine an initial educational goal. From the goals- generation engine, VIC would present information regarding possible educational roadmaps for further exploration. The user then learned that these roadmaps could be used to generate a more formal student educational plan (SEP), and multiple roadmaps were provided in order to guarantee that there was always a provided path towards eventual transfer.

\section{Student Attitudes and Perceptions}

In order to gain a full understanding of how these online academic advising tools would be received, student attitudes and perceptions were examined. This final examination used a mixed methods approach, sequential explanatory design (Creswell \& Plano Clark, 2010). A sequential explanatory design allowed quantitative results to 
be explained using qualitative data. The initial quantitative results were attained using a pre-validated instrument, with follow-up interviews with students used to provide the necessary platform for a richer interpretation of these findings.

In order to determine potential equivalency between VIC with the academic advising services provided by Peninsula College (PC), an experimental design was utilized for the quantitative data portion. The control group was a group of students asked to use the AAI to rate their experiences with face-to-face advising services provided by PC. A separate group of students were then asked to rate their experiences using VIC with this same instrument.

\section{Measurement - AAI Instrument}

In order to determine student attitudes and perceptions regarding an online academic advising service, the Academic Advising Inventory (AAI) was selected. I located this instrument after an exhaustive search of the Buros Institute (2011) of Mental Measurements and the academic advising literature. This survey instrument (Appendix 2) was developed by Winston and Sandor (1984b) and has been made available to researchers through the National ACademic ADvising Association (NACADA). The AAI was designed as "a measurement tool that can be used to evaluate advising programs from a theoretically-grounded perspective and that would allow comparisons across institutions [treatments]" (Winston, Jr. \& Sandor, 2002, p. 8). The AAI is reliable, with an overall Cronbach's alpha (Cronbach, 1951; Santos, 1999) 
of 0.78 . With regard to validity, the AAI device is grounded in Crookston's (1972) theoretical work.

The AAI is composed of four parts. Part 1 measures the behavioral style of academic advising, using the theoretical constructs of developmental and prescriptive advising (Crookston, 1972), and was used to determine the nature or style of advising perceived by students of either group. The two style of advising are developmental and prescriptive modes. Developmental approaches are characterized as having strong collaboration between the advisee and advisor to foster an environment of joint responsibility. Whereas, prescriptive advising connotes a power imbalance in favor of an all-knowing advisor with the advisee not sharing in the responsibilities of this activity.

Although part 1 of the AAI cannot be modified as a term of use and must be used in its entirely, the behavior data captured was of the form of discrete choices overlaid with a continuum. These two discrete choices are either of the two form of advising and the continuum determines the magnitude of the choice. It was realized that randomization of the binomial data would eliminate possible random error of participates that selected the immediate answer choice and provide more informative results. Therefore, these answers were presented in a random order and later reassembled in the software for analysis, eliminating this possible source of error.

The other three parts could be modified as per the needs of the researcher, and in the present study not all parts of this instrument were used. Part 2 was designed to 
provide a total picture of all academic advising activities that take place during a typical session. Since it was designed specifically around traditional notions of college advising, it was not used, as the exact wording of the questions could not be made to include online academic advising tools. Part 3 was used as it measured overall satisfaction using a Likert-type scale and lent itself well to current study needs. The last part of the AAI captured demographic data such as age, gender, and ethnicity. It was decided to capture this data using the same terminology and data bins used by the CCCCO Data Mart project to permit later comparison with this statewide resource.

The final format of the instrument (with its allowable modifications) was then published using an online survey management system: www.surveymonkey.com. The use of this portal permitted the instrument to be sent to students with minimal manual efforts and was informed by the literature (Guillen, 2010). The final form of the instrument that was provided to participants can be seen in Appendix 3.

\section{Measurement - Analysis}

All data relating to the Academic Advising Inventory (AAI) were first analyzed using the included manual (Winston, Jr. \& Sandor, 1984b). The manual provided a uniform scoring protocol and allowed for consistency between the VIC group and control group. The control group was students that had only used academic advising services provided by Peninsula College. All AAI data were disaggregated across gender and ethnicity, looking for differences within these subcategories. All data were first scored using the official manual, and then analyzed using comparison of means 
between the two treatment groups to assess equivalency (Simonson, 1999) of these two systems. In addition, one-way analyses of variance (ANOVAs) were used to determine effects of demographic and goal related attributes of students upon their AAI scores. Initerviews

Interviews of nine students were also conducted to determine their academic advising experiences both at Peninsula College as well from VIC. Students were recruited from the Math Science Division, to share their perspectives on academic advising services through a series of two interviews. These interviews were separated into two 30-minute sessions that were spaced apart from one another by at least one month. The spacing was to permit adequate time for students to use the online academic advising system. Both interviews had interview guides developed beforehand to ensure the time was well spent, please see Appendix 17 and Appendix 18 (Weiss, 1995). The guides were designed to be minimally restrictive, acting as a helpful pathway of inquiry to be negotiated and explored mutually (Weiss, 1995).

The first interview sought to understand how participants developed their educational goals upon entering college. This information would allow for a more elegant understanding of how the goals generation engine could be designed for maximal impact. The second interview probed student perceptions and the utility of the educational roadmaps generated by VIC. Determining the value of these roadmaps would yield insight into how best to present this type of information. 
Sessions were conducted in one of two locations that provided a safe and quiet space: the researcher's office or a private room in the college learning center. Participants were given a brief synopsis of the study goals and provided an individually signed copy of the consent form, Appendix 19. Interviews were electronically recorded using a digital voice recorder. Efforts were taken to position the recording devices in a location that was not obvious to assuage anxiety due to having a recorder present.

These audio files allowed for the creation of a verbatim transcript. In order to protect the privacy of participants, all transcripts were immediately assigned pseudonyms. Then transcripts were independently reviewed by the researcher and individual participants, when possible, to allow for member checking. It was not always possible to have the participant view the hard copy of their transcript; electronic copies were not used due to document control concerns. The researcher took a minimal set of notes in order to foster a more naturalistic or conversationalist approach (Bogdan \& Biklen, 2007). These notes were then integrated within the transcripts for later analysis.

Interviews - Analysis

Analysis of the interviews began with the open coding of the data and used "some imagination, some ingenuity" (Glaser \& Strauss, 1967, p. 161) through an application of grounded theory. All transcripts were printed, organized within a three ring binder, and read at least twice before any codes were written on the pages. 
Analysis and coding were performed in a batch manner; batches consisted of all the data from only one of the two interview sessions at a time.

After a number of keywords were generated, these were collected and considered carefully. For each set of interviews, generated keywords became subthemes and processed into larger groupings, or themes. The final step in this thematic analysis was linking each sub-theme to the set of main themes. In order to perform this task in an efficient manner required the assistance of a previous cohort member.

Transcripts, sub-themes, and themes were collected into a single electronic file, an excel workbook, provided by a critical colleague (Wick, 2011). This electronic file allowed the researcher to label individual statements made by either the interviewer or interviewee with a sub-theme that encapsulated the main idea. Drawing on all the benefits of a spreadsheet, the researcher highly modified the electronic file to apply themes dynamically. These modifications made it possible to quickly reprocess and regroup sub-themes, as well as to quickly sort and present the interview data. These modifications essentially allowed the data to be handled in a manner similar to pivot tables.

\section{Opportunities}

One goal behind the VIC test platform was to demonstrate possible gains in either efficiency and effectiveness in the providing of academic advising services to students. Efficiency gains were studied using the interview data. Effectiveness of VIC over current practices was analyzed using both advisor load (Drake et al., 2010; Habley, 
$2004 \mathrm{~b}$ ) and cost as dimensions of the analyses. Advisor load is a ratio of advisees per advisor and has been used as a unit of analysis to understand this student support service across systems. Cost was determined using California Community College Chancellor`s Office (CCCCO) CCFS-113 financial filings of the 71 reporting districts for the most current year on record, fiscal year 2009/2010. These financial figures were then normalized against faculty headcount as well as full-time equivalent students (FTES). These two normalized results would then permit an analysis and comparison across institutions in a consistent manner.

\section{Conclusion}

The goal of this chapter has been to show how the research questions were to be answered by providing an accounting of the research site, study assumptions, methods employed, and data analysis techniques used. Peninsula College (PC) characteristics were for comparison to the target population, the California community college system. Study specific parameters and assumptions were provided to understand how data would be captured and analyzed later. The study overall used mixed methods and a complete description of the specific methods for the three separate phases of the project. The following chapter will provide the actual found data using these methods. 


\section{Chapter Four: Findings}

This study had two research goals. The first was to determine whether features that are currently supported by modern academic advising practices and theories would be needed to create a meaningful experience. A meaningful experience will be taken to mean an academic advising session in which both the advisee and advisor enter into a mutually collaborative space, in order for the advisee to be able to seek guidance. This follows from the definition of academic advising advanced by NACADA (2003), and is considered by this professional organization as best practice. The second goal was to understand the perceived value of an online academic advising tool. Student attitudes and perceptions were probed using a mixed methods approach (see Chapter Three: Methodology).

This chapter presents findings first across each of the three separate phases of the project: discovery, tool creation, and value added. During the discovery phase, a combination of national data and a custom survey instrument were used to collect data to determine critical features necessary for an academic advising system. Next in the tool-creation phase, the information gathered was used to create a working online academic advising website. In order to determine how this online system was seen by students, in the value added phase, a validated instrument was used to compare the online academic advising of VIC using as the control the system currently implemented at Peninsula College. Interviews were then conducted to aid in understanding of the data captured by providing necessary context to the purely numerical findings. 


\section{Discovery Phase: Features}

The discovery phase sought to determine key features which current academic advising systems offer students. Understanding how advising systems currently offer services would permit VIC to provide an equivalent online educational experience (Simonson, 1999). The form of equivalency sought, is towards an aggregate satisfaction of service delivery and not individual level performance.

Using current advising systems as a baseline, the proposed online approach seeks to move towards aggregate satisfaction levels. The use of aggregate satisfaction was selected as data has predictable behavior (M. D. Johnson, Anderson, \& Fornell, 1995). Research in the use and adoption of self-service technologies (Meuter, Bitner, Ostrom, \& Brown, 2005; Meuter, Ostrom, Roundtree, \& Bitner, 2000) suggests that service satisfaction is coupled to characteristics that would not have been captured in the present study at the individual level.

The approached utilized to determine the academic advising feature set was a combination of national level data and data specific to Peninsula College. The national data provided a review of best practices, with local data permitting a refinement of services that should be implemented within VIC. A combination approach was used to minimize the overweighting of any single service component and acted as a form of triangulation during this phase of the project.

In selecting the dataset to be used for a preliminary survey of the characteristics of an advising system, the researcher sought data that captured various aspects of this 
activity on a national level. In speaking with current members of the advising profession and in performing an extensive library search, the researcher was led to the National ACademic ADvising Association (NACADA). This organization produces a peer-reviewed scholarly journal on the state of the profession, maintains an extensive library of white papers, and performs extensive training in best practices. This organization represents both individuals in the field as well as advising systems from all across the nation (NACADA, 2012), and has a reputation for advancing the state of the profession (Tuttle, 2002).

In addition, NACADA conducts a national survey that reports on current practices in the field of academic advising. The sixth such instrument (Habley, 2004a) was used in the present study to understand advising systems. It should be noted that at the time of this study, the 2012 survey had been conducted but the data unavailable to the researcher. The data are separated by institutional type (among other subclassifications) and unless otherwise noted, this study examined only data from twoyear public schools. Having a foundational understanding of services to which students have become accustomed would provide the initial insight into how to structure VIC.

A custom survey instrument, Appendix 1, was developed to determine probe Peninsula College (PC) student perceptions of the services offered by the college. The services considered encompassed more than academic advising (AA) and sought to understand AA in relationship with the entire service experience. Having a full understanding of how PC students view and understand academic advising services 
would make it possible to customize VIC to meet these site-specific needs. This instrument also provided a means of better understanding the connections between student data and the NACADA data, as the questions could be designed to tease out additional information.

NACADA Dataset - Current Service

During the discovery phase of the study (determining key features of advising systems), chapter four of the monograph produced by NACADA (Habley, 2004a) was utilized. The data in this chapter focus on the roles and functions of academic advising systems at the national level. The systems considered were those of formal advising centers employing dedicated advising professionals, individuals whose sole responsibility is one of academic advisor. These considerations were made to mirror the types of systems commonly found in CCC.

The responsibilities of academic advising offices can be grouped into one of two category descriptions, those functions that directly influence students and tasks that are primarily administrative in nature. One example of an administrative function, 'Developing a campus-wide advising handbook" (Habley, 2004a, p. 60). This study was concerned only with student interactions with an academic advising system, and these administrative responsibilities were not considered. This narrowed definition resulted in a list of three responsibilities that were then sorted based on the percentages of schools that reported carrying out these responsibilities for the last year of data (see Figure 8). 
In the selection of academic advising (AA) service responsibilities to be implemented within VIC, the percentage reporting was utilized. The greater the number of AA offices reporting one of these responsibilities, the more likely the service is transferable across differing organizations and familiar to a larger set of potential future users of VIC. As this study is focused on California community college students, and due to resource constraints not all of these reported AA responsibilities would be fully implemented within VIC.

Figure 8. Responsibilities Reported by Academic Advising Offices

\begin{tabular}{lccccc}
\hline Responsibility & 1983 & 1987 & 1992 & 1998 & 2003 \\
$\quad$ & $\%$ & $\%$ & $\%$ & $\%$ & $\%$ \\
\hline $\begin{array}{l}\text { Advising on general Educational } \\
\quad \text { requirements }\end{array}$ & 85 & 89 & 92 & 78 & 81 \\
$\begin{array}{l}\text { Establishing and maintaining advising } \\
\text { records }\end{array}$ & 55 & 66 & 64 & 60 & 57 \\
$\quad$ Evaluating transfer credit & 40 & 45 & 52 & 37 & 42 \\
\end{tabular}

NOTE. Data reproduced from NACADA 2004 Status of Academic Advising.

Figure 7 shows that the primary responsibilities of the academic advising systems - assisting students with general educational requirements - consistent with NACADA's (2006) listing advising on educational requirements as a core concept. The next most common function reported for advising offices was the establishment and maintenance of records. The third reported responsibility of advising systems is evaluating transfer credit, or understanding how prior efforts integrate within different 
educational institutions. These three responsibilities will need to be considered during the tool creation phase.

Custom Survey - Service Needs

A custom survey instrument was then developed to better understand how students at Peninsula College (PC) perceived support services (Appendix 1). The wording of this custom instrument was a direct result of student interviews. Figure 9 shows a demographic breakdown of students that completed this instrument regarding the scope and nature of their experiences with academic advising services at Peninsula College. 
Figure 9. Demographics of Peninsula College student participants in a custom survey instrument to probe features necessary for an online academic advising experience, Spring 2010

\begin{tabular}{|c|c|c|}
\hline Gender & & $(\%)$ \\
\hline & Male & 33.3 \\
\hline & Female & 52.3 \\
\hline & Unknown & 14.4 \\
\hline \multicolumn{3}{|l|}{ Age } \\
\hline & 18 to 19 & 19.6 \\
\hline & 20 to 24 & 32.7 \\
\hline & 25 to 29 & 12.4 \\
\hline & 30 to 34 & 8.5 \\
\hline & 35 to 39 & 0.6 \\
\hline & 40 to 49 & 4.6 \\
\hline & $50+$ & 6.5 \\
\hline & Unknown & 15.0 \\
\hline \multicolumn{3}{|c|}{ Eihnicity } \\
\hline & African-American & 3.3 \\
\hline & American Indian/Alaskan Native & 0.0 \\
\hline & Asian & 22.9 \\
\hline & Filipino & 8.5 \\
\hline & Hispanic & 9.2 \\
\hline & Multi- Ethnicity & 6.5 \\
\hline & Pacific Islander & 2.0 \\
\hline & Unknown & 26.1 \\
\hline & White Non-Hispanic & 21.6 \\
\hline
\end{tabular}

Note: Students completing survey $(n=153)$

Figure 9 shows that the majority of respondents from this custom survey $(52.3 \%)$ were below the age of 24 , with the two largest ethnicities being either Asian $(22.9 \%)$ or White $(21.6 \%)$. More females $(52.3 \%)$ than males $(33.3 \%)$ participated in 
this instrument. The large percentage of unknowns in age (15.0\%) and ethnicity (26.1\%) was a result of the researcher failing to apply the proper settings in the online survey software to make answering these questions a requirement.

With regard to students' perceptions of academic advising as reported on the survey, the majority of the 153 participants $(70.6 \%, n=108)$ stated that they had seen an advisor, providing reasonable assurance that these participants had at least a working definition of academic advising services. For the set of students that had seen an advisor, most $(81.5 \%, n=88)$ would recommend these services to other students, and most $(78.7 \%, n=85)$ would themselves like to work more with an advisor. The desire to see an advisor, either for oneself or for another student, suggests that the experience at Peninsula College was viewed favorably.

In an academic advising session, one product is the creation of an educational goal. Using a student educational plan (SEP) as a metric of analysis for this goal, all participants were asked if they had a SEP, and $60.1 \%$ answered in the affirmative. Considering only students that stated they had a SEP, it was seen that working with an advisor increased the likelihood of having a plan $(75.0 \%, n=81)$ versus those that had not worked with an advisor $(25.0 \%, n=11)$. This suggests that the creation of a SEP is an important function during an academic advising session. This last result lent support to the need to include a component that would help students to develop a SEP-like device or educational roadmap. 
To guide efforts during the tool creation phase, students were also asked to select features would be important for an online academic advising website.

Participants were presented with an individually randomized list of six possible choices, (see question 5 of Appendix 1). These choices were then ranked by percentage (Figure 10), allowing the researcher to focus on those components on the online academic advising website accordingly. The choice to use the student selection percentages of a particular item for focus had been due to constrains on the availability of data.

Figure 10. Relative Priority of Online Academic Advising Components

\begin{tabular}{lcc}
\hline & $n$ & $\%$ \\
\hline Future Academic Needs & 67 & 77.0 \\
A Space to Talk & 57 & 65.5 \\
Forums & 56 & 64.4 \\
Calendaring & 52 & 59.8 \\
Study Skills & 51 & 58.6 \\
Real Time Chat & 46 & 52.9 \\
Student Specific Choice & 9 & 10.3 \\
\hline
\end{tabular}

The three most selected features for an online academic advising website were: considering future academic needs, having a space to talk, and participating in forums. The importance of planning was seen earlier during the analysis of the SEP item, as well as in the responsibilities of advising systems listed in the NACADA data. The need for individuals to express themselves demonstrates a need to be aware of the power of collaboration, an important element of developmental advising. The choice of an artificial intelligence, as embodied in the idea of a robot named VIC, was made in 
order to provide a means by which the visiting student could immediately become involved with the experience through chat.

The choices selected to a lesser degree were: calendaring, developing study skills and engaging in real-time chat. The need for a calendar to help monitor and ensure academic planning was suggested in the NACADA data (Gordon et al., 2008; Habley, 2004a). Specifically, records management and the evaluation of credits were a responsibility of academic advising systems. A small selection of students when asked by the researcher what they understood the "study skills" selection meant to them, indicated that they wanted a place that would provide information about how to be a better overall student. This particular choice, using this potential definition of the choice, suggests prescriptive advising.

The desire for real-time chat with an actual human advisor, was only added to the instrument after extensive talks between the researcher and critical colleagues. These individuals suggested that students would still rather speak to an actual person during an advising session. The relatively low percentage of students that selected this choice $(52.9 \%)$ suggests that this feature is not as critical as originally believed. Further evidence of this possible interpretation came from a personal discussion had by the researcher and an expert in the field (Roderick, 2011).

The goal of this custom survey instrument was to understand the academic advising experiences of Peninsula College students and to determine the components believed necessary to provide this service online. A majority of students taking this 
instrument had interacted with an academic advisor (70.6\%) and therefore was considered to an understanding of AA services. Participants wanted an online experience that would allow them to see their needs going forward, a developmental idea, while a purely prescriptive advising technique was not as highly endorsed in a ranked order of choice selections.

\section{Tool-Creation Phase: Overview}

During the tool creation phase, the online academic advising instrument (VIC) was developed. The development of this online site involved incorporating the information found during the discovery phase into a working website. This website then acted as a test platform to determine how online academic advising experiences are received by students of Peninsula College.

\section{Value-Added Phase: Quantitative Findings}

In order to evaluate VIC as academic advising system, a tool was needed. The academic advising inventory (AAI) was used, as it has been designed to permit direct comparison of different academic advising systems (between institutions). This instrument provides a means to understanding academic advising along a continuum, using developmental and prescriptive academic advising ideas as its endpoints. This continuum is a direct result of the theoretical grounding of this instrument, and followed from the work of Crookston (1972). The manual for this instrument was used in the evaluation of all findings (Winston, Jr. \& Sandor, 2002). This manual has been 
specifically prepared to aid in both the scoring and interpretation of results from this instrument, for maximal consistency.

In addition to providing an overall scoring for these two styles of advising via a DPA score, the manual details a mechanism for further understanding question groups based on three contained subscales. These subscales allow for analysis across additional dimensions such as: personalizing education (PE), academic decision making (ADM), and selecting courses (SC). PE subscale provides a measure of the student's overall educational experience, taking into consideration both purely academic as well as external commitments. ADM subscale captures the process of academic decision-making and the responsibilities assigned to between the advisor and advisee. Lastly. SC subscale deals with the act of selecting coursework and is meant to reflect the level of trust an advisor has with the advisee in making these choices.

Results from the AAI instrument are presented first from current student reports at Peninsula College (PC). A demographic breakdown of PC student participants can be found in Figure 11. The findings from PC will act as a baseline to understand survey results from students using VIC, for whom a demographic breakdown of participants can be found in Figure 12. 
Figure 11. Demographics of Peninsula College Student Participants in the AAI to Probe Current Academic Advising, Fall 2010

\begin{tabular}{llr}
\hline Gender & & $(\%)$ \\
& Male & 30.5 \\
& Female & 69.5 \\
& Unknown & 0.0 \\
\hline Age & & \\
\hline 18 to 19 & 6.7 \\
20 to 24 & 54.3 \\
25 to 29 & 16.2 \\
30 to 34 & 9.5 \\
35 to 39 & 3.8 \\
40 to 49 & 7.6 \\
50 + & 1.9 \\
Unknown & 0.0 \\
\hline Eihnicity & \\
\hline African-American & 5.7 \\
American Indian/Alaskan Native & 0.0 \\
Asian & 17.1 \\
Filipino & 8.6 \\
Hispanic & 23.8 \\
Pacific Islander & 9.5 \\
Unknown & 5.7 \\
White Non-Hispanic & 29.5 \\
\hline
\end{tabular}

Note: Students completing survey $(n=105)$ 
Figure 11 shows that the majority of individuals that used the AAI to rate PC were female (69.5\%). In addition, most of the participants were under the age of 24 $(61.0 \%)$ results that are similar for students that completed the custom survey instrument, see Figure 9. The majority of students to take this survey instrument were White (29.5\%) and Hispanic (23.8\%).

The alternative treatment group, students that only rated the academic advising experiences provided by VIC were also similarly evaluated using the AAI instrument. A demographic breakdown of these participates, VIC only users, can be found in Figure 12. These two groups were seen to be similar in their overall composition. 
Figure 12. Demographics of Peninsula College Student Participants in the AAI to Probe Online Academic advising Experiences using VIC, Fall 2011

\begin{tabular}{llr}
\hline Gender & & $(\%)$ \\
\hline & Male & 35.2 \\
& Female & 63.6 \\
& Unknown & 1.1 \\
\hline Age & & \\
\hline 18 to 19 & 19.3 \\
20 to 24 & 33.0 \\
25 to 29 & 27.3 \\
30 to 34 & 12.5 \\
35 to 39 & 2.3 \\
40 to 49 & 1.1 \\
50 & 0.0 \\
Unknown & 4.5 \\
\hline & \\
African-American & 4.5 \\
American Indian/Alaskan Native & 0.0 \\
Asian & 15.9 \\
Filipino & 14.8 \\
Hispanic & 15.9 \\
Multi- Ethnicity & 6.8 \\
Pacific Islander & 14.8 \\
Unknown & 3.4 \\
White Non-Hispanic & 23.9 \\
\hline
\end{tabular}

Note: Students completing survey $(n=88)$

In Figure 12, it was again seen that the majority of students participating in the AAI instrument to rate VIC were female $(63.6 \%)$. The majority of students were also under the age of $24(52.3 \%)$. White $(23.9 \%)$ was also one of the largest ethnicities with 
the second largest shared among Asian (15.9\%), Filipino (14.8\%), and Hispanic $(15.9 \%)$.

Data from the first part of the AAI are visualized using box-and-whisker plots, the selection of this format was to provide the necessary information to the reader in a rapid manner. It should be noted that each plot had its axis selected to encompass the range of possible values of the scale considered and differs among the four scales presented. Results have been disaggregated across gender and ethnicity. Lastly, each plot had a dashed line to denote the boundary between developmental or prescriptive approaches, with this value taken directly from the manual (Winston, Jr. \& Sandor, 2002). Values that are close to this cut-off region, one standard deviation, can be understood using an integrative or comprehensive approach to academic advising (Broadbridge, 1996; Fielstein, 1994; Heisserer \& Parette, 2002). AAI Part 1 - Developmental-Prescriptive Advising (DPA)

The Developmental-Prescriptive Advising (DPA) scale "describes the nature of the advising relationship and the breath of topics and concerns addressed during advising sessions" (Winston, Jr. \& Sandor, 2002, p. 11). The scoring for this scale ranges from 14 to 112 units, with the transition between the style of academic advising occurring between $56 / 57$ units. This scale measures the behavioral approach used during an advising session, as perceived by the advisee. A prior study has suggested that the developmental approach would be the preferred system by students (Broadbridge, 1996; Winston, Jr. \& Sandor, 1984a). 
Figure 13. Developmental-Prescriptive Advising (DPA) Experiences Currently at Peninsula College

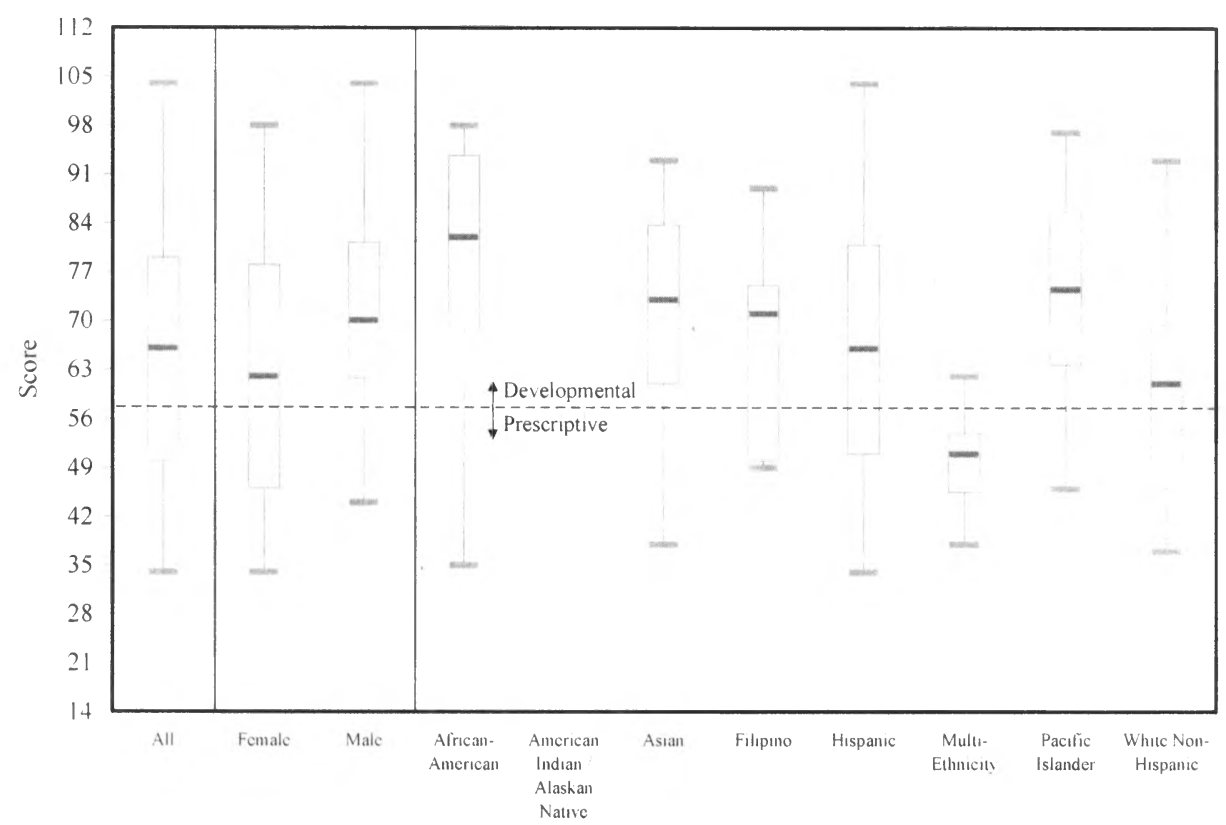

A survey of student attitudes of the current academic advising services at Peninsula College is shown in Figure 13. The mean DPA score $\left(M=65.51^{3}, S D=\right.$ 17.86) of all participants was within the developmental range set by the manual, above than the 56 57 cut-off (Winston, Jr. \& Sandor, 2002), see Figure 13. The data demonstrated a statistical effect due to gender, with men reporting higher DPA scores $(M=71.25, S D=14.56)$ than women $(M=63.00, S D=18.67) ; t(75)=2.44, p=.008$,

\footnotetext{
${ }^{3}$ Please note the apparent difference between the reported mean score and the median value shown in the plot. A study assumption has been that all groups are normally distributed and by definition, the mean and median are the same value. However, this may not be the case and is a study limitation.
} 
one-tailed, $d=.56$. A one-way ANOVA also showed a significant association of ethnicity and the DPA score, $F(6.97)=2.53, p=.026$.

Figure 14. Developmental-Prescriptive Advising (DPA) Experiences using the Online Academic advising System VIC

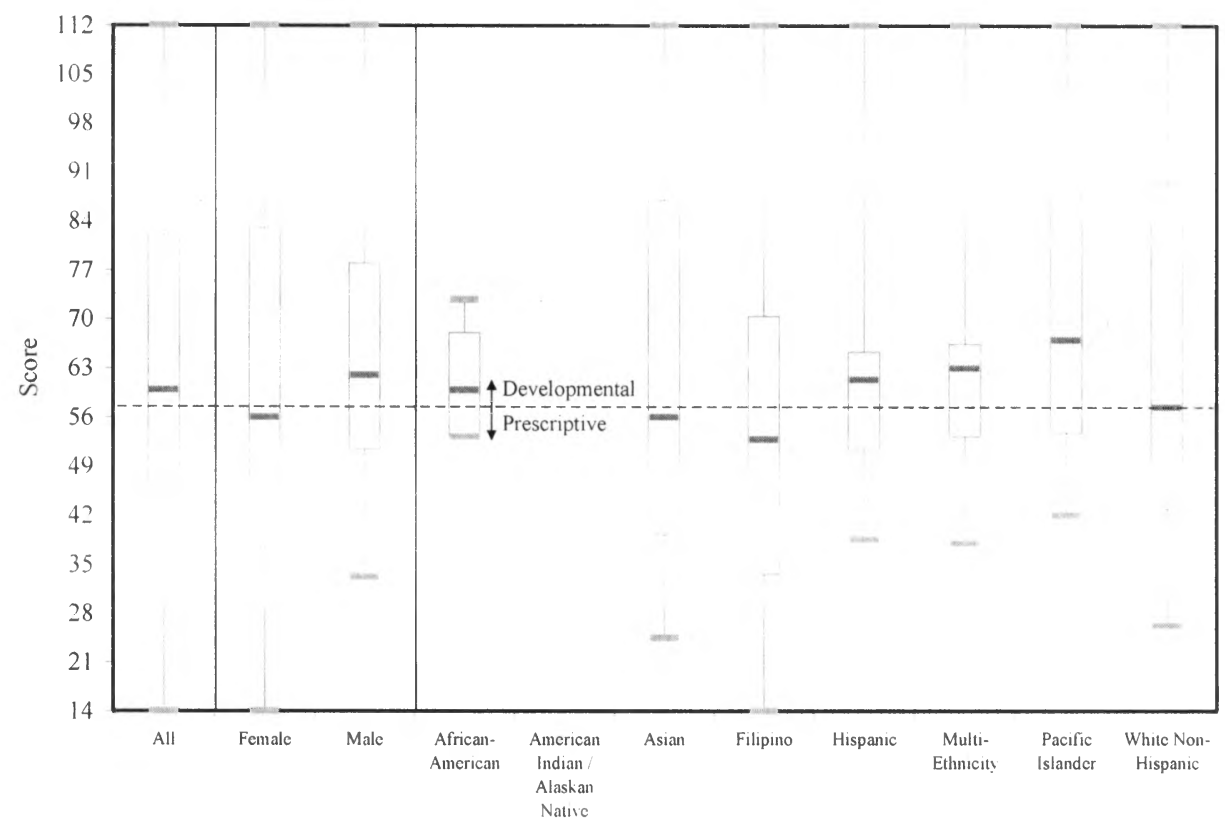

The AAI was also given to probe attitudes of a different sample of students, those using the online academic advising instrument, VIC, Figure 14. The mean DPA score $\left(M=64.84^{4}, S D=24.78\right)$ falls to at least one standard deviation in an integrative advising region. Female mean scores $(M=63.29, S D=25.18)$ and male mean scores

\footnotetext{
${ }^{4}$ Please note the apparent difference between the reported mean score and the median value shown in the plot. A study assumption has been that all groups are normally distributed and by definition, the mean and median are the same value. However, this may not be the case and is a study limitation.
} 
$(M=68.00, S D=24.55)$ scores were not significantly different; $t(56)=.819, p=.208$, one-tailed, $d=.22$. In addition, a one-way ANOVA demonstrated that attitudes were not associated with ethnicity, $F(6,77)=.48, p=.822$.

A comparison of reports of current Peninsula College services and VIC, did not show any significant differences with regard to overall DPA scores, $t(146)=.21, p=$ .417 , one-tailed, $d=.03$. This suggests that these two treatments are equivalent, relative to the DPA scores measured and the way that students view either academic advising system along the developmental and prescriptive advising paradigms.

\section{AAI Part I - Personalizing Education (PE)}

The first subscale of the AAI instrument is the personalizing education (PE). This scale seeks to capture the experience of the student in and out of the classroom. The PE subscale measures perceived attempts to integrate all other interests of the student. High values (33 and above) indicate a developmental approach "characterized by a mutually-derived relationship that is warm, trusting, and purposive" (Winston, Jr. \& Sandor, 2002, p. 11). Scores that are below this range indicate a prescriptive path, a relationship that is more formally structured around only the academic experience and that fails to take into account other student interests. Students can be thought of as receivers of information, with the advisor acting as an information provider. 
Figure 15. Personalizing Education (PE) Experiences Currently at Peninsula College

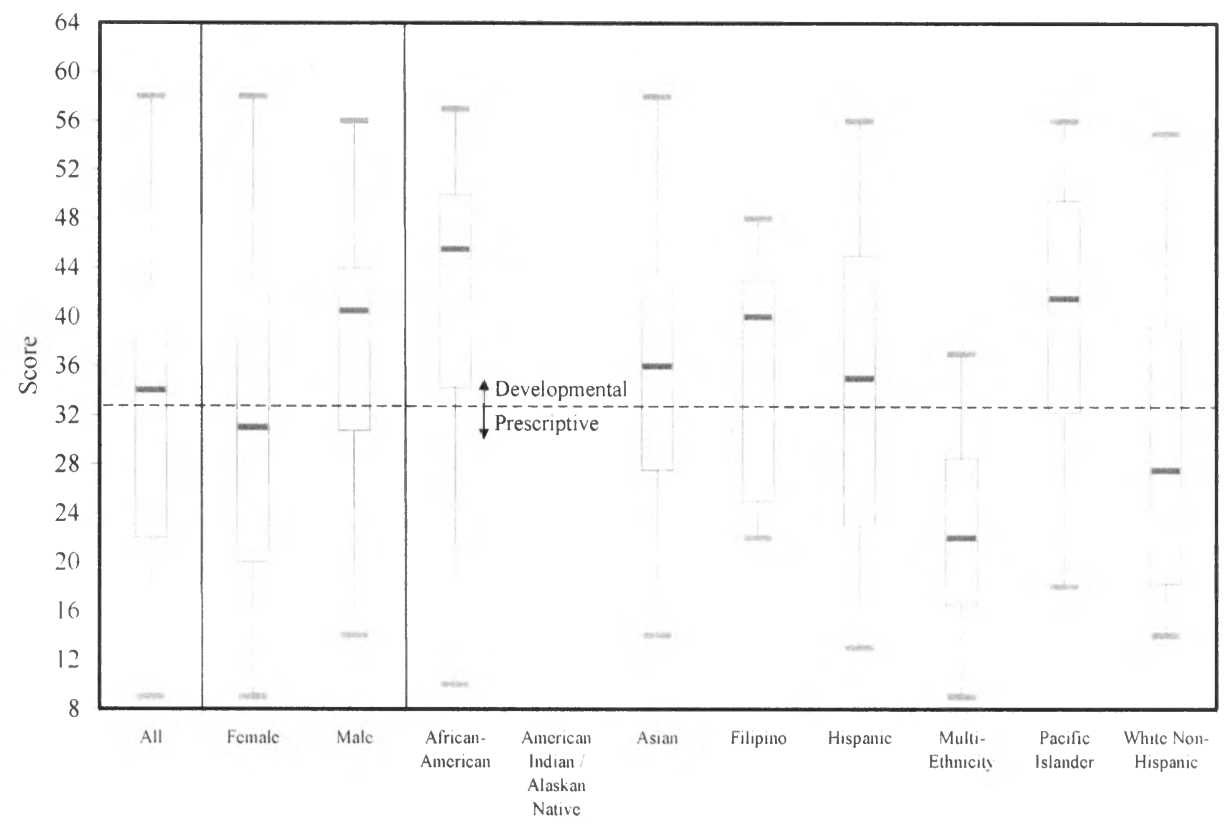

For students reporting on Peninsula College services the mean PE subscale scores for measuring the personalization of academic services $\left(M=33.26^{5}, S D=12.63\right)$ is best understood as within an integrative academic advising region (Fielstein, 1994; Heisserer \& Parette, 2002), Figure 15. The integrative advising region straddles the borderline between developmental and prescriptive activities (33). Women's mean PE score $(M=31.41, S D=13.09)$ tended to be lower than men's mean score $(M=37.47$,

\footnotetext{
${ }^{5}$ Please note the apparent difference between the reported mean score and the median value shown in the plot. A study assumption has been that all groups are normally distributed and by definition, the mean and median are the same value. However, this may not be the case and is a study limitation.
} 
$S D=10.51) ; t(73)=2.52, p=.007$, one-tailed, $d=.59$. Additionally, a one way ANOVA showed that ethnicity was associated with the score reported, with differences among these groups, $F(6,79)=2.78, p=.015$. African-American and Multi-Ethnicity identified students falling in the developmental or prescriptive regions respectively. These findings suggest that African-American students perceive their advising sessions as having a greater level of trust. Multi-Ethnicity students feel that academic advising was more along the path of providing pure information to students.

Figure 16. Personalizing Education (PE) From the Online Academic Advising Experience

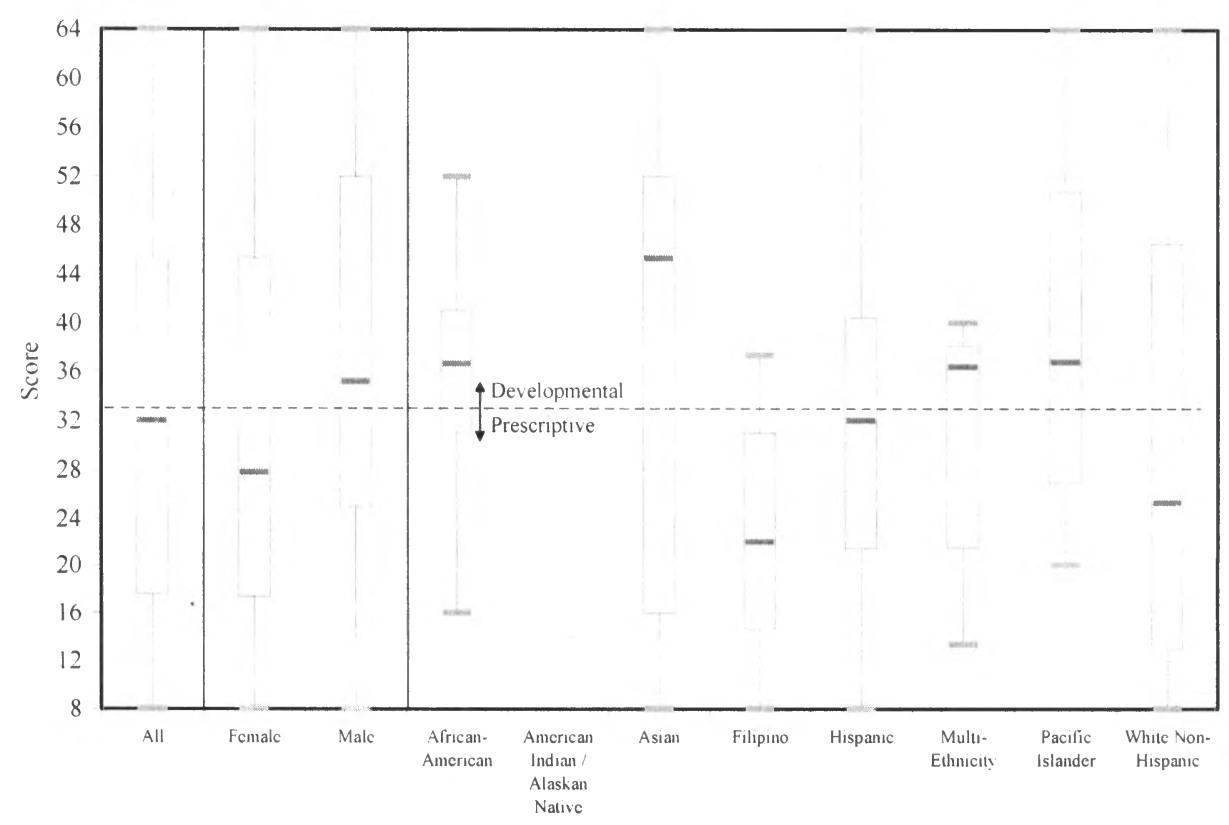


The mean PE score of those students who rated using the online academic advising services of VIC $\left(M=32.34^{6}, \mathrm{SD}=17.19\right)$ was also within the integrative region (Figure 16). There was no statistical difference of mean PE scores between women $(M=30.65, S D=17.11)$ and $\operatorname{men}(M=35.55, S D=17.52) ; t(51)=1.20, p=$ .118 , one-tailed, $d=.33$. An ANOVA showed no effect for ethnicity in intergroup findings, $F(6,75)=1.24, p=.294$. Students that identified as Filipino $(n=11)$ perceived the academic advising of this treatment was towards the prescriptive region as opposed by the other subgroups considered.

There was no difference of PE scores between students rating either currently provided advising services or VIC, $t(144)=.41, p=.343$, one-tailed, $d=.07$. In short, perceptions of the current treatment were associated with differences in student gender and ethnicity, whereas perceptions of the online academic advising service (VIC) were not associated with these variables. These data suggest that student perceptions of the personalizing educational experience of VIC are similar to views of present services and not related to differences in the type of student considered.

\footnotetext{
${ }^{6}$ Please note the apparent difference between the reported mean score and the median value shown in the plot. A study assumption has been that all groups are normally distributed and by definition, the mean and median are the same value. However, this may not be the case and is a study limitation.
} 
AAI Part 1 -Academic Decision Making (ADM)

This subscale is a measure of processes and responsibilities behind the implementation of academic decision-making (ADM), including reports of academic progress and behaviors that assist students with class registration. Scores that are 17 and above are characterized as being developmental, such that the advisor and advisee enter into a mutually constructed relationship: a relationship in which the advisor assists the student in the formulation of all the necessary planning actions with the student understanding that he or she is responsible for implementation. A prescriptive advisor score below this threshold, 17, indicates that the advisor holds all information and is responsible for both making decisions as well as ensuring the student carries out specific actions. 
Figure 17. Academic Decision-making (ADM) Experience at Peninsula College

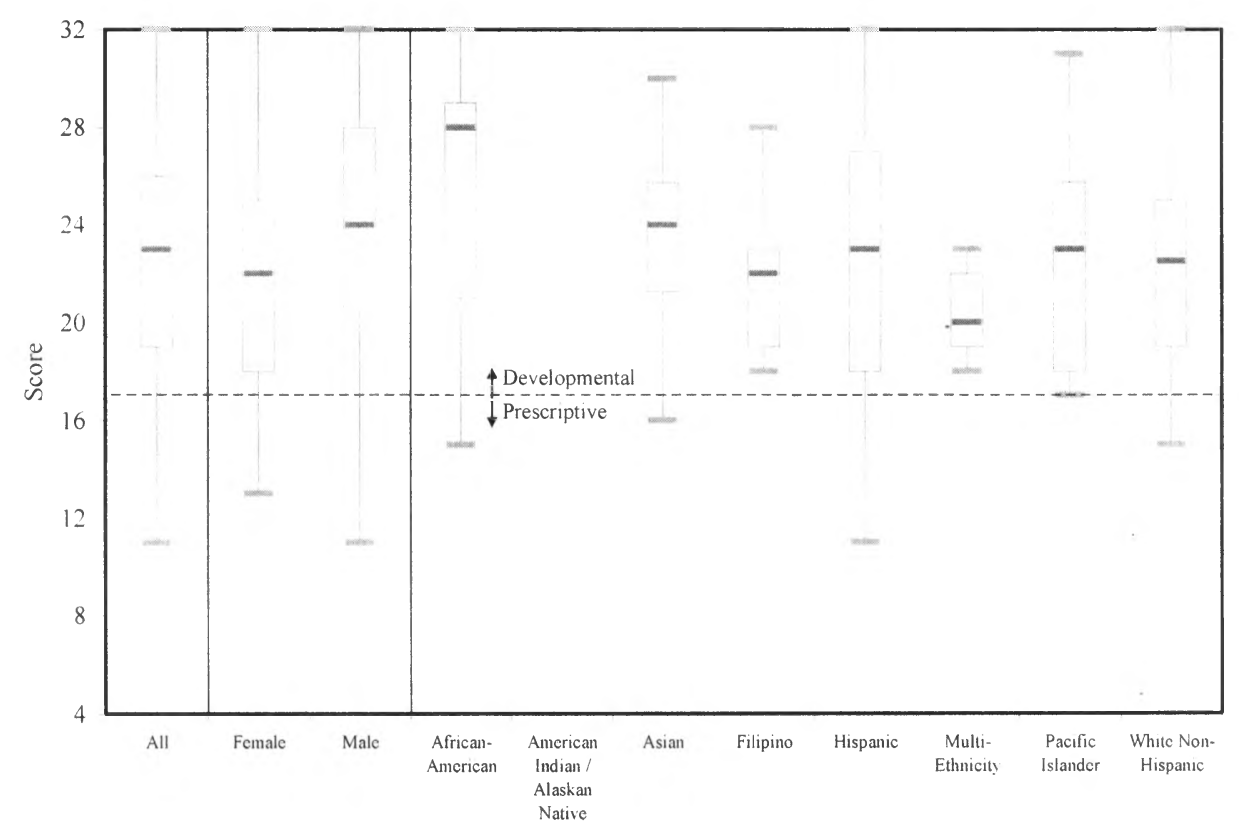

On average, students viewed the academic advising services at Peninsula College $\left(M=22.66^{7}, S D=4.76\right)$ as having following a developmental paradigm. The scores of this subscale were at least one standard deviation within the developmental region, regardless of the subcategories considered, Figure 17. There was no significant difference observed between women $(M=22.19, S D=4.73)$ and $\operatorname{men}(M=23.72, S D=$ 4.72) mean scores; $t(59)=1.52, p=.066$, one-tailed, $d=.40$. In addition, a one-way

\footnotetext{
${ }^{7}$ Please note the apparent difference between the reported mean score and the median value shown in the plot. A study assumption has been that all groups are normally distributed and by definition, the mean and median are the same value. However, this may not be the case and is a study limitation.
} 
ANOVA failed to demonstrate any effect due to ethnicity; $F(6,97)=.70, p=.647$. These two findings are significant, as they show the ADM score was not associated with demographic characteristics of the student.

Figure 18. Academic Decision-making (ADM) From the Online Academic Advising Experience

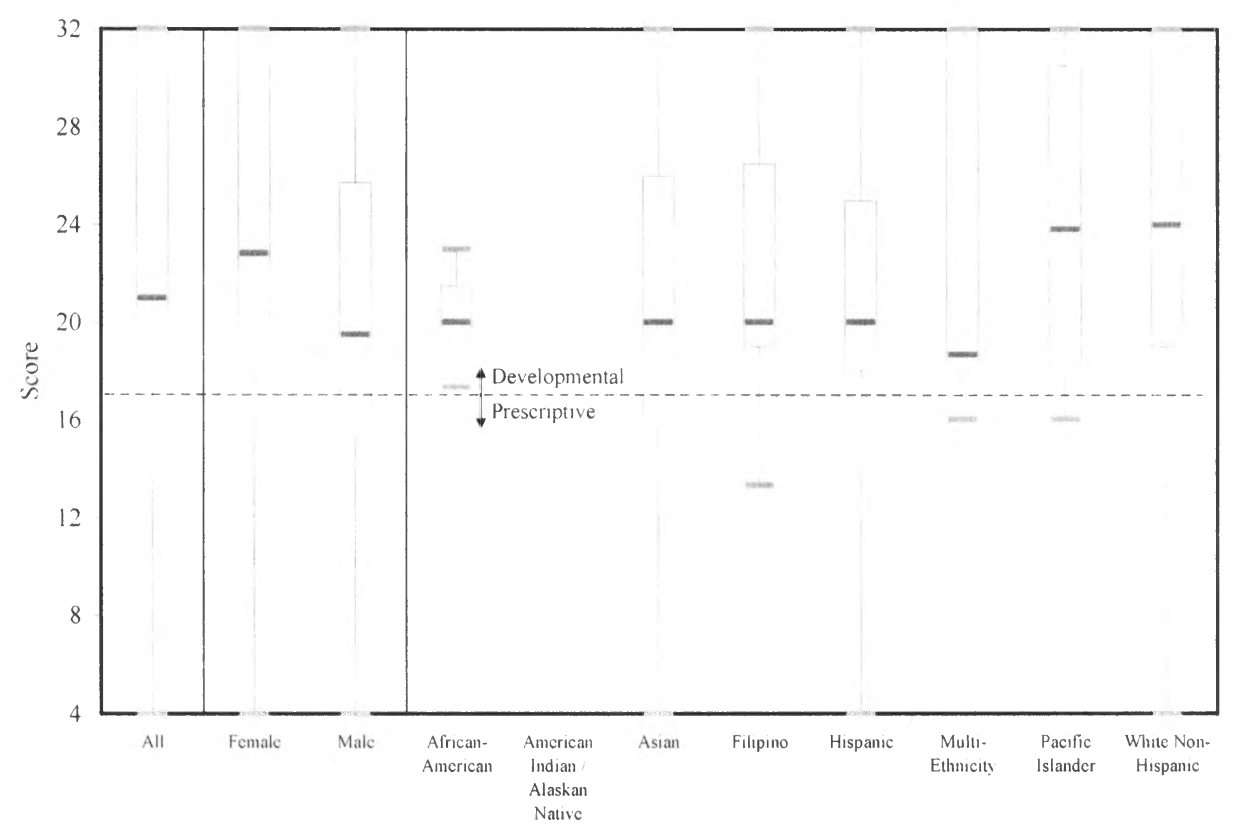

The mean ADM scores of students rating VIC $\left(M=22.31^{8}, S D=7.79\right)$ were also in the developmental region (Figure 18). As with other measures for VIC, this score did not differ significantly for women $(M=23.40, S D=7.29)$ compared to men

\footnotetext{
${ }^{8}$ Please note the apparent difference between the reported mean score and the median value shown in the plot. A study assumption has been that all groups are normally distributed and by definition, the mean and median are the same value. However, this may not be the case and is a study limitation.
} 
$(M=20.48, S D=8.56) ; t(42)=1.45, p=.077$, one-tailed, $d=.45$, and did not demonstrate differences by ethnicity, $F(6,67)=.64, p=.700$. Again, the ADM score was not associated with student ethnicity.

Mean student ADM scores of those rating present service delivery at Peninsula College and VIC were similar, $t(111)=.34, p=.340$, one-tailed, $d=.06$. This was the first scale, as measured by the AAI instrument, in which current advising practices at Peninsula College were unaffected by gender or ethnicity. It is of note that this subscale uses the monitoring of student progress, a relatively objective dataset, to arrive at its score.

\section{AAI Part 1 - Selecting Courses (SC)}

The initial determination of needs and subsequent planning of courses needed is captured within the selecting courses (SC) subscale. The co-creation of an academic plan of action between the advisor and advisee, one that recognizes the final authority of the student to successfully implement it, is encapsulated by developmental principles and SC scores above nine. A prescriptive approach implies that the advisor holds principal responsibility for the planning a course of action, as indicated by SC scores of eight or below, with the advisee as receiver of these planning activities with little input. 
Figure 19. Selecting Courses (SC) Experience of Students Rating Services at Peninsula College

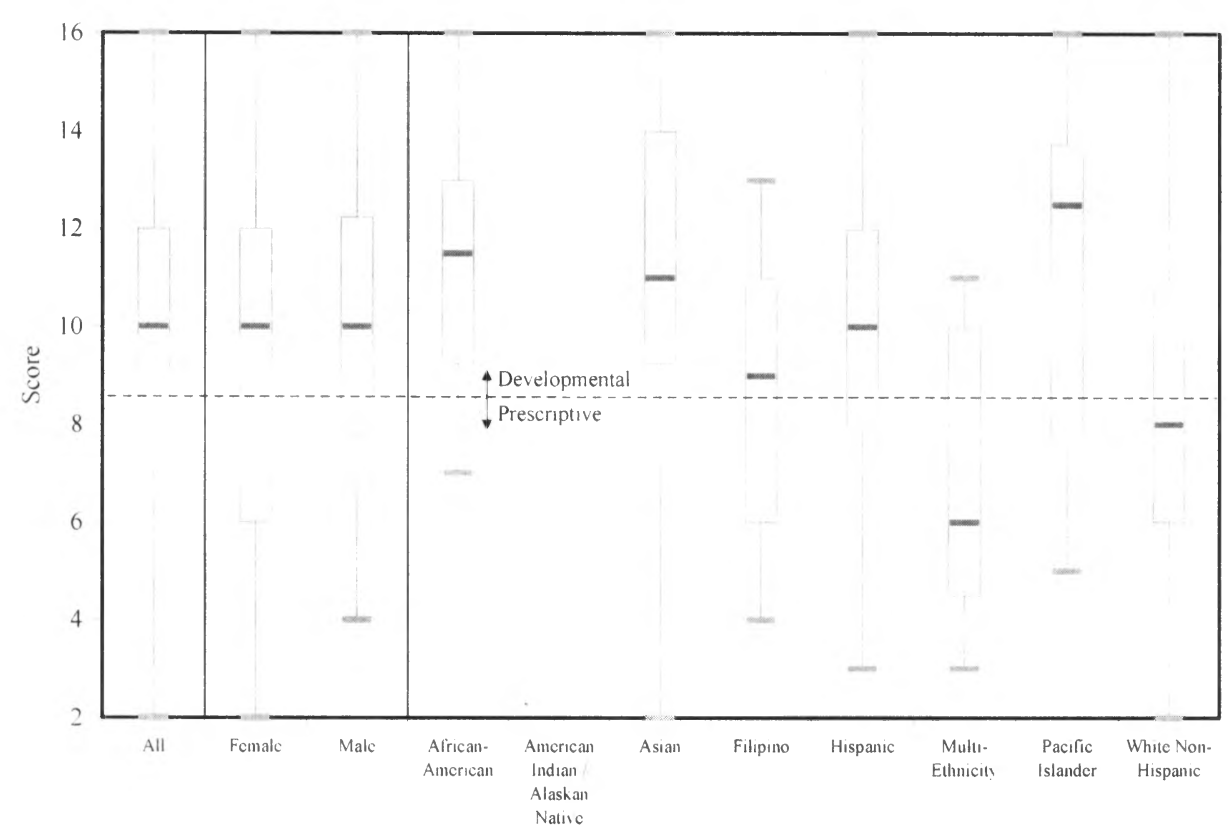

Mean SC scores $\left(M=9.60^{9}, S D=3.68\right)$ were about the 8.5 cutoff indicating the developmental advising region for students rating the Peninsula College advising services (Figure 19). There was no significant difference in women's SC scores $(M=$ $9.40, S D=3.89)$ compared to men's $(M=10.06, S D=3.15), t(72)=.92, p=.179$, one-

\footnotetext{
${ }^{9}$ Please note the apparent difference between the reported mean score and the median value shown in the plot. A study assumption has been that all groups are normally distributed and by definition, the mean and median are the same value. However, this may not be the case and is a study limitation.
} 
tailed. $d=.22$. A one-way ANOVA demonstrated no association of SC score and ethnicity, $F(6,97)=1.97, p=.078$.

Figure 20. Selecting Courses (SC) Experiences of Students Rating the Online Academic Advising Experience of VIC

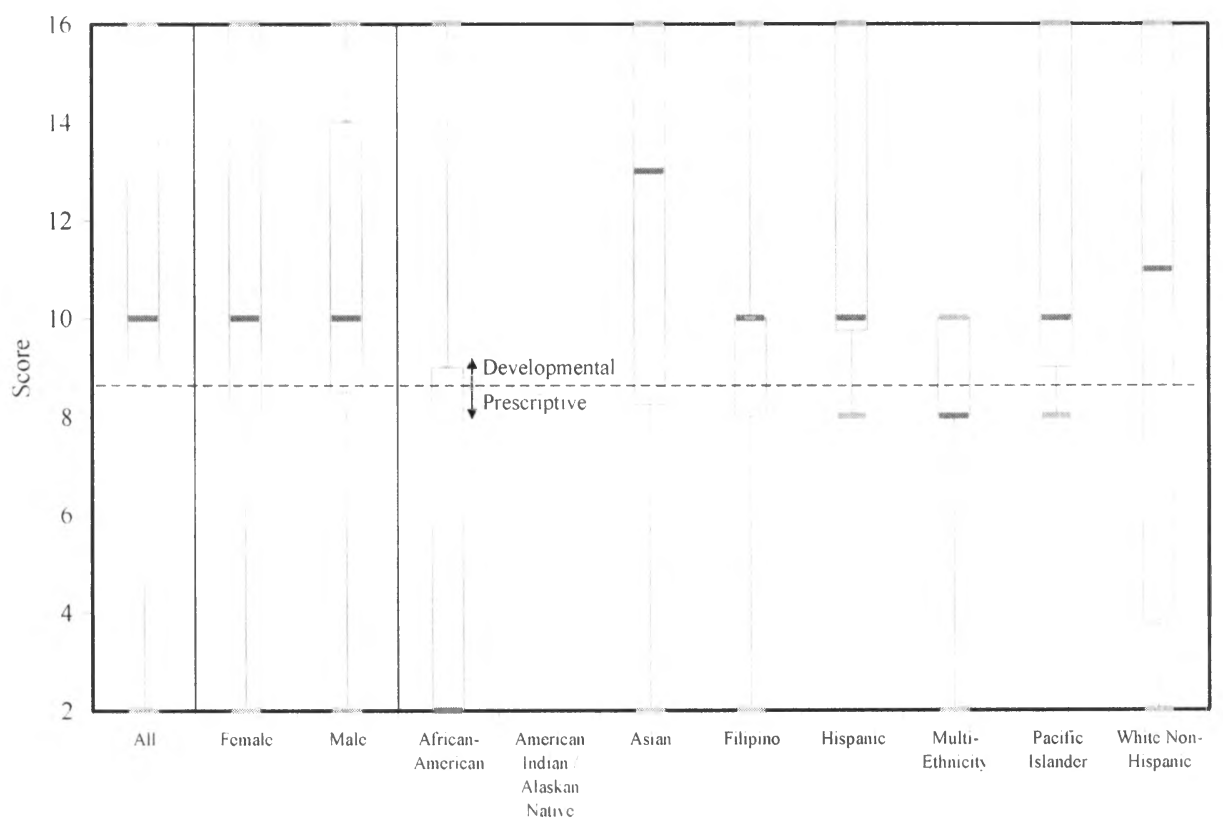

The mean SC scores of those students rating the online academic services of VIC $\left(M=10.20^{10}, S D=4.9\right)$ fell within the development region, with the exception of students identified as African-American or Multi-Ethnicity (Figure 20). As with other measures of the AAI instrument, this metric did not show any effect between women

\footnotetext{
${ }^{10}$ Please note the apparent difference between the reported mean score and the median value shown in the plot. A study assumption has been that all groups are normally distributed and by definition, the mean and median are the same value. However, this may not be the case and is a study limitation.
} 
$(M=9.95, S D=5.47)$ and $\operatorname{men}(M=10.78, S D=3.87) ; t(45)=.66, p=.256$, onetailed, $d=.20$, or by ethnicity, $F(6,53)=.82, p=.557$. One possible explanation for the observed values for African-American students, were the limited number sampled for this subcategory.

The overall SC score for students reporting on current academic advising services at Peninsula College compared to VIC also showed no differences; $t(96)=.82$, $p=.208$, one-tailed, $d=.17$. Students from these two groups reported receiving equivalent academic advising services, as measured by the SC subscale. Additionally, there was no observed association either of gender or ethnic identity with these two treatments.

Influence of Goals on the AA Experience

The AAI instrument used (Appendix 3) was modified to capture additional characteristics of study participants, such as having a goal prior to any form of academic advising. Goal inclusion was deemed important during the initial stages of VIC (i.e. in the discovery and tool creation phases). Study participants were asked if they had a goal upon entering college in order to determine if this characteristic was associated with the scores found on Part 1 of the AAI (see Figure 21). Mean scores within the four scales were tested using a one-tailed t-test. 
Figure 21. Association of Having a Goal With Perceptions of Academic Advising (AAI Part I Scores) for Peninsula College and VIC Participants

\begin{tabular}{|c|c|c|c|c|c|c|}
\hline & $M$ & $S D$ & $d f$ & $t_{S T A T}$ & $p$ & $d$ \\
\hline \multicolumn{7}{|l|}{ Peninsula College } \\
\hline \multicolumn{7}{|c|}{ Developmental/Prescriptive Advising (DPA) } \\
\hline Goal & 64.20 & 18.63 & \multirow[t]{2}{*}{65} & \multirow[t]{2}{*}{1.64} & \multirow[t]{2}{*}{.053} & \multirow[t]{2}{*}{.41} \\
\hline No Goal & 69.90 & 14.63 & & & & \\
\hline \multicolumn{7}{|c|}{ Personalized Education (PE) } \\
\hline Goal & 31.93 & 13.02 & \multirow[t]{2}{*}{61} & \multirow[t]{2}{*}{2.11} & \multirow[t]{2}{*}{.019} & \multirow[t]{2}{*}{.54} \\
\hline No Goal & 37.21 & 10.73 & & & & \\
\hline \multicolumn{7}{|c|}{ Administrative Decision Making (ADM) } \\
\hline Goal & 22.52 & 5.01 & \multirow[t]{2}{*}{63} & \multirow[t]{2}{*}{.73} & \multirow[t]{2}{*}{.235} & \multirow[t]{2}{*}{.18} \\
\hline No Goal & 23.21 & 4.03 & & & & \\
\hline \multicolumn{7}{|c|}{ Selecting Courses (SC) } \\
\hline Goal & 9.75 & 3.65 & \multirow[t]{2}{*}{52} & \multirow[t]{2}{*}{.33} & \multirow[t]{2}{*}{.370} & \multirow[t]{2}{*}{.09} \\
\hline No Goal & 9.48 & 3.59 & & & & \\
\hline \multicolumn{7}{|l|}{ VIC } \\
\hline \multicolumn{7}{|c|}{ Developmental/Prescriptive Advising (DPA) } \\
\hline Goal & 62.06 & 25.48 & \multirow[t]{2}{*}{48} & \multirow[t]{2}{*}{1.88} & \multirow[t]{2}{*}{.033} & \multirow[t]{2}{*}{.54} \\
\hline No Goal & 72.89 & 22.92 & & & & \\
\hline \multicolumn{7}{|c|}{ Personalized Education (PE) } \\
\hline Goal & 30.57 & 17.32 & \multirow[t]{2}{*}{43} & \multirow[t]{2}{*}{1.67} & \multirow[t]{2}{*}{.051} & \multirow[t]{2}{*}{.51} \\
\hline No Goal & 37.52 & 16.56 & & & & \\
\hline Administrative De & $\operatorname{sion} \mathrm{Ma}$ & $\mathrm{g}(\mathrm{ADN}$ & & & & \\
\hline Goal & 21.94 & 7.47 & 36 & 1.24 & .112 & .41 \\
\hline No Goal & 24.38 & 7.66 & & & & \\
\hline Selecting Courses & & & & & & \\
\hline Goal & 9.49 & 5.08 & 29 & 1.54 & .067 & .57 \\
\hline No Goal & 11.69 & 4.76 & & & & \\
\hline
\end{tabular}

NOTE: Results for come from one-tailed $t$-tests. 
Figure 21 shows that for PC participants, having a goal had a significant association with the PE subscale. Additionally the computed effect size, $d$, was .54 indicating a medium relationship between these variables according to Cohen (1992). It is noteworthy that for the DPA score reported, the p value was, to one significant digit, at the $\mathrm{p}$ value set under study assumption. Students who did not have a goal reported higher scores on both measures, the developmental region. Having a goal was not associated with either ADM or SC scores. This suggests that perception of the type and scope of relationship felt between advisor and advisee depends in part upon whether the individual has a goal.

An association of having a goal and with the part $1 \mathrm{AAI}$ scores for participants rating VIC is also shown (see Figure 21). The computed effect size of the variables of goal and no goal was .54 indicating a medium level relationship between these variables (Cohen, 1992). Findings were similar to those for students rating the academic advising services at Peninsula College. A significant association was seen been having a goal and the DPA scale. The calculated $\mathrm{p}$ between having and goal and the PE subscale, to one significant digit, was seen to be on the $\mathrm{p}$ value set under the section of study assumptions. Overall DPA and PE mean scores were higher for students without a goal compared to those who did. Having a goal was not significantly associated with either the $\mathrm{ADM}$ or $\mathrm{SC}$ subscales.

These findings suggest that academic advising services at PC and those provided by VIC were equivalent as measured by this unit of analysis. In order to test this 
hypothesis, one-tailed $t$-tests were run to compare the mean scores respectively of students with a goal or without a goal between the two advising systems. T-tests showed no significant differences by setting in the scores of those who respectively had a goal or did not have a goal with regard to DPA ( $\underline{\text { Goal }}: p=.297, d=.11$; No goal: $p=$ $.292 . d=.17), \operatorname{PE}(\underline{\text { Goal }}: p=.311, d=.10$; No goal: $p=.469, d=.03)$; ADM ( $\underline{\text { Goal }}: p=$ $.315, d=.11$; No goal: $p=.263, d=.24)$; or SC ( $\underline{\text { Goal }}: p=.387, d=.10$; $\underline{\text { No goal }}: p=$ $.059, d=.65)$.

\section{AAI Part 3 - Satisfaction}

The third part of the academic advising inventory (AAI) was also used in the current study and was designed to measure the satisfaction with the advising experience. This part of the instrument has five portions that covered "(A) overall satisfaction, (B) accuracy of information provided, (C) adequacy of notice about deadlines, (D) availability of advising when desired, and (E) amount of time available during advising sessions" (Winston, Jr. \& Sandor, 2002, p. 12). These were measured on a four point Likert-type scale and provided a mechanism to compare VIC to the academic advising system of Peninsula College (see Figure 22). 
Figure 22. Comparisons of Peninsula College (PC) and VIC Satisfaction Scores

\begin{tabular}{|c|c|c|c|c|c|}
\hline & $M$ & $S D$ & $d f$ & $t_{S T A T}$ & $p$ \\
\hline \multicolumn{6}{|c|}{ Overall satisfaction } \\
\hline $\mathrm{PC}$ & 2.62 & 0.95 & \multirow[t]{2}{*}{188} & \multirow[t]{2}{*}{.29} & \multirow[t]{2}{*}{.383} \\
\hline VIC & 2.69 & 0.87 & & & \\
\hline \multicolumn{6}{|c|}{ Accuracy of information provided } \\
\hline $\mathrm{PC}$ & 2.70 & 0.85 & \multirow[t]{2}{*}{183} & \multirow[t]{2}{*}{.45} & \multirow[t]{2}{*}{.325} \\
\hline VIC & 2.68 & 0.84 & & & \\
\hline \multicolumn{6}{|c|}{ Adequacy of notice about deadlines } \\
\hline $\mathrm{PC}$ & 2.73 & 0.78 & \multirow[t]{2}{*}{168} & \multirow[t]{2}{*}{.59} & \multirow[t]{2}{*}{.278} \\
\hline VIC & 2.69 & 0.91 & & & \\
\hline \multicolumn{6}{|c|}{ Availability of advising when desired } \\
\hline $\mathrm{PC}$ & 2.85 & 0.83 & \multirow[t]{3}{*}{172} & \multirow[t]{2}{*}{1.09} & \multirow[t]{2}{*}{.139} \\
\hline VIC & 2.74 & 0.93 & & & \\
\hline \multicolumn{5}{|c|}{ Time available during advising sessions } & \\
\hline PC & 2.70 & 0.83 & \multirow[t]{2}{*}{170} & \multirow[t]{2}{*}{.32} & \multirow[t]{2}{*}{.373} \\
\hline VIC & 2.77 & 0.96 & & & \\
\hline
\end{tabular}

Figure 22 shows that the mean satisfaction scores for the two academic advising systems were similar and demonstrated no statistical differences.

\section{Value-Added Phase: Interview Findings}

Qualitative data used in this study comes from interviews conducted at Peninsula College (PC). These interviews were used to provide a source of rich data, to first probe how students developed their educational goals that resulted in their decision to come to college. These interviews then focused upon their perceptions of academic advising experiences at PC and then using VIC. These interviews allowed the 
researcher an understanding into the motivations of these individuals as well as how students interact with academic advising systems. The overall goal of this portion of the research was to give voice to potential end users of this student support service, a task that the survey instrument data was unable to accomplish.

\section{Student Interviewees}

Nine individuals asked by the researcher agreed to be interviewed for this study. The researcher either knew these individuals as former students or through mutual acquaintance. All were students taking at least one science class at Peninsula College (PC) and were recruited within the Math Science building. These students were not a statistically representative sampling of the larger PC community and can be thought to have been a result of convenience sampling. These student participants varied by gender, ethnicities, age group, and educational goals.

The initial objective of these interviews was to gain greater insight into the reasons students sought out a college education, probing their goals and motivations. The researcher then focused these interviews to investigate perceptions surrounding academic advising services. The aim was to provide evidence into how academic advising services are seen to interact and help students achieve their reasons for being at college.

Students gave their impression of Peninsula College's AA and the influence this student support service had upon their immediate collegiate aspirations. These same individuals then were asked to use VIC and give their appraisal as to the potentials of 
this online AA tool. The resulting data would later serve to provide actual student or end user voice to this service.

The first interview sought to determine why students had decided to pursue a college education, how they developed their goals, and their perceived support in this process. They were asked to share their preparation and planning to come to college, whether they had a set goal in mind or not. Students were then asked to describe their interactions with academic advising services and the influence upon the college experience. During the analysis of the first interview, emerged the idea of college as dream. As with any dream, a dreamer seeks the successful closure to the adventure using all available tools, such as academic advising. What was the genesis of this dream?

\section{The College Dream}

Interviewees were asked to share how they developed their college goal, their process and if they had someone they could look towards for guidance. For many, the reasons for coming to college focused upon the desire to have the necessary skills for a career that would offer future financial security. John spoke about the effect of witnessing the lifestyle of his father's employer had on his future educational ambitions:

My dad works as a chauffer for a plastic surgeon in San Francisco, his name's called Dr. David Rash (a pseudonym), and I saw the kind of lifestyle he was living. I kind of asked myself this guy's a regular human being, he had to start off from somewhere and the type of lifestyle he's living, I think anybody can do it. So I was like, you know, if he's able to do it, then I should be able to do it too and it just kind of gave me an added motivation to kind of say, 'You know 
what? This is something that I want to do, I want to make some good money at that too and help, help each other out'. I got into college.

Observing a lifestyle that, in John`s eyes, is made possible through education instilled the desire and motivation to pursue a college education. That is not to say that John's only motivator was potential rewards, it was also his heartfelt desire to help others in need of medical help due to his prior personal experiences:

I wanted to be successful and always I felt like being a doctor is where I could be [successful] and [...] help those people that are less fortunate than I am because - especially with health care. I mean, I was sick and I think it cost a lot of money with my medications, the tests, going to see the specialists and, you know, I was kind of blessed and thankful that my family was able to pay for health insurance because if they weren't, if I didn't have any type of health insurance, then I don't know what would have happened. So, you know, just thinking of the advantage and saying, "You know what? I'm blessed and I want to help those others that aren't as fortunate as I am," so coming to college I always knew that I wanted to do that and kind of had a concrete idea of, you know, where I wanted to go and where I wanted to end up.

John was not the only person whose decision to come to college was influenced by a desire for bright new future. A future that had been molded from prior life experiences. Daniel who currently works as an Emergency Medical Technician (EMT) spoke about coming to college without a clear direction initially:

initially I dropped out of college, when I transferred I wasn't ready for it and then I got my EMT license and I've been working as an EMT for I think like five years now.

While working in this field, he observed first hand a strict chain of command and how this made him talk about how he did not want to be "too servant" in his future career. He wanted to be able to distance himself from the occasional "arrogant 
Paramedic" that would "pull the leadership card." Daniel's goal was to break free and be in a position of greater personal responsibility and choice. College was a means for him to achieve a position that would allow him the personal freedom and choice.

In these stories, the motivation to attend college having been created from a strongly desired, if murky, goal. That goal was the creation of a person that would have the freedom and personal space to live the life that they desired. For John, it was having economic security as well as being in a position to give back to those that had helped him as a child. Daniel having first come to college only to drop out to work as an EMT, was ready to restart his studies towards a career where he would have greater personal freedoms over his work life. Like a dream, what feels real is nonetheless wrapped within a shroud of mystery.

That mystery was navigating the actual college experience towards these personal goals, having only limited personal support structures to use. When Daniel was asked if he had anyone he could turn to for help. he shared:

That actually is a huge obstacle for me because I' $m$ the first person in my immediate family to go to college and here I am fricking aiming for the stars planning to get a doctorate in something and my mom has, I think, maybe a year of community college, dad doesn't have any at all. So no one in my immediate family does [have a personal understanding of college systems], and I think in my entire family; I think we have two Bachelor's degrees. [...] So the short answer is no. I don't have any trusted individuals that are able to help me.

Daniel's story was not unique, Ian stated, "I didn't have any college experience" and he did not have anyone whom he could immediately turn to for guidance. 
In the absence of these external or personal support structures, students spoke about other means they used to stay on course, to achieve their dreams. Some used their heartfelt belief in the dream itself to sustain them. Others had deeply personal goals they could turn to, and others felt an obligation to develop these into tangible results. Regardless of the reasons, all were set on achieving the goal that they had set for themselves and college was the vehicle that they felt would allow them to accomplish this task.

\section{Believing the Dream}

For John, his dream was pursuing a job that required an education, "you go to school, man, so you have a career." It was a desire for a level of security in his own life that he felt was missing in his family experience:

I kind of viewed my mom and my dad and my brother as something that I didn't want to be. My brother's going down the same path where my dad is, where he's going to have to work really hard just to get, you know, chump change. That's something that I didn't want to - I don't want to end up and that's what kind of gives me that added motivation to keep on going.

John`s belief carried forth in a how he conducted himself going through college, "I'm [John] willing to stay those extra hours if I have to, I'm willing to go ask questions when needed." It was his desire to obtain his goal and seeing others that gave him the motivation to go to college and stick through the college experience.

Karen talked about her motivation, coming to college after nearly 25 years in her profession as a medical assistant. "I wanted to do more so I know that I needed to go to 
college." For her, she did not have the opportunity to attend college as her "parents couldn't afford college." Now after 25 years Karen "knew [her dream] was nursing" and it was her passion in seeing this goal that gave her a plan to get through college. "I'm really happy because I'm receiving the Associate of Science in pre-nursing at the right time." It was her desire to obtain her stated goal that provided her the personal drive she needed to get through college.

Students talked about life goals and in many cases had only their belief in this dream to sustain themselves as they moved through the college experience. Neither John nor Karen had anyone in their immediate social circle they could ask for help in refining their understanding of college. Instead, they had only an idea of what they wanted to provide the necessary motivation to make their way through college.

For these students, the desire to achieve their goal provided them the "belief in oneself" (John) to embrace an unfamiliar environment. Belief itself was the fuel that would power these individuals through college. It was their unfaltering beliefs that convinced the researcher that they could reach the heights they spoke about, and it was later that the researcher would be congratulating both of these students at their commencement from PC.

Personal Goals - Personal Reasons

The road to college and the reasons that some students found themselves in this environment were deeply personal. Ian talked about working in construction and not "hav[ing] any college experience", adding that he knew if he did go to college he 
would "have to take a lot of remedial courses." When asked why he sought such a path initially, he stated that he did not have a clear reason. He confided that at the start of his college experience, he was not initially convinced that this environment was right for him. It would take a personal crisis that would provide him a personal goal that would give him the needed focus and motivation to be successful.

He was working full time in construction and had started attending Peninsula College part-time for engineering, a major that he considered safe. "Originally I [Ian] wanted to be a Chiropractor but I figured that it's going to take me so long [of time], I'm already thirty four, I don't want to be like almost fifty when I'm done." While taking courses, the local economy turned for the worse and he found himself unemployed. The additional time he now had, allowed him a moment of reflection and he recalled the reasons he began college initially.

Ian talked about his visits to a chiropractor and the relief these sessions provided him: "Wow! I didn't know my body could move like this." From this personal crisis, that he was able to re-evaluated his goals and realize as a full-time student, he "might as well go into Chiropractic, which is what [he] want to do in the beginning." "So then after that first semester of Engineering [he] switched" majors and is pursuing a deeply personal goal. Pursuing a profession, he viewed as having brought him physical joy and undoing bodily damage from a lifetime of work in construction.

He talked about after embracing this switch; he felt he now had a clear direction. A direction that made him "become more proactive, at looking at his classes. If you 
want to take a sequence of class, you better fill in the right one." He became more active in the selection of his courses and took over the academic planning necessary at achieving his goal.

Paul talked about how his first college experience was not the one that he had wanted. He started with a goal that he thought would hold his interest but in the end just wanted to leave:

Okay, so [my] first experience as an undergrad, I was really in a position that a whole lot of other students were in. High school's over, what happens now? So two major options; either get a job or go to college; I had the option to go to college. So starting off in college I had no idea what I wanted to do, didn't have any really set goal. Sort of a loose understanding of a goal that I had at the time was I wanted to be a programmer, it was leaning towards mathematics and computer science. But, as it happens to everyone else, you know, things sort of changed and - it sounds kind of bad but halfway towards my undergrad experience I actually just wanted to graduate at this point and so I leaned towards my strengths which was reading and writing. That's why I took the Communications major. So at that point, it wasn't really career-based as an undergraduate, it was, you know, just playing to my strengths and just to try to get that Bachelor's at the very least.

After working six years in the field of quality control for a video game programming company, Paul was laid off. Finding himself now unemployed, he talked about how his "stress levels were through the roof." He attributed his stress as having stayed in a job that did not hold a clear future for him, "if I [Paul] wasn't dicking around for the last damn three years at my old job, who the hell knows where I'd be right now?" Again from a personal crisis emerged an individual asking where he wanted to be going forward. 
He enrolled at Peninsula College, unsure if he would be able to succeed in the sciences. He tested the waters and after being successful in his courses, "reaffirmed the fact that [he] was capable of learning the sciences." This gave him the courage necessary to reconsider his field of study and that, "EMT work is pretty fascinating." Paul then enrolled in classes that would allow him to pursue a career in the medical field, as he believed this field would provide him a personally rewarding future.

For Ian and Paul, the crisis of finding oneself unemployed allowed them the opportunity to reflect upon to their original spark that lit their interest to consider college. This spark was a personal reason and they attribute this desire as providing the necessary motivation to apply their full efforts at the college experience. Although they may have arrived at the steps of college with hesitation, through deep reflection they were able to rekindle their passion and find their motivation to push through this experience.

Achieving the Goal

For some students interviewed college and the sense of obligation to realize their future goals had a large influence upon their motivation to attend. Andrew shared, "my family works hard for me to even come here, for me to pay for the books [...] I [Andrew] wouldn't even been able to come here let alone want to transfer anywhere else." For Andrew, college represented a complex intersection in his life and it was his responsibility to be successful. "I mean, isn't that the whole point [to get out of college successfully]" (Andrew)? 
Lisa's goal and reason for coming to college was centered around procuring an associate degree. She attributed her focus around her achieving this goal from her having come to college later in life, "I [Lisa] was more situated because I'm an older student returning, so it was easier for me [I] have a focus." She readily acknowledged in her interview that had her younger self been asked about her focus in college, "I wouldn't know what to do." That is not to say that she knew precisely how to accomplish her goal of graduating with an associate degree.

She had initially come thinking that she wanted to do computer science, switching then to physical education. She was to change her major a couple of more times, and as she went through her studies the specifics surrounding what her major was be came into the same sharp focus as her desire to graduate with a degree. Through this entire experience, she never questioned her want to achieve her goal. It was her determination that in the end, "[she] was fortunate to have this AS degree."

Having a goal for these two students gave them a point of focus that they were able to parlay into a successful college experience. Their resolve to achieve was the source of motivation that allowed them to continue their studies. Andrew and Lisa talked about wanting to achieve the dream set out for themselves, and in the case of Andrew for his family as well. Academic Advising Experiences So Far

For the students that were interviewed, the decision to go to college was the want to realize a dream. The personal energy that would sustain this want and push 
these students to make the commitment was fueled in a number of manners. For John, it was his belief in himself and the potential reward of an intended future career that gave him the motivation to stay on track in college. Ian and Paul, found themselves through personal crisis asking what was the future they had originally envisioned for themselves providing the recalibration they needed to stay the course. For Lisa, her focus came from a deep personal desire to earn her degree, her goal

Though their goals may have emerged from divergent reasons, all came to college wanting to see their dream realized. Many lacked the fine understanding of the institution they now found themselves in, due to a lack of trusted individuals in their support network. Such as Daniel who shared, "I don't have any trusted individuals that [were] able to help me [understand college]." In the case of Tammy with whom her support network had no understanding of US based colleges, she had to develop her understanding using alternate methods. In the absence of trusted individuals from their lives to supplement their navigating various college systems, they reached out to the formal academic advising services provided by PC.

Student perceptions of academic advising (AA) at Peninsula College typically fell towards extremes and lacked uniformity. Some had wonderful experiences that ushered in college with a bang. Such as Karen whom described her first encounter with an advisor as "empowering" and giving her the tools to go after her dream. For other students, they came away feeling as though they had been greatly let down. "I don't 
think that counselors [advisors] look at an individual as an individual" (John). "It's (AA) not consistent" (Lisa) was one theme in the interviews obtained.

Talking with the students and determining their perceptions of how this service ought to be conducted was an important overall study aim. Student insight of this service will be necessary to successfully transition towards the online domain. Students began to unpack their interaction with the service by explaining how they came to seek out this help. Then they talked about how this information was processed and a value assigned. As each talked about their personal experiences with this support service, they used the example of a doctor's visit in an analogous manner.

Seeking Academic Advising Help

For Karen. the decision to come to college was an emotionally complex proposition and one that she had little personal understanding. She shared how meeting an advisor before starting college was a pivotal moment, one that empowered her to take on this task:

He [a PC advisor] told me what I needed to do, showed me an associate's degree and said, "If you didn't know what you wanted to do, just start here," and it was reasonable, I felt like it was do-able. I didn't feel nervous because I was the nontraditional student in my late 30 s coming into college for the first time. He did not make me feel embarrassed about it, I just felt comfortable. I feel like if I did not have him as my first counselor I do not think I would be here.

Karen "came in really wanting to start college for the first time in [her] life," realizing the need to augment her understanding of this environment in order to be successful. She reached out to the formal academic advising services offered by 
Peninsula College and was given "so much encouragement and I didn't even start a class yet." This initial experience gave her the needed strength "to keep going, so I'm still here [attending college]."

Others had experiences that were more of an indifferent nature. Lisa had come to college later in life to earn a college degree and routinely went to AA services in order to have an up to date student educational plan. When asked about her experiences with academic advisors during these sessions she sheepishly replied, "I had two yes [good advisors] and one no [not so great advisors]." During this portion of her interview, the researcher noted that Lisa seemed to shrug this off as a case of her having "seen three different counselors [advisors] each time [she] went" to AA. This lack of consistency was noted in her interview. Lisa saw AA as a service that provided a plan of action and had learned to manage her expectations. Christine summed up nicely this sentiment, "there are great ones [advisors] and there have been bad ones."

Daniel sought out academic advising, after dropping out and coming back to college after years on the job he wanted to make sure this time would be different. Daniel shares of his first experiences with PC advising services:

When I went there [to PC advising], especially for me, I needed a leader to help me answer, "You know, this is what I want to do, how can I do it?" Not someone who would follow my lead. I don't know what I'm doing, so why are you going to follow me and make a plan off what I'm saying? I'm an idiot. I've never gone to college before, none of my family has before, why am I leading the show? 
Daniel knew that he needed help and reached out to the official services offered to him by the college. Neither the form of the assistance nor the actual advice given gave him the satisfaction he had sought.

His goal of transferring from PC within two years had been dealt a serious setback in the first year due to an oversight from one of these sessions. Upon learning of the error he took it in stride, "it didn't end up being a bad thing but it was funny that something as simple as that [taking non-articulating classes] was overseen." This experience did make him more aware of his needs and brings this additional awareness during future advising sessions. Where he shares that, "I'm sitting there and I know it's [the advice] is wrong, so I don't go back to" those advisors and has come to trust a handful of staff to give him the help he seeks.

Karen, Lisa, and Daniel all sought out advising at PC for similar reasons. The perceived knowledge gap navigating the college experience brought them to use this service. Although these three students shared comparable reasons and interacted with the same academic advising system, their experiences were unlike one another. For Karen, "I felt like I could actually do it, like I was excited to start." Lisa was able to obtain her educational planning needs, but was less than impressed with the overall quality of those delivering this service. Daniel realized that he would need to have to learn how to perform educational planning in order to double check the work units coming out of this office, after an error left him one year behind schedule. 
Belief in the Help Provided

Seeking out this assistance was for many students the first step, the next was how they would process this information ultimately into an action. For lan taking in this newly discovered information from his first advising session was exciting:

Well the first time I went there [to an advisor] I felt like I got a lot of help, I was like, wow I didn't know I knew so little (laughs) and I was kind of glad they were there to point me in the direction I needed to know.

These initial feelings would change, after he "started being a little more proactive and looking at what I [Ian] needed to do, there was whole bunch of stuff" he did not need to do. He talked about talking to "other students and they had the same feelings" of the information being provided. He had originally held great belief in the help provided, only to have to revaluate how he would use this service.

Paul indicated that "[advising] would probably be a waste of time at this point because [he] already [know]" what he needs to do in order to graduate. As a returning student, Paul was unable to access PC advising services without first completing a workshop to be "able to set up an appointment with an advisor, which would be about twenty minutes anyway." He did not believe that there was enough benefit and interacting with advising staff from his intended transfer institutions.

Like a Doctor`s Visit

When students talked about their experiences with academic advising, the phrase, 'like a doctor's visit' was a favorite analogy. Seeking out specialized 
knowledge from individuals perceived to hold answers, there exists enough resemblance to understand why separate individuals came up with this phrase. The difference was in how these students perceived this activity.

When asked if the advisor taught him how to perform planning Ian responded, "no, he [the advisor] just looked it up on assist[.org] and it was kind of like going to the doctor." He added, "they [an advisor] just wants to hear something really quick and they just look up the classes [answers] for you." In this scenario, Ian had been made aware of the power imbalance and expected to follow the "recommendation of classes needed to take" (Ian).

Others saw these sessions where the individual seeking help had greater cocreation in the process. With this shared responsibility, Karen talked about how she viewed her role during her advising sessions:

It's like a doctor's appointment, you know, because I work with patients all the time, I tell them all the time, "As a patient, you can't go in and expect to have answers to curing an ailment or a problem without coming in first with symptoms or things about yourself that only you can say," your doctor's not going to sit there and just only subjectively or just look at you and go, "Hmm, you look fine, what's wrong?" I mean, you have to go in with some information, you have to.

Karen saw advising as a cherished moment with a more capable individual that could offer her personal assistance if only she also was a contributing member. "I didn't feel like he was putting me in a stack of others but I felt like he was comfortable talking and suggesting to me that he knew worked" (Karen). Going to the advisor for 
Karen "actually empowered" her during these sessions and gave her the "understanding and confidence" she needed.

Even though John "didn't know what the hell [he was] doing" he would rather "use [his] best judgment because [he's] too scared to go ask" for assistance. John was "too scared to go ask the counselor. It's like a doctor." He viewed his advising sessions with apprehension and felt that advisors failed to ask him what he really wanted:

$[\ldots]$ the doctor says, "So what brings you here?" And they're like, "Oh, I've been having this pain," "How long have you been having this pain?" "For about a day or two," when in reality they've probably been having it for, you know, two weeks or whatever because they're a little timid and what the doctors try to do, what the good doctors try to do is, "You know what? Be honest with me, what's really going on?" Just as I feel a counselor or a teacher should be, "Be honest with me, why are you having trouble understanding the material? What's really going on?" But a lot of people are a little nervous or scared or -

John's experience with the majority of advising at PC was one devoid of the meaningful personal connection he had hoped for. "That disconnect, that alienation, between the teacher, counselor, student, patient, doctor, what have you" (John). John did mention a good advisor, "a really cool guy." The reason given, "because he understands, he grew up in Hunter's Point and [also] took classes for EOPS."

\section{Online Academic Advising Potentials}

Students shared about their experiences using Peninsula College's academic advising services. Lisa talked about how she felt rushed during her time working in with this support, "[...]you're kicked out as soon as that half an hour" session is up. She was not the only one that talked about the difficulties in getting the work sought 
during these sessions accomplished. "When you have like fifteen or twenty minutes you can't get your educational plan laid out" (Ian). "In that twenty minutes [of academic advising at Peninsula College] I've never had an opportunity to get to know a counselor" (Andrew).

The college has recognized the importance of this service and has recently invested in a new college specific technological solution to bolster the efforts of this department. The technology is thought to provide a cost effective solution, an important consideration in the current financial times of the college (College President, personal communication, 2011). An understanding to how students perceive academic advising, both in person and online, was necessary in order to determine acceptance of VIC.

\section{Using Current Online Systems}

Students were asked during their interviews to share their experience interfacing with VIC. This line of inquiry had been originally intended to determine thoughts around the use of the educational roadmaps provided by VIC; however, many students answered the researcher's questions using their usage of other online advising tools. Students talked about these other advising tools, as they related to current academic advising practices at Peninsula College, or used these other tools as points of reference in order to compare VIC.

For many students at PC, their primary experience with online advising tools was using the statewide assist.org database. This tool has been promoted by PC AA 
staff, both in and out of advising sessions. Daniel shared one time during an AA session, "I went in there [advising], and we pulled up one of the colleges on assist." Ian had a similar story of his advising sessions at PC, "he [the advisor] looked up on assist [...] and write up a plan for you" using what is shown on this online tool. The heavy use of this tool, assist.org, can be understood as it covers all public institutions and is freely available to all interested parties.

More recently the college has procured DegreeWorks, a custom tailored online tool. The promise behind this tool is to provide a more complete online advising session by providing greater planning instruments to students. Whereas assist.org provides only general information sorted by schools, DegreeWorks has been intended to provide some of the planning activities traditionally associated with academic advisors. Only one student, of the nine interviewed, had used this more advance online instrument at the time of this study, Lisa.

Lisa's first interview had been scheduled to take place in a private study room located in the student activities building. Selection of this room seemed appropriate, as she was to speak with an advisor, also in this same building, prior to her interview. Upon the start of her interview the researcher asked if she was feeling well, as she appeared anxious and withdrawn. Lisa expressed her frustration of her advising session, citing the use of DegreeWorks and pulled out a stack of printouts: 
Lisa: Well, this is DegreeWorks and one thing is, that DegreeWorks isn't finished yet either, it doesn't upload your transcripts, it has to be manually added to it.

Researcher: I've heard a lot about Degree Works.

Lisa: It looks great, it's not running just yet but you know, with anything, you have to run through it until you can perfect it.

Researcher: So a lot of this information is still manually entered?

Lisa: Yes.

Researcher: And then it looks like they even wrote on top of the printout a lot.

Lisa: They had to because these are the transcripts that I needed for my requirements of my degree.

Researcher: So they can't upload that in?

Lisa: No, but my documents that I do have, the application for the evaluation of the transcript, it's scanned in the system where you can click on that button but once you click on that button to get that, you have click out to go back, to go look at Degree Works to make sure, you have to print that page, you know, to match it up, they don't run together, they're incompatible. [i.e. DegreeWorks and the system used for the evaluation of a transcript are separate programs, using either one of these programs requires the user to close down the other program.] 
Researcher: Okay, so you basically have to have a picture of this and if you want to look at the picture, you have to get out of the program and to get back in you have to log back in.

Lisa: Yeah, everything is a separate entity.

Researcher: That looks like a massive problem.

Lisa: It is, so when I came out today, I had to bring this [the evaluation of her transcript] from the past, so everything was separate and she [the advisor] had to verify everything.

Researcher: What, she had to verify this? But it looks like a lot of this stuff should already be in the system.

Lisa: $\quad$ She just had to verify this information from the documents that I had.

Researcher: Aren't these Peninsula College documents?

Lisa: $\quad$ Yes.

Researcher: But it would seem like all Peninsula College documents should be automatically verified.

Lisa: $\quad$ But she didn't have that up just yet, so she had to click out of everything to go back.

Researcher: So it sounds like DegreeWorks, even as a place to dump data, isn't very good.

Lisa: $\quad$ No, not yet, it needs a lot of work, maybe VIC can figure this out. 
Researcher: Looking at the numbers, three things that people talk about for something like this [i.e. an online academic advising instrument], is to help create a goal, evaluate materials, and then to store the materials. The easiest is the storing of the materials, because everyone knows how to store information. It sounds like this [DegreeWorks] doesn't even know how to store the materials.

Lisa: $\quad$ No, it doesn't have that capability.

Researcher: So if you can't store materials, how can you have it evaluate materials automatically?

Lisa: It's only going to evaluate the classes taken at this one college.

Researcher: And everything else is manual?

Lisa: $\quad$ Yes.

Researcher: And then did it help you come up with a goal?

Lisa: $\quad$ No.

DegreeWorks was intended to give students the planning tools to allow them to matriculate as well as to make AA sessions more productive; however, it seemed to Lisa that this particular tool was unable to perform its task. Lisa was presented with a tool that required her to perform data entry from home prior to seeing her advisor, but was unable to leverage this bought time to really understand planning needs: 
Researcher: It sounds like you spent most of your advising session talking about doing this work [data entry] and not really talking about what it all means.

Lisa: $\quad$ Exactly, I was pretty shocked.

Lisa's overall experience with DegreeWorks as an online AA instrument was best summarized by her statement, "I don't like it."

Interacting with VIC

"I've never talked to a computer before", was offered by Daniel when asked about his interactions with VIC. He described this experience as, "kind of fun" and shared a smile with the researcher. For many of the students that interacted with VIC, a playfulness with the computer developed and drew them in. This engagement piqued their interest to discover more.

Beyond the initial enchantment of talking with a computer, students talked about the overall design of the online tool as it related to its practice usage. "In terms of the functionality, very simple, very easy to use. I'm sure if was worked on a little bit more it would look a bit nicer" (Andrew). Daniel shared, "I like how [VIC has] all these things." Daniel was referring to the individual components that are accessible to the end user, such as goals engine, roadmaps, and other tools. Paul states that "it is a great tool $[\mathrm{VIC}]$ and someone might - hell, it might even be something I can use." 


\section{Thoughts Around Roadmaps}

One of the more important components behind VIC are the educational plans or roadmaps that are provided to students. After they either have created a goal or have an idea as to their major, they can see an entire preset list of courses they could take at PC. There are a number of paths provided, so students can select the one most appropriate to their needs. "I can always customize it [a particular roadmap]" (Ian) and then consider how it would affect the achieving of his educational goal. In addition, these roadmaps offer students a ready-made map to chart their progress at all times.

"VIC really does help the students see different pathways, it gives advice that advisors give" Mary replied to being asked for her opinion of the roadmaps provided by VIC. John stated, "it's the pathway to success, you know." He added after looking at a roadmap for himself, "I checked the student educational plan and for the most part I thought it was helpful." In addition to having a predefined course of action, students appreciated having a tool to monitor their progression towards transfer.

Daniel: "it's nice to always just have a reference, it's kind of reassuring too. I'm not doing this on my own and having second thoughts, 'what if I did something wrong?' I can always go look back and look." By having the "whole big picture", Ian felt that this new perspective allows him the ability to see more easily options.

The interactions with VIC were by design to be different from other online tools, such as assist.org or DegreeWorks. VIC sought to engage the student in order to draw them further into the system. Once there, flowchart logic guided students to either visit 
the goals generation engine or other tool before providing them an educational roadmap. These roadmaps provided students with an overview of courses needed, to allow them to plan different scenarios of study at Peninsula College and to monitor their progress.

\section{Potentials - Efficiency and Effectiveness}

"The technological revolution has not yet consistently reached advising systems" (Habley, 2004a, p. 96)

The pursuit of novel systems is predicated upon the desire for an improvement over current praxis. These intended improvements are often framed in terms of efficiency and effectiveness arguments. Technological innovations have been to be powerful amplifiers for achieving such improvements in the service sector (Faiz, 2002; Gallouj \& Weinstein, 1997), medical (Wu et al., 2006) and financial fields. In creating a sustainable platform for future academic advising, VIC offers potential opportunities for non-linear advancements in the efficiency and effectiveness of this service based on its using the power an expert system (Waterman, 1986) and social media (Feczak \& Hossain, 2011).

\section{Efficiency}

The operational definition of efficiency will be based upon student perceptions of the ability of academic advising services to serve their needs within the time allotted. When performing a program evaluation, the use of observational and interactive 
experiences of program clients can be used as a source of data (McDavid \& Hawthorn, 2006). The use of student voices to understand efficiency around academic advising naturally emerged in the majority of interviews, as interviewees independently brought up challenges with getting this support service to address their needs in the allotted time.

In a majority of student interviews participants used the phrase, "like a doctor's visit." When asked about how academic advising was first presented upon entering college, Ian responded, "[...] it was kind of like going to the doctor. They only have like. I don't know, twenty minutes or something so they just want to hear something really quick and they just look up the classes and write up a plan for you $[\ldots] . "$ Other students also talked about the length of time of their academic advising session and the fact that at Peninsula College the amount of time allotted for these sessions has been decreasing in recent years.

Lisa talked about her recent experiences with academic advising sessions and the fact that she recalls a time at PC when students were allotted much more time to have their needs addressed. "When you go see a counselor [advisor] now, [...], they only give you half an hour; before it was an hour." When asked about possible reasons to explain this new pattern, Lisa spoke about how she has seen two advisors retire at PC and those positions have not been filled. With current fiscal constraints throughout the CCC system, it is unlikely that these positions will be filled in the near future. 
Students talked about the number of tasks that they can accomplish in their academic advising sessions. Lisa spoke about this frustration by providing a laundry list of the tasks one can perform per a session, listing them out as either "fill(ing) out an application, a student educational plan, if you need to get your transcripts, that's all they [the advisors] will do" due to the limited time available. Should a student have multiple needs to be filled, Lisa spoke about the need to schedule future appointments.

The need for these future academic advising appointments introduces problems for students to access this service. The setting up of future appointment times requires flexibility. When asked when is she able to secure these meetings Lisa states, "anytime you can get." Not only one must be highly flexible with times, there is the lack of consistency with the advisor that one is able to see and how this is non-ideal for a student. Again Lisa shares, "usually you want to stick to that same counselor but when it - the last year, I have seen three different counselors each time I went, three, it's not consistent. I first had my appointment with a nursing counselor but she got pulled away because she had to go to a district meeting."

The time for meetings between advisor and advisee are become shorter. These short sessions are resulting in students having to schedule multiple meetings that may not be possible for every student's unique situation. Furthermore, students may see a different advisor each time they need assistance to accomplish a task requiring one of these trained individuals. One means of assuaging these challenges is to off load these tasks directly unto the students, to provide the necessary tools for self-advising. 
When asked if he was provided the necessary tools to perform self-advising activities, Ian responded, "He [the advisor] told me, 'oh, this is assist or you can check what classes you need here,' but that's about it." Probing further, as to whether Ian was provided additional guidance in using the assist system, "no, he [the advisor] just asked me what I wanted to do" and then generated a student educational plan without an in depth explanation as to how this task could be accomplished by the student. In fact, it was only during an advising session with an external institution that Ian realized the need to learn how to select his courses, "that's when I started becoming more proactive and looking at classes" as he realized that he had been provided an incomplete educational roadmap for his academic goals. Academic advising sessions at PC may not provide the necessary instruction to allow students to self-advise and make the informed choices that will guide them towards an intended goal. If advisors are unable to provide these tools, perhaps then the tools themselves could be further improved.

I feel like for all the technology that we have, there's a much more efficient way to teach what we need to teach, you know. [...] You know, there's a lot of grey area in that but I think that in terms of the system itself, there could be, there's so much room for improvement. (Andrew)

Peninsula College (PC) has come to realize the need enhance the institution's ability at providing academic advising services and has recently sought technological solutions. Andrew comments on the present system as:

He [the advisor] types it up and then he printed it out, it was just nice, I mean, with all due respect to them, you know, they're definitely trying their best too, they have a lot of people that they have to [assist]- you know what I mean? It's 
just kind of difficult to adhere to every person's, you know, and especially in a twenty minute span. So there should be, especially in a time like this where, I mean, it's [Peninsula College], I mean, we're the Bay Area, we are the Silicon Valley.

Andrew is questioning why it has taken so long to retool the present system of providing this service in order to overcome its current limitations. Andrew had not yet seen a newly procured DegreeWorks. Lisa was one of the first students to have directly used the recently acquired DegreeWorks, and her experience with this solution was troubling.

This particular piece of software relies heavily upon the student to manually enter data. After this initial data entry, this tool was unable to assist her in either the evaluation of her materials nor the creation of an educational goal. These tasks are still given to an advisor, requiring that Lisa make an appointment. Most troubling from her interview was the discovery that an advisor lacks the ability to make corrections in the data. Lisa tells, "I have to be there and they have to run a checking program, they [an advisor] can't change it. You would think that the counselors would be able to go in and change it [student data] with you sitting right there in that office." This latest attempt of PC to modify academic advising tasks still relies on human advisors and subject to the prior challenges of scheduling and inconsistencies with whom a student is able to see.

The majority of students interviewed talked about the diminishing window of time that they are permitted to see an academic advisor, often times using the analogy of 
a quick doctor`s visits. Students have seen this window of service diminishing during their college experience. Peninsula College aware of the need to make the most productive use of time for the delivery of this service has turned towards a technological solution. However, this particular solution may not have been designed around the end user or rather, the correct end user: students.

During student advising sessions, participants talked about the challenges of getting all of their advising needs met. When they were unable to attend to these advising needs. student needed great flexibility in their personal schedule. In addition to a high degree of flexibility, students often times were not able to see the same advisor. Self service options, such as the newly acquired Degree Works, was not seen as a viable solution at assuaging these challenges as too many tasks could still only be performed by actual academic advisors and not the students themselves.

Using the operationalized definition of efficiency, i.e. the attending to students' academic advising needs during a session, there may be room for improvement. The types of tasks that this service provides need to be performed in order to support students seeking their educational goal. As the window of time is shrinking due to external fiscal constraints, making the possibility of increasing these sessions impractical, these needs must be achieved in a quicker fashion. This did not appear to be the case from the students interviewed at Peninsula College. 


\section{Effectiveness}

An advisor load is one useful dimension of analysis for assessing the effectiveness of academic advising (Gabb, 2007; Habley, 2004b). The Council for Academic Standards (CAS) in Higher Education states, "academic advising caseloads must be consistent with the time required for the effective performance of this activity" (CAS, 2009, p. 13). The interview data showed that the time provided for this service is fixed within a 20- to 30 -minute time interval. The actual ratio of advisees per advisor thus provides a measure of effectiveness using the CAS definition.

Data from the NACADA monograph (Habley, 2004a) provides mean ratios for advisor loads for survey years 1998 and 2003, see Figure 23. Data suggests that the ratios have increased considerably since then and have broken the 800 barrier for fouryear public universities (Drake et al., 2010). These extreme advisor loads have resulted in "a large fraction of students only self-advise [...] more attention and resources should be given to make sure all students get proper advising" (Drake et al., 2010, p. 12).

Figure 23. Advisor Load

\begin{tabular}{llcc}
\hline & & 1998 & 2003 \\
\hline Two-Year & Public & 357.3 & 375.4 \\
& Private & 158.8 & 121.0 \\
Four-Year & Public & 267.4 & 284.9 \\
& Private & 127.7 & 153.2 \\
\hline
\end{tabular}

NOTE: Results retrieved from the 2004 NACADA Monograph 
Figure 23 shows the advisor loads for the four types of institutions probed in the NACADA produced monograph. Public colleges and universities show a dramatic increase in load relative to their private counterparts. These figures are thought to have undergone a dramatic increase since these results were last taken, with some public four-year institutions reporting advisor loads that are more than double to these shown in the above figure.

In the interview data, in current online academic advising systems, the time spent in order to communicate potential educational pathways was seen as presenting an unnecessary barrier between student and advisor. VIC has the potential more effectively to help students with self-advising, providing a platform that permits student exploration of possible roadmaps. The use of an expert system to simulate the decisionmaking activities necessary for creating pathways can shift a time-intensive activity out of the face-to-face arena. Students can then talk about their exploration with an academic advisor to make best use of this contact, in a diminishing environment.

Cost can also be used to frame the effectiveness of a treatment. In this study, the new treatment was the use of VIC compared to traditional academic advisors, and unit cost can be normalized across faculty and students. Unit cost will be operationally defined as the total discretionary amount budgeted, using the most recent district filings from the California Community College Chancellor’s Office (CCCCO), fiscal year 2009-2010, CCFS-311 reports. These reports provide budgetary information on discretionary spending for the 71 reporting California Community College districts, and 
an analysis was confined to the $63 \times x x$ account field. This account field provided a measure of how many dollars are spent on advising-related activities.

Understanding the dollar amount allotted to these activities provides a pseudomeasure as to the level of resources spent among these institutions. Dollars spent for student services has recently been empirically linked to graduation rates (Eisen, 2009; Webber \& Ehrenberg, 2010). In order to analyze these expenditures across these college districts, these values required normalization.

Normalization was carried out using both staff headcount and full-time equivalent student numbers taken from the CCCCO data mart project for academic year 2009-2010. Total headcount (of both full- and part-time staff members) was used instead of the precise numbers of faculty assigned to academic advising activities, as these values were unavailable. This required the additional assumption that relative ratios of faculty members performing advising are consistent across college districts. FTES data did not require this type of assumption, as values were precisely known for each district.

Spending between college districts showed wide variations on a per headcount basis $(M=\$ 5,614.66, S D=\$ 2,301.67)$. This variation can be seen in a ratio analysis of mean cost per standard deviation of 2.4 units (Koopmans \& Rosenblatt, 1964). In order to estimate the cost per advisor, the mean dollar spent per faculty member would need to be scaled. If one assumed one advisor per 15 faculty members, a mean salary would be $\$ 84,219.90$ per advisor. This computed value agreed with the mean advisor salary 
$(M=\$ 91,916.03, S D=\$ 17,711.70)$ using available Peninsula College data (Daily Post, 2010).

A more transferable unit of analysis between districts was cost per full-time equivalent student (FTES). The FTES for each of the 71 reporting college districts provided values $(M=\$ 634.21, S D=\$ 262.14)$ had similar variations using a ratio analysis of mean cost per standard deviation of 2.4 units, as well (Koopmans \& Rosenblatt, 1964). This finding was surprising, as this method of analysis did not have additional assumptions. It was also seen that nearly $20 \%$ of the districts reported spending amounts that were more than one standard deviation different from the mean (see Figure 24). These findings suggest that spending for this student service was not uniform across the state.

Figure 24. Districts Spending More Than One Standard Deviation from the Mean

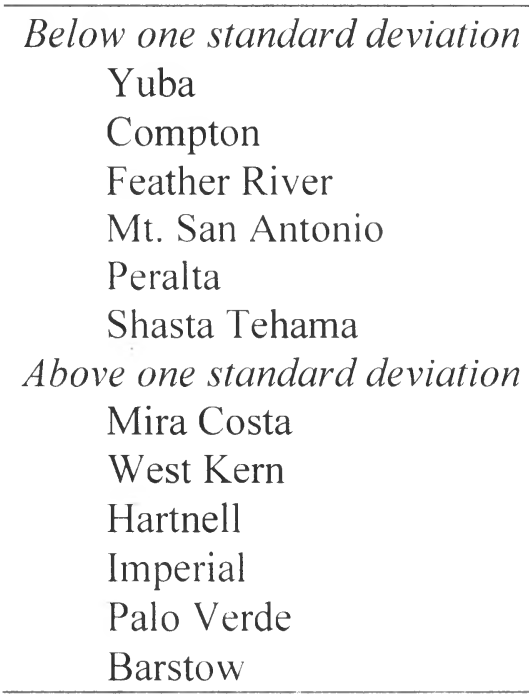


The use of cost to measure effectiveness is another potential opportunity for a system such as VIC. As software, VIC performs the same regardless of overall usage or total number of users assisted (Duhigg \& Bradsher, 2012). The performance of VIC requires a paradigm shift in order to fully understand that the scalability of software is fundamentally different from other services and products. If VIC were to be licensed out at a set cost per student of $\$ 10$ against the present cost of the nearly 544,000 FTES, it would result in a potential savings of $\$ 340$ million per semester throughout the entire California Community College system. A figure twice as large as a recently announced emergency mid-year cut to the CCC system (Dorr, 2012).

\section{Conclusion}

This chapter presented findings from the three research phases of this study. Beginning with discovery, data on a national scale (Habley, 2004a) combined with a custom survey instrument were used to isolate current practices of academic advising systems. These findings informed design choices taken during the tool creation phase during the creation of the online advising test platform, VIC. During the value added phase, a program evaluation of VIC was conducted using Peninsula College as a control. This program evaluation used a pre-validated instrument devised for the purpose of comparing different advising systems, the academic advising inventory (AAI). and student interview data. The findings from the AAI were presented for both advising systems. Interview data was also presented. 


\section{CHAPTER FIVE: Discussion}

A goal of this study was to determine individual components of academic advising (AA) in order to achieve an equivalent experience online. Advising components were determined using both national and local area data in order to create the online test platform, VIC. Equivalency was taken to mean similarity of score between the two advising systems considered as indicated the AAI and by student interviews. The AAI was designed as a tool for program evaluation for assessing and comparing different advising systems. The study sought to address the following research questions:

1. How can an academic advising website be created with features that incorporate current theories in order to foster an experience that is equivalent to modern praxis?

2. What are student perceptions of an academic advising website that assists in the co-creation of academic goals and the generation of education-planning instruments?

This chapter will present a summary of findings from the three phases of the study along with a discussion. Each of these phases sought to address the research questions of the study, with the findings building atop one another. 


\section{Discovery Phase}

In order to begin development of the online test platform, VIC, the researcher sought to determine current practices in the field of academic advising (AA). This would then inform this research as to the components VIC would require. These AA practices were probed using a national dataset along with a custom-generated survey instrument of Peninsula College (PC) students.

The NACADA (Habley, 2004a) survey of academic advising was used to determine those responsibilities that are immediately seen by students. The responsibilities reported by these advising offices included advising about general educational requirements, records management, and the evaluation of transfer credit. Sorting these three responsibilities by the percentages these offices reported for the latest year on record yielded: $81 \%, 57 \%$, and $42 \%$ respectively. Thus, it appeared that most advising offices considered general educational advising an important service to their students, but the evaluation of transfer credit was less important. According to an academic advisor at PC (PC advisor, personal communication, 2011), one possible explanation as to why evaluation was not as well reported was that computer-assisted checking was not suitable for this task, and this responsibility was given to students.

Next, a survey was conducted of student perceptions of support services provided to PC students. This survey sought to determine if students had seen a member of the advising staff (70.6\%) had and asked about their experiences using this service. A student educational plan (SEP) was used as a measure of academic planning 
during these sessions. The selection of a SEP as an important planning tool for college students emerged from discussions with a critical colleague who had studied this topic in depth (S. Myers, personal communication, 2011). Students who had seen an advisor reported a higher percentage of having a SEP (75.0\%) than those who had not seen an advisor. It thus appeared that one activity of an advising session at PC was the creation of educational planning tools. This finding suggested that PC students seeking advising assistance might expect such a planning instrument from an online experience.

To probe student needs for an online academic advising experience, part five of the custom survey instrument asked students to select components they believed were important. The top three selections were future academic needs $(77.0 \%)$, a space to talk $(65.5 \%)$, and forums $(64.4 \%)$. Based on informal discussions with students who had taken this survey, the researcher thought selection of future academic needs meant students wanted academic planning tools. Planning tools would become the centerpiece of VIC and be represented in a goals generation engine and educational roadmaps. (These tools will be discussed within the tool creation phase discussion.) The importance of a space to talk and forums suggested the importance of sharing between the student and others. Of these communications selections, concern for future academic needs was more private and the latter two more public.

The importance of private communication can be understood using the construct of social advantage. Sullivan (2002) has shown that some college students benefit from the anonymity that an online environment offers. This environment permits free and 
honest exploration that may not have been available otherwise, due to personal biases and stereotyping from others.

Students also indicated support for forums or public communication, consistent with work that has demonstrated the use of forums to increase student motivation and engagement (Weisskirch \& Milburn, 2003). Having access to this online tool may increase student usage of a website as well as letting students support one another.

The other selections from this portion of the custom survey were: calendaring $(59.8 \%)$, study skills $(58.6 \%)$, real time chat $(52.9 \%)$, and the option for a write-in choice $(10.3 \%)$. It was decided that students ought to be able to have a calendar available to them at all times, so that important due dates could easily be retrieved. The researcher viewed this component as another method of records maintenance, as seen in the NACADA data (Habley, 2004a). As for the choice of study skills, the researcher again spoke to a number of students who had taken this survey who indicated this choice as meaning tips towards becoming a better overall student, general-purpose study strategies. Students seeking advice should also be expected to ask for useful strategies to assist them through their college experience. Real-time chat was taken to indicate students' needs to be heard expressing their needs to the advising individual.

To summarize, the goal of the discovery phase was to determine what service components of an online academic advising system are required to provide an experience that matches current practice. Based on data from NACADA (Habley, 2004a), an initial set of requirements emerged. These national findings suggested that 
future planning efforts hold greater perceived value than records management. The custom survey instrument provided guidance as to the specific online components that PC students thought would be important. Initial efforts in the creation of VIC would focus on designing these planning tools and the components students selected from the custom survey.

\section{Tool-Creation}

As the website emerged and students acted as early testers, the importance of an anchoring construct emerged. This construct took the form of a virtual intelligent counselor, the origin of the term VIC used to describe the website. VIC would dispense academic advising services to student visitors (Appendix 6). It was readily apparent to the researcher that VIC's importance to the goals behind the study was complex.

The researcher thought this construct would engage students to use the site, using a combination of magic and transparency (Turkle, 2005). Beyond this initial draw into the website, students felt comfortable delving deeper into the website. As a robotic representation of the website, VIC greatly assisted in the collection of studentlevel data. Turkle (2011) has suggested this observed behavior is an artifact of how individuals see and interact with programs. Programs can be created to take into account a person's interests, in other words "programming means that robots can be trusted" (Turkle, 2011, p. 71).

Additionally, the choice to use VIC emerged from the importance of immediacy or nonverbal communication (Barnett et al., 2006; Gorham, 1988; Mehrabian, 2007; 
Witt, 2004) to learning activities. Academic advising is a learning activity under NACADA (2006), and perceived effectiveness of a learning activity has been shown to be influenced by nonverbal communication (Witt, 2004). Student satisfaction with an online course has also been shown to increase when immediacy is considered during design (Arbaugh, 2001). As the website would be evaluated against a pre-existing academic advising system using the AAI instrument (a device that measures both perceived behaviors and satisfaction), concepts of immediacy were an important consideration to assist VIC, specifically in increasing perceived effectiveness of advising and satisfaction with this activity.

VIC was helpful in the final selection for the name of the website: w'w. vicandme.com. The name connotes a mutual teaching and learning environment, one that promotes both co-creation and collaboration between the learner and VIC. These are prerequisites under a developmental academic advising model (Crookston, 1972): a model considered as a best practice (NACADA, 2006) and a possible benchmark for online equivalency (Simonson, 1999), which was thus used throughout the current study due to its current importance in the field (Barnett et al., 2006; Mottarella, Fritzsche, \& Cerabino, 2004).

Although the actual construction and coding of the website has been thoroughly covered in Chapter Three: Methodology, the researcher would like to discuss how educational roadmaps were devised. Initially these were to be procured directly from PC's advising staff. The researcher had been told by members of both the teaching 
faculty and advising staff that these preconfigured roadmaps existed for a handful of majors. These educational roadmaps were found to be out-of-date, in many cases indicating classes that the college no longer offered. When these tools were effectively unavailable, three alternative methods for generating them were considered.

The first involved training a neural network, a form of artificial intelligence, to act as an engine capable of producing these roadmaps. This method would yield an engine that could generate these roadmaps dynamically, with little human involvement. The researcher had procured an administrative-level account at assist.org and believed this level of access would provide sufficient training materials for this engine. The researcher worked closely with colleagues in Pasadena California, but this method of creating educational roadmaps proved too difficult, due primarily to a lack of standardization between institutional systems.

The second path was to have the researcher produce these educational roadmaps personally, after procuring college catalogs, articulation agreements, and other supporting documentation. This method also proved too difficult for the current study. Although the researcher felt capable of creating such a plan, having earned a bachelor's degree decades before, he realized that he had forgotten the necessary steps in preparing this planning document. He could have devised an educational roadmap but quickly realized that it would most likely not be optimal, in that considerations beyond his capabilities included how to select coursework strategically so as to balance credit hours earned during a given semester and prerequisites. 
It was after this second attempt that the researcher sought out undergraduate research assistants. These individuals had demonstrated an ability to create these plans, and demonstrated the potential of using actual students for peer-generated strategies. This key component of VIC would not have otherwise been possible without this novel solution.

After the educational roadmaps were finalized, other design components from the custom survey were incorporated within VIC. Students had indicated the need for "calendaring," so an ability to log into VIC and save important dates in a calendar object was provided. As a result of students indicating a need for "study skills," a section called resources was included within VIC and contained study strategies and small applets, such as a GPA calculator. Students visiting the website would be able to use these resources on how to be a better overall student. Real-time chat with an actual person was also included within VIC. An academic advisor could potentially log into the system and converse with visiting students. VIC was now ready to be tested with actual Peninsula College students to determine the perceived value such a website could offer.

To summarize, findings from the discovery phase were used during the creation of the online academic advising website. A construct, VIC, was used to promote engagement and student use of this online tool. Different methods were attempted in the generation of educational roadmaps. The use of students to write these planning 
tools showed promise and allowed for this component of VIC to be included during this study.

\section{Value-Added Components}

The second research question dealt with student perceptions of an academic advising website. The creation of VIC allowed for a comparison of an online experience with that of PC's advising system. During this phase of the study, VIC was offered to students to use and explore.

In order to gauge student perceptions of VIC, PC students were asked for their perceptions of current advising services from the college using the AAI instrument. A separate group of students was then asked for AAI data for VIC. These two datasets allowed a comparison between these two advising systems. Using the individual sections within the AAI instrument allowed for an understanding of students perceptions of a website that is capable of performing academic advising.

Nine students were also selected to participate in two sets of interviews. The first interview sought to determine how students arrived at their educational goals and had experienced academic advising at college. The second interview delved into their use of VIC and the perceived value such an online tool may hold for college students. These interviews sought to ground the quantitative findings from the AAI instrument and provide greater context for the numbers. 
Aspects of Academic Advising: Comparing The Two Systems

The first part of the AAI instrument "was designed to measure [all] aspects of academic advising" (Winston, Jr. \& Sandor, 2002, p. 10) using the developmentalprescriptive paradigm (Crookston, 1972). The utility of this paradigm derives from historical and theoretical foundations within the field of academic advising (Gordon et al., 2008). This portion of the AAI would compare perceptions between the two academic advising (AA) systems considered for this study along the developmentalprescriptive paradigm.

Student perceptions of the behavioral style used in either AA system were further measured in terms of four scales: DPA, PE, ADM, and SC. The DPA scale measures the overall advising (A) system along the developmental (D) and prescriptive (P) continuum, hence the term DPA. Additionally, the DPA scale is composed entirely from the other three scales. The personalizing education (PE) subscale measures perceived concern with a students' total education. The academic decision making (ADM) subscale focuses upon the responsibilities and processes used to make academic decisions. Lastly the selecting courses (SC) subscale deals with the manner that class needs and planning are carried out.

Using aggregate data from the two advising systems, one-tailed t-tests were performed to compare student reports of the systems on the four scales. These tests demonstrated no differences in student perceptions of the advising systems, as measured by the AAI. 
The AAI instrument provides a formative evaluation tool of processes (Winston, Jr. \& Sandor, 2002), and in the current study was used to compare VIC to an existing AA system. The first research question sought to understand whether an online academic advising system could provide an equivalent experience to current practice, and the study shoed that VIC indeed provides a similar advising environment to current practice.

Although aggregate comparisons of student reports of the two advising systems suggested similar perceptions of them, the researcher also sought to understand the role of gender and ethnicity in these perceptions. Gender and ethnicity have been shown to influence the type of advising style preferred (Alexitch, 1997, 2002; Mottarella et al., 2004; Smith, 2002).

Alexitch (2002) has shown that females have greater preference for developmental advising, and thought this was a result of women's greater help-seeking behaviors. In this study, gender was associated with the PC group's preferred style of advising. Females gave lower reports on the personalizing education (PE) subscale, which thereby affected the DPA scale; women's lower ratings were within the integrative region $(M=31.41, S D=13.09)$ of 33 units. Males scored this subscale higher, the opposite trajectory of a prior study (Alexitch, 2002), suggesting that the advising services at PC were not addressing female students' academic and personal needs adequately. 
No differences were observed in the scores reported for the VIC group, suggesting that this advising experience was similar for men and women. VIC is a fully automated system that is not programmed to consider student characteristics; thus, it follows that ratings of the perceived service should be the same for either gender. This may be a limitation of VIC, in so far as prior studies suggest gender affects the student's preferred type of advising style (Alexitch, 2002; Mottarella et al., 2004).

A one-way ANOVA of the AAI subscales also demonstrated that ethnic identity was associated with personalizing education for PC students. Although paired t-tests for each of the ethnicities considered was not performed due to study time constraints. an examination of Figure 14 suggests that the multi-ethnic and white students perceived AA services at PC as more prescriptive than African-American students did. Another study of minority students and their white counterparts "[ highlighted] the importance of academic advisors understanding that students' academic, psychological, and social problems are not isolated issues" (Museus \& Ravello, 2010, p. 54). Their finding matches the definition of the PE subscale, which asks whether advising addresses both academic and personal concerns. The finding in the present study of African-American students seeking greater developmental AA over white students seems to follow from the Museus and Ravello (2010) study.

Results from the VIC group demonstrated no association of ratings with student ethnic identity. VIC was not programmed to factor ethnic identity into the manner or type of academic advising provided. Prior studies (Mottarella et al., 2004; Museus \& 
Ravello, 2010) conflict with one another, and the role of ethnic identity in preferred academic advising style is not well understood. More research into the influence ethnicity has upon academic advising style needs to be performed before modifying VIC's underlying framework specifically to address ethnicity. Influence of Goals on the AA Experience

The development of both life and career goals are important under currently used definitions of academic advising provided by NACADA (2006). Students that participated in either AAI survey were also asked if they had a defined educational goal prior to starting college. The study showed that having a goal influenced the way the academic advising experience was perceived (see Figure 21) in some cases.

The personalizing education (PE) score was seen to be sensitive to goal ownership for the PC student group, with DPA, ADM, and SC scales failing to demonstrate an association with having a goal. The PE scale measures the perceived behavioral styles used to address the academic and non-academic needs of a student, and is a proxy for the perceived relationship between advisor and advisee. The advising system at PC may eliminate this variability by concentrating efforts initially on the creation of goals (Crookston, 1972; O`Banion, 1994). Another possible explanation, which emerged from student interviews, is that this finding may be an artifact of student concern over non-academic aspects of their future endeavors are especially concerned with the task of goal creation and subsequent attainment. 
Analysis of scores for the VIC group demonstrated goal influence on the DPA scale. The DPA scale is a linear combination of the three subscales of the AAI instrument. The three subscales failed to show significant associate of score and goal ownership, so the result for the overall score may be an artifact of aggregating the data.

These findings demonstrated the utility of the goals generation engine developed within VIC. The goals generation engine is an adaptive circuit that assists a student during the initial formation of an educational goal using developmental academic advising principles of co-creation (Crookston, 1972; O'Banion, 1972). This engine, decoupled from the academic roadmaps, gave students the ability to analyze their motivations for coming to college before having planning ideas presented.

The initial design approaches used during tool creation, a focus on goal creation, allowed VIC to achieve an academic advising system equivalent to that of PC. The respective separation of the goals generation engine and individual roadmaps along developmental and prescriptive lines yielded an online experience that was virtually indistinguishable to students comparing these systems with the AAI instrument.

In either the PC or VIC groups, students with a goal had scores across the four scales that were more prescriptive than students without. Students with a goal saw the role of an academic advising system as being less dependent on their interpersonal relationship and more weighted towards an ability to acquire relevant information. The serving of information follows a more prescriptive pathway. 
Further refinements to the goals engine to assist students in defining their academic ambition may result in a subsequent shifting of perceptions away from the quality of the relationship between VIC (the advisor) and the student (the advisee). Fostering the creation of a goal may result in a student experience defined by the quality or relevancy of information VIC is able to present. The providing of purely prescriptive assistance, i.e. the serving up of purely informational requirements, is a task that can be more easily accomplished in VIC and merits future exploration.

\section{Satisfaction With The Two Advising Systems}

The third part of the AAI has been designed as a satisfaction inventory covering overall satisfaction, accuracy, adequacy, availability, and amount of advising services provided by an advising system. Harrison (2009) has shown that some of the traits of effective advising are having knowledge, fostering growth, and great communication between advisor and advisee. When the advising systems of PC and VIC were compared using these five independent satisfaction metrics, no significant differences were observed. Students of either group had a combined weighted average score of $2.72(S D=.053)$ out of a possible 4 on a Likert-type scale. Students' reports thus suggested that these two academic advising experiences were equivalent using this measure of satisfaction.

\section{Qualitative Findings: Beyond VIC}

Nine students were also asked to take part in two interviews. These interviews allowed students to share their experiences of college and to understand their 
motivations and goals upon entering this institution, as well as to share their thoughts about the use of online academic advising. All interviews were analyzed using grounded theory (Glaser \& Strauss, 1967). The main themes to emerge from this approach were the college dream, academic advising experiences so far, and online academic advising potentials. These main themes allowed for a logical grouping of sub-themes and ideas. The goal of these interviews was to share student perspectives on this support service using their own voices. These were to supplement the quantitative findings of student perceptions using the AAI instrument and to determine whether an online advising website could be made to yield a similar experience. These findings were discussed in Chapter Four; here, a new theme will be explored.

The research questions that drove the present study focused on how an academic advising website ought to be designed and how students would perceive such a tool. The second interview with students suggested the future of such an enterprise. What should be the next steps to go beyond VIC in its current form, and what are the implications for such a tool?

During Daniel's second interview, he was asked for his ideas about VIC's utility and usefulness. Daniel thought the roadmaps were "a really good idea," allowing a student to "[perform] $80 \%$ of the work with VIC on your own [and to then] take the roadmap to the counselor for that tough $20 \%$," which impressed Daniel as a real utility: he could reassign and personally direct some of his own educational planning activities. 
Daniel's interaction with VIC stemmed from the reassurance the educational roadmaps provided him, "[it's] nice to always to just have a reference, it's reassuring." Turkle (2011) has shown that individuals are able to develop trusting relationships with artificial agents, reporting that "programming means that robots can be trusted" (p. 71). The continued development of an environment that builds upon trust will affect the number of students who are able to feel comfortable with and able to take care of their own academic planning needs.

Others saw VIC's utility and usefulness in relation to their current inability to connect to traditional approaches provided by the student support service. Andrew talked about how his academic and work schedules conflicted with his "opportunities to see a counselor." Andrew followed, "[it's] not just me, there's a lot of people in the exact same boat as me-people that live very difficult lives," and he cited work, family, and educational commitments as sources of these difficulties to be overcome. Andrew saw the ability to perform educational planning activities "[at] the end of the day when [he] gets off at 10" as being more congruent with his current life.

Students may have had differing views of VIC, but many felt the underlying concept was worthwhile. Student descriptions of how they initially decided to go to college pointed to the complexity of this choice. Current tools may not be able to handle and process this complexity. This may explain some of students' prior advising experiences and point towards their accepting the potential online tools represent. 


\section{Conclusion}

This chapter presented a discussion of findings beginning with the discovery phase; where both national and local data were presented. These two sources of information were analyzed using an online lens to determine key components of an online advising tool; this analysis in turn influenced design choices made during tool creation for VIC. Also within the tool creation phase, reasons for designing VIC were presented, along with an in-depth discussion of a novel technique used to create educational roadmaps. In order to determine equivalency, VIC and an existing advising system were compared using the academic advising inventory. This instrument allowed for a formative evaluation along developmental and prescriptive paradigms. Interviews were performed regarding student perceptions of VIC and interpretations advanced regarding students' perceptions of its utility. 


\section{CHAPTER SIX: Conclusion}

This study began with the researcher asking both advising staff members and students the most pressing needs at Peninsula College (PC) (Flowers, 2010b). At the time of these initial discussions, PC was facing unprecedented budgetary challenges. Whole departments and programs were being eliminated or scaled back. This was having immediate effects on students' abilities to procure support services, such as academic advising.

Academic advising (AA) was selected as a topic of study, as the researcher believed this support service was important to students as well as holding great potential for the use of online technologies. Advising services have been shown to promote college student retention and graduation rates (Eisen, 2009; Webber \& Ehrenberg, 2010) suggesting that the loss of such services would have an immediate negative effect

upon PC students. Furthermore, interacting with advising staff members and reviewing the literature (Habley, 2004a) lent support to the researcher's belief that online technologies would help amplify services during a time of diminishing resources.

The movement towards a greater online presence has been a goal of the PC administration (STOT instructional staff, personal communication, 2012). These efforts have come directly from district board members, as online courses are seen as a mechanism to maintain fiscal stability by holding down operational costs. The college has seen an expansion of distance-learning and the promotion of hybrid and online course offerings across divisions (Math Sciences Dean, personal communication, 2009). 
The expansion of classes in the online domain left open the question of how to provide support services (such as advising) online.

As the study began to take shape, the research questions that emerged were:

1. How can an academic advising website be created with features that incorporate current theories in order to foster an experience that is equivalent to modern praxis?

2. What are student perceptions of an academic advising website that assists in the co-creation of academic goals and the generation of education-planning instruments?

In order to address these questions, a multi-phased mixed methods design was selected. This design was partitioned into three phases, with the first phase, discovery, addressing the first research question. The findings from this portion would then be integrated within a working academic advising website during the tool creation phase. The third "value added" phase would then address the second research question.

This chapter will begin by presenting an interpretation of the findings from each of the three phases. Study limitations will be addressed, followed by future research endeavors. A conclusion stating long-term implications ends the chapter.

\section{Interpretation of Results}

A NACADA-sponsored (Habley, 2004a) survey suggested that general educational advising was one key responsibility of any academic advising system. This led the researcher to focus on general educational advising for the online tool that would 
be later created. Next, a custom survey instrument was given to PC students to determine online components that were considered important for an academic advising website. The actions taken during the discovery phase were to create a website and to address the first research question. The researcher believes that these measures permitted the creation of a website informed by current praxis.

In order to answer the second research question, during the creation of VIC, a quasi-experimental sequential explanatory mixed-methods design was utilized. A prevalidated instrument used in the field of academic advising to evaluate advising systems was located. the AAI. This instrument was the primary measure of student perceptions of VIC and was given to two separate groups of students. PC, assumed to use current advising praxis, acted as a benchmark or control for the evaluation of the VIC system. Interviews were then performed to allow for addition explanation of study results.

The first part of the AAI has four scales of measurement. The overall scale, DPA, measures student perceptions of behavioral styles used by the two systems. This scale is composed of three sub-scales which permit a more nuanced understanding of an advising system (Winston, Jr. \& Sandor, 2002). The third part of the AAI was also used in the study, and measures student satisfaction of an advising system along five separate dimensions. No differences were found in students' reports of PC or VIC advising in either of these two parts.

This instrument was selected as it is currently used in the field of academic advising to compare differing systems. Using the AAI as a measurement device 
demonstrated that these two advising systems were equivalent in terms of the scores achieved from either group of students. These results suggested that VIC performed as well as a current AA system and validated design choices made during tool creation.

Data from the AAI were also disaggregated along gender and ethnicity for each of the two AAI datasets. Gender and ethnicity were shown to have some influence upon the AAI scores from the PC advising system but had no effect upon reports of the VIC system. These findings may actually point towards a deficiency within the underlying structure of VIC, as a one-size fits all approach may not be ideal. Prior studies have suggested that gender and ethnicity do influence the preferred style of advising (Alexitch, 1997, 2002; Mottarella et al., 2004; Museus \& Ravello, 2010; Smith, 2002).

Student characteristics may need to be integrated within VIC so that it can account for variations in student characteristics and provide a more suitable advising experience. Behavioral targeting has been shown to increase the engagement that individuals have with websites (Yan et al., 2009) and is a potential source of refinement in predictor models (Canny et al.. 2011), much like the goals generation engine and the educational roadmaps. Integrating this technique within VIC may yield an online experience more in line with the perceived expectations of students.

When the AAI data were disaggregated based on educational goal ownership, students with a predefined goal in either system seemed to view the role of AA services as more prescriptive. This finding suggests that future iterations of VIC will benefit 
from an expansion of the goals generation engine. As students are better able to generate a clearly defined educational goal, they should be more likely to seek out academic advising services of a more prescriptive style, or the serving of pure information.

Student interviews demonstrated that the reasons to embark upon a college education might not always be well defined. The motivations for attending are varied and at times based upon perceptions that change rapidly once a student has begun to attend. Students talked about their reasons for seeking a college education and the challenges they faced alone, unable to call upon support from family and friends. They talked about reaching out to student support services offered by the college and how their experiences using academic advising could affect their studies at college. Students also verified the dramatic changes that this service has undergone in the past three years, with decreasing access and difficulties in using the service due to external commitments. Students such as Andrew and Daniel talked about how online technologies would allow them to help themselves and how this would allow them to consider possible variations in how they used these services.

\section{Limitations}

The nearly singular focus of designing VIC around general education advising was due to time constraints of the study. VIC did not incorporate two other responsibilities indicated from NACADA data--records management and evaluation of transfer credit — which would have created a more complete advising system (Habley, 
2004a). The lack of features addressing these two key responsibilities may also have limited VIC's ability to provide general academic advising.

Final selection of advising components for VIC also came exclusively from local data, based on a custom survey completed at one site, Peninsula College. The survey was not pre-validated, which calls into question the true nature of the data captured. In addition, having only one site of data collection may have limited the generalizability of these results to other sites within the larger California community college system.

During tool creation phase, a quasi-experimental study of student perceptions of VIC and PC advising services was performed. Those students were asked to provide their perception of VIC's advising abilities, and were instructed not to consider any prior advising experiences at PC. Although efforts were taken so that VIC-only students provided only perceptions of this advising system, students may have still been influenced by their own or others' experiences with the PC advising system. However, the potential intermingling of student experiences should have resulted in gender and ethnicity influencing the AAI scores obtained for the VIC group, and the fact that this was not observed suggests that participants rated VIC's services only.

The AAI data were disaggregated and analyzed across gender and ethnicity for the two PC and VIC ratings. A goal of disaggregation was to determine any effects that these two student characteristics had on the AAI scores obtained. This separation 
resulted in some sub-groups having low sample sizes. In the event of low sample sizes, the researcher included exact counts in the findings section.

Gender was not fully considered during the analysis of interview data. Some research suggests differences in how genders perceive technology (Comber, Colley, Hargreaves, \& Dorn, 1997; Cooper, 2006). Interviews were conducted to understand student perceptions of VIC, a technological solution, and therefore the interpretations advanced should have been analyzed separately across gender.

All student interviews utilized guides to ensure certain lines of inquiry were followed. These guides were provided by the researcher to the students at the time of their interviews in written format. At the start of these interviews, students were told that these were only meant to facilitate discussion and not to limit any talk that they felt would be important in exploring their perceptions of academic advising. Since these guides were created by the researcher, they may have biased the interviewing. Weiss (1995) defines biased interviewing as occurring "when we encourage respondents to provide material supportive of our thesis" (p. 212). Interview findings need to be understood as potentially having been biased due to the nature of the interview guides created and utilized for this study.

\section{Future Research}

This study asked if the act of academic advising could be transferred to the online domain and how this would be viewed by students using this technology. As this study began, the researcher thought about the more fundamental questions of why and 
for what purpose such an endeavor should be taken. The answer to these questions came from an idea advanced by Khan (2011): that technology can be used to humanize the educational experience. Therefore, a future trajectory of this study could be to ask: can the experience of academic advising at California's community college become more humane through the proper utilization of empowering technologies?

To understand what it means to humanize the educational experience, some background is necessary. Khan Academy (Khan, 2011) started off as an idea in one person's apartment but has since come to embody the possibility of using an online environment that enables individuals to learn wherever and whenever. These empowering technologies exist completely online. Khan Academy has since begun to develop tools needed to allow collaboration between actual learners and mentors, improving the toolsets available to distance-educators. These tools are being built with a focus on maximizing finite learning time. The optimization of learning time through online technologies represents a core idea behind the humanizing of education. This same concept is at the core of the present study, can VIC be used to maximize the value of the time spent by a college student with his or her advisor?

This study has demonstrated how the application of online solutions can amplify the efforts of the advisee, especially in creating an educational goal and viewing a model plan of action. Students now had a clear educational roadmap that they could present to an advisor; they could build on it or ask much more far-reaching questions that might not traditionally be addressable due to resource constraints. To promote VIC 
as a platform to support these ideas, technical hurdles will need to be addressed in the ability to develop roadmaps.

The creation of educational roadmaps was greatly hindered by a lack of standardization of the nomenclature used between educational institutions. Although the assist.org project acts as a repository of articulation agreements between public colleges and universities, each institution is permitted to have different naming formats. Under the current study's constraints, these differing systems made it impossible to create an algorithm that could determine an optimized path of matriculation.

Although an expert system that used true artificial intelligence methods were not employed in the study, such methods have shown promise in the field of academic advising (Grupe, 2002; Hamdi, 2006a, 2006b, 2007). These methods would allow for more rapid generation of educational roadmaps than were possible in the present study. Exploring the potential of these types of techniques would require a model dataset. Such a dataset would open the field to a wider array of researchers and act as a standard to judge the abilities of any given algorithm. This dataset could be created from existing data, following a university cohort through their college experience. VIC would potentially benefit from any increase in the speed and quality with which educational roadmaps could be provided to students.

The method this study did use to create educational roadmaps also warrants future research. These pathways were generated using recent transfer students from Peninsula College in a gaming-type environment. Social networking could be better 
integrated into the VIC platform to permit the crowdsourcing of academic advisingthat is, the creation of educational roadmaps could be performed in a competitive manner with teams of actual college students developing and voting on the pathway deemed most optimized. These activities could be initiated by users, with the system engaging participants to compete. Only the roadmaps voted most effective would then be presented to the student who had made the initial request. This idea calls for the creation of an environment that can tap the collective knowledge of students; for the near real-time generation of educational roadmaps. Such techniques have been successfully applied to complex systems that are not well definable, such as the foldit project (Cooper et al., 2010).

The ideas of using either algorithms or social networking techniques to yield better educational roadmaps are methods aimed at improving VIC's overall ability to provide services. One finding observed, that was not specifically tied to improving VIC, was particularly intriguing given a social-justice lens and meriting future research. During the examination of cost- effectiveness, the dollars spent on advising services fluctuated between institutions. The funding source used for this analysis was initially thought to have been more stable (on a per full-time equivalent student) given that these came directly from the state, and this was not the case. Understanding the funding model for academic advising services in California's community colleges will provide for a more complete depiction of the challenges faced by this student support service, and help to understand these fluctuations. 


\section{Conclusion}

This study sought to determine how the act of providing academic advising support can be transferred to the online domain. As the educational landscape continues to incorporate more space in the online domain, out of economic necessity and the need to better serve students, what will become of academic advising services? Will components of current praxis in academic advising simply be transferred wholesale online and wrapped in the superficial gloss of a Web 2.0 site? The researcher is very much opposed to the notion of applying only the veneer of technology; instead, one must embrace entirely new forms of thought and construction during all phases of design.

Proper design will facilitate the transformation of academic advising as it goes online. The design of these expert systems can be based upon the use of either artificial intelligence or tapping into the power of the crowd, as glimpsed during the creation of VIC. Once trained upon the challenges behind this transition, these tools can provide an equivalent online experience, providing academic advising services that are similar for

all students, regardless of their individual characteristics: an experience that is devoid of potential bias. 


\section{References}

Ahern. T. C., \& El-Hindi, A. E. (2000). Improving the instructional congruency of a computer-mediated small-group discussion: a case study in design and delivery. Journal of Research on Computing in Education, 32(3), 385-400.

Ahern, T. C., Thomas, J. A., Tallent-Runnels, M. K., Lan, W. Y., Cooper, S., \& Lu, X. (2006). The effect of social grounding on collaboration in a computer-mediated small group discussion. The Internet and Higher Education, 9(1), 37-46.

Alexitch, L. R. (1997). Students" educational orientation and preferences for advising from university professors. Journal of College Student Development, 333-343.

Alexitch, L. R. (2002). The role of help-seeking attitudes and tendencies in students' preferences for academic advising. Journal of College Student Development, $43(1), 5-19$.

Arbaugh. J. B. (2001). How instructor immediacy behaviors affect student satisfaction and learning in web-based courses. Business Communication Quarterly, 64(4), $42-54$.

Arendale, D. R. (1994). Understanding the Supplemental Instruction (SI) Model. New directions for teaching and learning, 60(4), 11-21.

ASSIST. (2011). Retrieved from http://www.assist.org/web-assist/welcome.html

Astin. A. W. (1999). Student involvement: A developmental theory for higher education. Journal of College Student Development, 40, 518-529.

Astin, A. W., \& Sax, L. J. (1998). How undergraduates are affected by service participation. Journal of College Student Development, 39(3), 251-263.

Barnett, S., Roach, S., \& Smith, M. (2006). Microskills: advisor behaviors that improve communication with advisees. NACADA journal, 26(1), 6-12.

Barreau, D. K. (1995). Context as a factor in personal information management systems. Journal of the American Society for Information Science, 46(5), 327339. doi:10.1002/(SICI) 1097-4571(199506)46:5<327::AID-ASI4>3.0.CO;2-C

Bean, J. P. (1985). A conceptual model of nontraditional undergraduate student attrition. Review of Educational Research, 55(4), 485-540. doi:10.3102/00346543055004485

Berger, J. B., \& Milem, J. F. (1999). The role of student involvement and perceptions of integration in a causal model of student persistence. Research in Higher Education, 40(6), 641-664. doi:10.1023/A:1018708813711 
Bergman, O., Beyth-Marom, R., \& Nachmias, R. (2003). The user-subjective approach to personal information management systems. Journal of the American Society for Information Science and Technology, 54(9), 872-878. doi:10.1002/asi.10283

Bogdan, R. C., \& Biklen, S. K. (2007). Qualitative research for education (5th ed.). Pearson.

Broadbridge, A. (1996). Academic advising - traditional or developmental approaches?: Student perspectives. British Journal of Guidance \& Counselling, 24(1), 97113. doi:10.1080/03069889608253711

Buros Institute. (2011). Retrieved from http://buros.unl.edu/buros/jsp/search.jsp

California Community Colleges. (2012). Retrieved from http://cccco.edu/communitycolleges/tabid/830/default.aspx

Canny, J., Zhong, S., Gaffney, S., Brower, C., Berkhin, P., \& John, G. H. (2011, April $5)$. Granular data for behavioral targeting using predictive models. Retrieved from http://www.google.com/patents?id=0hRzAQAAEBAJ

CAS. (2009). CAS self-assessment guide for academic advising programs (pp. 1-35). Washington, DC: Council for the Advancement of Standards in Higher Education.

Cohen, J. (1992). A power primer. Psychological bulletin, 112(1), 155-159. doi:10.1037/0033-2909.112.1.155

Coleman. J. S. (1988). Social capital in the creation of human capital. American Journal of Sociology, 94(s1), S95-S120. doi:10.1086/228943

Comber, C., Colley, A., Hargreaves, D. J., \& Dorn, L. (1997). The effects of age, gender and computer experience upon computer attitudes. Educational research, 39(2), 123-133. doi:10.1080/0013188970390201

Congos, D., \& Schoeps, N. (1993). Does supplemental instruction really work and what is it anyway? Studies in Higher Education, 18(2), 165-177. doi:10.1080/03075079312331382349

Cooper, J. (2006). The digital divide: The special case of gender. Journal of computer assisted learning, 22(5), 320-334. doi:10.1111/j.1365-2729.2006.00185.x

Cooper, Khatib, F., Treuille, A., Barbero, J., Lee, J., Beenen, M., Leaver-Fay, A., et al. (2010). Predicting protein structures with a multiplayer online game. Nature, 466(7307), 756-760. doi:10.1038/nature09304

Creswell. J. W., \& Plano Clark, V. L. (2010). Designing and conducting mixed methods research (Second ed.). Sage Publications, Inc. 
Cronbach, L. J. (1951). Coefficient alpha and the internal structure of tests. Psychometrika, 16(3), 297-334. doi:10.1007/BF02310555

Croninger, R. G., \& Lee, V. E. (2001). Social capital and dropping out of high school: Benefits to at-risk students of teachers' support and guidance. Teachers College Record, 103(4), 548-581.

Crookston, B. B. (1972). A developmental view of academic advising as teaching. Journal of College Students Personnel, 13, 12-17.

Daily Post. (2010). 2010 Salaries for PC College. WM. Baker Associates, pp. 8-9. San Bruno, CA.

Denzin, N. K., \& Lincoln, Y. S. (1994). Competing paradigms in qualitative research. Handbook of qualitative research (pp. 105 - 117). Thousand Oaks, CA: Sage.

Dorr, P. M. (2012). California community colleges chancellor Jack Scott sounds alarm at the additional $\$ 149$ million unexpected budget cut the system will sustain this academic year. Press Release, p. 1. Sacramento, CA.

Drake, P., Smith, S., Schneewind, S., Brehm, D., Espanola, M., Goodison, S., Harrington, C., et al. (2010). Report of the undergraduate academic advising task force (pp. 1-33). San Diego: University of California.

Duhigg, C., \& Bradsher, K. (2012, January 21). Apple, America and a squeezed middle class. The New York Times. Retrieved from https://www.nytimes.com/2012/01/22/business/apple-america-and-a-squeezedmiddle-class.html

Eisen, B. (2009). Cut student services? Think again. Washington, DC: Inside Higher Ed. Retrieved from http://www.insidehighered.com/layout/set/print/news/2009/07/29/gradrate

Ellwood, J. (2009). The California budget crisis (Vol. 17355). UC Berkeley. Retrieved from http://www.uctv.tv/search-details.aspx?showID=17355

Engstrom, C., \& Tinto, V. (2008). Access without support is not opportunity. Change, 40(1), 46-50. doi:10.3200/CHNG.40.1.46-50

Etter, E. R., Burmeister, S. L., \& Elder, R. J. (2001). Improving student performance and retention via supplemental instruction. Journal of Accounting Education, 18(4), 355-368. doi:10.1016/S0748-5751(01)00006-9

EUREKA, CCIS. (2012). Retrieved from http://www.eureka.org/public/students.shtml

Faiz, G. (2002). Innovation in services and the attendant old and new myths. Journal of Socio-Economics, 31(2), 137-154. doi:10.1016/S1053-5357(01)00126-3 
Falk, S. C., Avery, G., \& McGee, C. (1999). Implementing LIMS: A "how-to" guide. Analytical Chemistry, 72(1), 57-62.

Feczak, S., \& Hossain, L. (2011). Exploring computer supported collaborative coordination through social networks. The Journal of High Technology Management Research, 22(2), 121-140. doi:10.1016/j.hitech.2011.09.005

Fielstein, L. L. (1994). Developmental versus prescriptive advising: Must it be one or the other? NACADA Journal, 14(2), 76-79.

Flowers, J. L. (2010a). Surviving - a qualitative student attitudes and perceptions study. Unpublished manuscript, San Francisco State University.

Flowers, J. L. (2010b). A mixed-methods study of student perceptions of academic advising at hilltop college. Unpublished manuscript, San Francisco State University.

Gabb, R. (2007). Models of academic advising (pp. 1-23). Victoria University.

Gallouj, F., \& Weinstein, O. (1997). Innovation in services. Research Policy, 26(4-5), 537-556. doi:10.1016/S0048-7333(97)00030-9

Glaser, B., \& Strauss, A. (1967). Grounded theory: The discovery of grounded theory. Aldine Transaction.

Goertzel, B., \& Pennachin, C. (2007). Artificial general intelligence. Springer.

Gordon, V. N., Habley, W. R., \& Grites, T. J. (2008). Academic advising: A comprehensive handbook (sec. ed.). Jossey-Bass.

Gorham, J. (1988). The relationship between verbal teacher immediacy behaviors and student learning. Communication Education, 37(1), 40-53. doi:10.1080/03634528809378702

Grant, J. (2002). Learning needs assessment: assessing the need. BMJ. British medical journal, 324(7330), 156-159. doi:10.1136/bmj.324.7330.156

Grubb, W. N. (2001). "Getting into the world": Guidance and counseling in community colleges (pp. 1-21). New York, NY: Community College Research Center.

Grupe, F. H. (2002). An internet-based expert system for selecting an academic major: The Internet and Higher Education, 5(4), 333-344. doi:10.1016/S10967516(02)00129-X

Guillen, C. (2010). Undergraduate academic advising and its relation to degree completion time. Humboldt State University, United States -- California.

Habley, W. R. (2004a). The status of academic advising: Findings from the ACT sixth national survey. National Academic Advising Association. 
Habley, W. R. (2004b). Advisor Load. Retrieved May 15, 2011, from http://www.nacada.ksu.edu/Clearinghouse/AdvisingIssues/advisorload.htm

Habley, W. R. (2011). Email on technologies in academic advising.

Hagen, P. L., \& Jordan, P. (2008). Theoretical foundations of academic advising. Academic advising: A comprehensive handbook (2nd ed., pp. 17-35). San Francisco, CA: National Academic Advising Association.

Hamdi, M. S. (2006a). MASACAD: A multi-agent system for academic advising. International journal of intelligent information technologies, 2(1), 1-20. doi:10.4018/jiit.2006010101

Hamdi, M. S. (2006b). MASACAD: a multi-agent based approach to information customization. Intelligent Systems, IEEE, 21(1), 60-67. doi:10.1109/MIS.2006.14

Hamdi, M. S. (2007). MASACAD: A multi-agent approach to information customization for the purpose of academic advising of students. Applied Soft Computing, 7(3), 746-771. doi:10.1016/j.asoc.2006.02.001

Harrison, E. (2009). What constitutes good academic advising? Nursing students' perceptions of academic advising. The Journal of Nursing Education, 48(7), 361-366.

Hayward, G. C., Jones, D. P., McGuinness Jr., A. C., Timar, A., \& Shulock, N. (2004). Ensuring access with quality to California's community colleges (pp. 1-105). San Jose, CA: The National Center for Public Policy and Higher Education.

Heisserer, D. L., \& Parette, P. (2002). Advising at risk students in college and university settings. College Student Journal, 36, 69-83.

Jennings, N. R. (2000). On agent-based software engineering. Artificial Intelligence, 117(2), 277-296. doi:10.1016/S0004-3702(99)00107-1

Johnson, H. (2009). Educating California, choices for the future. San Francisco, CA: Public Policy Institute of California.

Johnson, M. D., Anderson, E. W., \& Fornell, C. (1995). Rational and adaptive performance expectations in a customer satisfaction framework. The Journal of consumer research, 695-707.

Khan, S. (2011). Salman Khan: Let's use video to reinvent education|video on ted.com. TED. Retrieved from http://www.ted.com/talks/salman_khan_let_s_use_video_to_reinvent_education. html 
Koopmans, L. H., \& Rosenblatt, J. I. (1964). Confidence intervals for the coefficient of variation for the normal and log normal distributions. Biometrika, $5 l(1 / 2), 25-$ 32.

Kulik, C., Kulik, J. A., \& Shwalb, B. J. (1983). College programs for high-risk and disadvantaged students: A meta-analysis of findings. Review of Educational Research, 53(3), 397-414.

Lantolf, J. P. (2000). Sociocultural theory and second language learning. Oxford University Press.

Lantolf, J. P. (2006). Sociocultural theory and L2: State of the art. Studies in Second Language Acquisition, 28(1), 67-109. doi:10.1017/S0272263106060037

Males, L. M., Otten, S., \& Herbel-Eisenmann, B. (2010). Challenges of critical colleagueship: examining and reflecting on mathematics teacher study group interactions. Journal of mathematics teacher education, 13(6), 459-471. doi:10.1007/s10857-010-9156-6

Maxwell. W. E. (1998). Supplemental instruction, learning communities, and students studying together. Community College Review, 26(2), 1-18. doi:10.1177/009155219802600201

McDavid, J. C., \& Hawthorn, L. R. L. (2006). Program evaluation \& performance measurement: An introduction to practice. Thousand Oaks, CA: Sage Publications, Inc.

McNemar, Q. (1947). Note on the sampling error of the difference between correlated proportions or percentages. Psychometrika, 12(2), 153-157. doi:10.1007/BF02295996

Mehrabian, A. (2007). Nonverbal communication. New Brunswick: Aldine Transaction.

Meuter, M. L., Bitner, M. J., Ostrom, A. L., \& Brown, S. W. (2005). Choosing among alternative service delivery modes: An investigation of customer trial of selfservice technologies. Journal of marketing, 69(2), 61-83. doi:10.1509/jmkg.69.2.61.60759

Meuter, M. L., Ostrom, A. L., Roundtree, R. I., \& Bitner, M. J. (2000). Self-service technologies: Understanding customer satisfaction with technology-based service encounters. Journal of Marketing, 64, 50-64.

Moore. (1998). An expert system approach to graduate school admission decisions and academic performance prediction. International Journal of Management Science, 26(5), 659-670. 
Moore, C., \& Shulock, N. (2006). State of decline? Gaps in college access and achievement call for renewed commitment to educating Californians. Sacramento, CA: Institute for Higher Education Leadership and Policy.

Mortenson, T. (2009). California at the edge of a cliff. The failure to invest in public higher education is crushing the economy and crippling our kids' future (pp. 114). Sacramento, CA: California Faculty Association.

Mottarella, K. E., Fritzsche, B. A., \& Cerabino, K. C. (2004). What do students want in advising? A policy capturing study. NACADA Journal, 24(1), 48-61.

Museus, S. D., \& Ravello, J. N. (2010). Characteristics of academic advising that contribute to racial and ethnic minority student success at predominantly White institutions. NACADA journal, 30(1), 47-58.

NACADA. (2003). Paper presented to the task force on defining academic advising. Retrieved from NACADA Clearinghouse of Academic Advising Resources Web site: http://www.nacada.ksu.edu/Clearinghouse/Research_Related/definitions.htm

NACADA. (2006). Concept of academic advising. Retrieved May 15, 2011, from http://www.nacada.ksu.edu/clearinghouse/advisingIssues/Concept-advisingintroduction.htm

NACADA. (2012). About NACADA. Retrieved January 8, 2012, from http://www.nacada.ksu.edu/AboutNACADA/index.htm

Newcombe, R. G. (1998). Interval estimation for the difference between independent proportions: comparison of eleven methods. Statistics in medicine, 17(8), 873890. doi:10.1002/(SICI)1097-0258(19980430)17:8<873::AIDSIM779>3.0.CO;2-I

O'Banion, T. (1972). An academic advising model. Junior College Journal, 42, 62-69.

O'Connell, J. (2009). State schools chief Jack O'Connell highlights impact of budget cuts to education (News Release No. 09-86). Sacramento, CA: California Department of Education. Retrieved from http://www.cde.ca.gov/nr/ne/yr09/yr09rel86.asp

Open Source Matters. (2011). Retrieved from http://www.joomla.org/

Paechter, M., \& Maier, B. (2010). Online or face-to-face? Students' experiences and preferences in e-learning. The Internet and Higher Education, 13(4), 292-297. doi:10.1016/j.iheduc.2010.09.004

Paolacci, G., Chandler, J., \& Ipeirotis, P. G. (2010). Running experiments on amazon mechanical turk. Judgment and decision making, 5(5), 411-419. 
Paulus, T. M. (2009). Online but off-topic: negotiating common ground in small learning groups. Instructional science, 37(3), 227-245. doi:10.1007/s11251007-9042-5

Perterson, G. W., Sampson Jr., J. P., Lenz, J. G., \& Reardon, R. C. (2002). A cognitive information processing approach to career problem solving and decision making. Career Choice and Development (4th ed., pp. 312 - 369). San Francisco, CA: Jossey-Bass.

Portes, A. (1998). Social capital: Its origins and applications in modern sociology. Annual Review of Sociology, 24(1), 1-24.

Ramirez, G. M. (1997). Supplemental instruction: the long-term impact. Journal of Developmental Education, 21(1), 2-13.

Reiman, A. J. (1999). The evolution of the social role taking and guided reflection framework in teacher education: recent theory and quantitative synthesis of research. Teaching and Teacher Education, 15(6), 597-612. doi:10.1016/S0742051X(99)00016-5

Rocket Theme. (2011). Retrieved from http://www.gantry-framework.org/

Roderick, A. (2011). Personal Communication: Online advising technologies and their implementation.

Rovai, A. P., \& Barnum, K. T. (2003). On-line course effectiveness: an analysis of student interactions and perceptions of learning. Journal of Distance Education, $18(1), 57-73$.

Rovai, A. P., \& Downey, J. R. (2010). Why some distance education programs fail while others succeed in a global environment. The Internet and Higher Education, 13(3), 141-147. doi:10.1016/j.iheduc.2009.07.001

Russell, S. J. (2010). Artificial intelligence: a modern approach (2nd ed.). New Jersey: Prentice Hall.

Santos, J. R. A. (1999). Cronbach's alpha: A tool for assessing the reliability of scales. Journal of Extension, 37(2), 1-5.

Schlisserman, C. (2009, November 20). California was among states with record unemployment. Retrieved from http://www.bloomberg.com/apps/news?pid=20601068\&sid=adNCgwKNKNe0

Schwen, T. M., \& Hara, N. (2003). Community of practice: a metaphor for online design? The Information Society, 19(3), 257-270. doi:10.1080/01972240309462

Sengupta, R., \& Jepsen, C. (2006). California's community college students. California Counts, 8(2), 1-23. 
SFSU. (2012). Retrieved from http://www.sfsu.edu/ admisrec/reg/dars.html\#dars

Simonson, M. (1999). Equivalency theory and distance education. TechTrends, 43(5), 5-8. doi:10.1007/BF02818157

Simonson, M., Schlosser, C., \& Hanson, D. (1999). Theory and distance education: A new discussion. The American journal of distance education, 13(1), 60-75. doi:10.1080/08923649909527014

Smith, J. S. (2002). First-year student perceptions of academic advisement: A qualitative study and reality check. NACADA Journal, 22(2), 39-49.

Sullivan, P. (2002). "it's easier to be yourself when you are invisible": female college students discuss their online classroom experiences. Innovative higher education, 27(2), 129-143. doi:10.1023/A:1021109410893

Sun Gard Corp. (2011). Retrieved from http://www.sungard.com/

Tappan. M. B. (1997). Language, culture, and moral development: A Vygotskian perspective. Developmental Review, 17(1), 78-100. doi:10.1006/drev.1996.0422

Thrun, S., \& Norvig, P. (2011). Introduction to artificial intelligence. Video lecture series, Stanford School of Engineering, Palo Alto, CA. Retrieved from https://www.ai-class.com/

Tinto, V. (1975). Dropout from higher education: A theoretical synthesis of recent research. Review of Educational Research, 45(1), 89-125. doi:10.3102/00346543045001089

Tinto, V. (1993). Building community. Liberal Education, 79(4), 16-22.

Tinto, V. (1998). Colleges as communities: Taking research on student persistence seriously. Review of Higher Education, 21, 167-177.

Tinto, V. (2000). Taking student retention seriously: Rethinking the first year of college. NACADA Journal, 19(2), 1-8.

Turkle, S. (2005). The second self: computers and the human spirit. Cambridge, MA: MIT Press.

Turkle, S. (2011). Alone together: why we expect more from technology and less from each other. New York: Basic Books.

Tuttle, K. N. (2002). Academic advising. New directions for higher education, 2000(111), 15-24. doi:10.1002/he.11102

Vygotsky, L. S. (1978). Mind in society: The development of higher psychological processes. Cambridge, MA: Harvard University Press.

Waterman, D. (1986). A guide to expert systems. Reading, MA: Addison-Wesley. 
Webber, D. A., \& Ehrenberg. R. G. (2010). Do expenditures other than instructional expenditures affect graduation and persistence rates in American higher education? Economics of Education Review, 1-26.

Weiss, R. S. (1995). Learning from strangers: The art and method of qualitative interview studies. Free Press.

Weisskirch, R. S., \& Milburn, S. S. (2003). Virtual discussion: understanding college students' electronic bulletin board use. The Internet and Higher Education, 6(3), 215-225. doi:10.1016/S1096-7516(03)00042-3

Wenger, E. C. (2000). Communities of practice: The organizational frontier. Harvard Business Review, 78(1), 139-145.

Wenger, E. C. (n.d.). Communities of practice: A brief introduction. Retrieved June 2, 2012, from http://ewenger.com/theory/index.htm

Wick, D. (2011). Excel worksheet for qual analysis.

Winston, Jr.. R. B.. \& Sandor, J. A. (1984a). Developmental Academic Advising: What Do Students Want? NACADA Journal, 4(1), 5-13.

Winston, Jr., R. B., \& Sandor, J. A. (1984b). Academic advising inventory. Athens, GA: Student Development Associates. Student Development Associates, Inc.

Winston, Jr., R. B., \& Sandor, J. A. (2002). Evaluating academic advising: manual for the academic advising inventory (pp. 1-30). Athens, Georgia: Student Development Associates, Inc. Retrieved from http://www.nacada.ksu.edu/clearinghouse/links/AAI-info.htm

Witt, P. (2004). A meta-analytical review of the relationship between teacher immediacy and student learning. Communication Monographs, 71(2), 184-207.

Wu, S., Chaudhry, B., Wang, J., Maglione, M., Mojica, W., Roth, E., \& Shekelle, P. G. (2006). Systematic review: impact of health information technology on quality, efficiency, and costs of medical care. Annals of Internal Medicine, $144(10)$, $742-752$.

XAP Corporation. (2012). Retrieved from http://www.csumentor.edu/AboutMentor/

Yan, J., Liu, N., Wang, G., Zhang, W., Jiang, Y., \& Chen, Z. (2009). How much can behavioral targeting help online advertising? Proceedings of the 18th international conference on World wide web - $W W W$ '09 (pp. 261-270). ACM. doi:10.1145/1526709.1526745 
Appendices 
Appendix 1: Custom Survey Instrument of Student Services

\section{Academic Advising v2b}

\section{Section 1}

Hello, this survey is to determine how academic advising is seen on campus with regard to: effectiveness, ability, and overall impact on student success. Your time in taking this survey is greatly appreciated. Thank you.

1. During your time on campus, have you had any contact with anyone in academic counseling?

Yes

No

Other (please specify)

2. Would you recommend academic counseling to a friend?

$$
\begin{aligned}
& \text { Yes } \\
& \text { No }
\end{aligned}
$$

Other iplease specify)

3. Do you want to work more with an academic counselor?

Yyes

No

Other (please specify)

4. Do you have a Student Educational Plan (SEP) or career plan?

Yes

No

Maybe

5. What was your feeling about working with academic counseling?

Overall Impression
Technical Advice
Communication




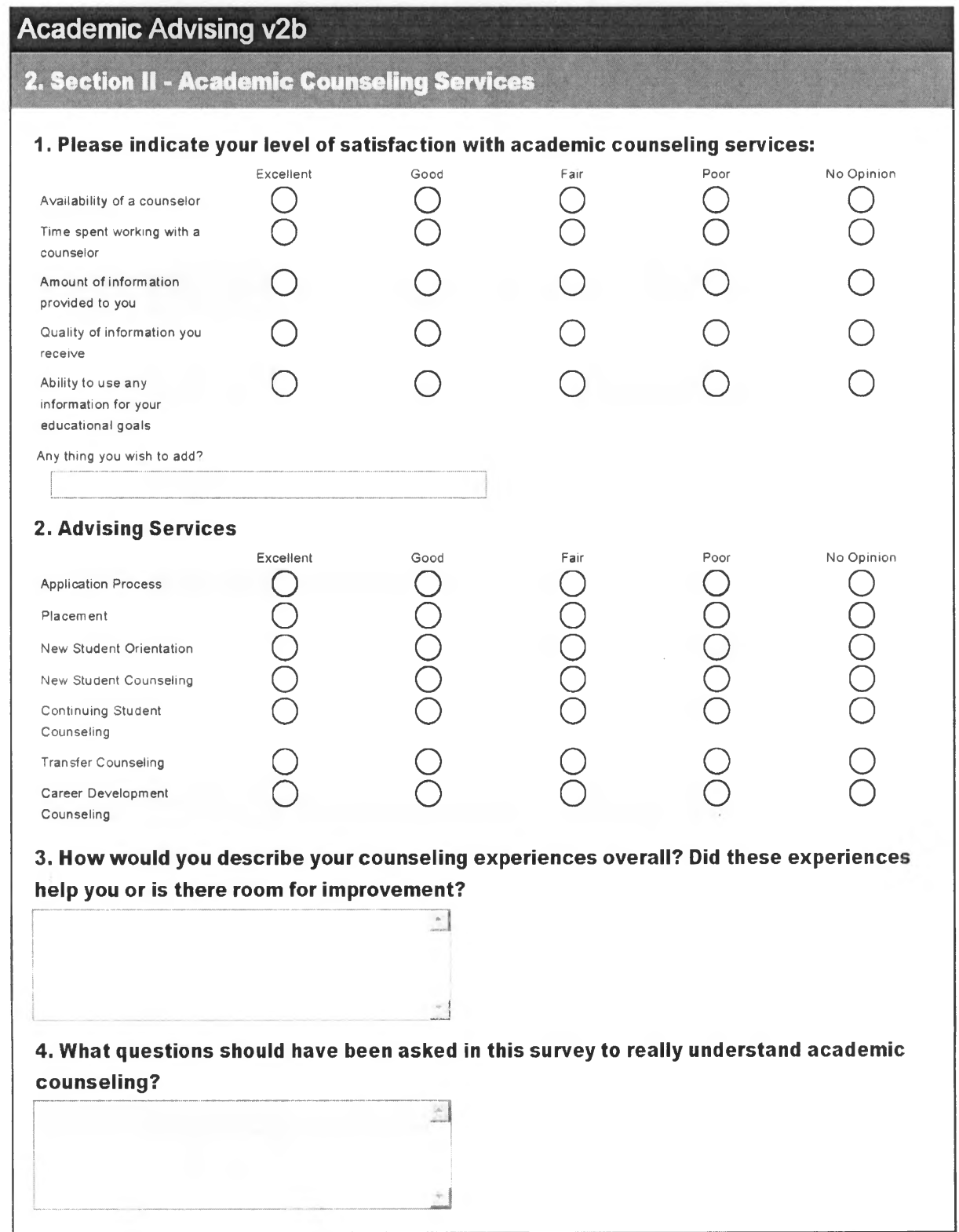




\section{Academic Advising v2b}

5. If there was an online counseling website, what features should be there? (Select all that you feel would be important)

$\square$ A place to just talk to someone

$\square$ Chat or Skype now button

$\square$ study skills

$\square$ Forum to share with others

$\square$ Calendar for me to put due dates

A place to put all my classes and future classes for my future needs

Other (please specify) 


\section{Academic Advising v2b}

\section{Section III - Instructional Quality}

Quality of academic instruction and student services

1. Please rate the following:

Quality of instruction in
your classes
Content of courses
Availability of courses
Faculty availability
$\begin{aligned} & \text { Accuracy of information } \\ & \text { about programs }\end{aligned}$

about programs

2. Please indicate your level of satisfaction with the following student services:

Classroom and Classroom
Equipment
Library Services
Study Areas
Learning Centers

Other (please specify) 


\section{Academic Advising v2b}

\section{Seotion IV - Dencgraphies}

We would greatly appreciate some basic demographic information about yourself - in order to better understand the data overall

\section{Gender}

Your

$$
\text { Gender }
$$

2. Please provide the following information - Exact numbers not required but whole numbers (i.e. no-decimals) are:

Age

Units Enrolled

3. Your overall GPA

Around

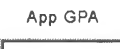

4. Educational Goal

Your Goal

Educational Goal

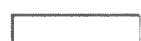

5. Please provide the following information:

Ethnicity

6. Thank you so much for taking the time to perform this survey. Your opinions and concerns are most helpful. If you would like to write anything at all, please feel free to do so. 
Appendix 2: Unmodified Academic Advising Inventory (AAI) Instrument

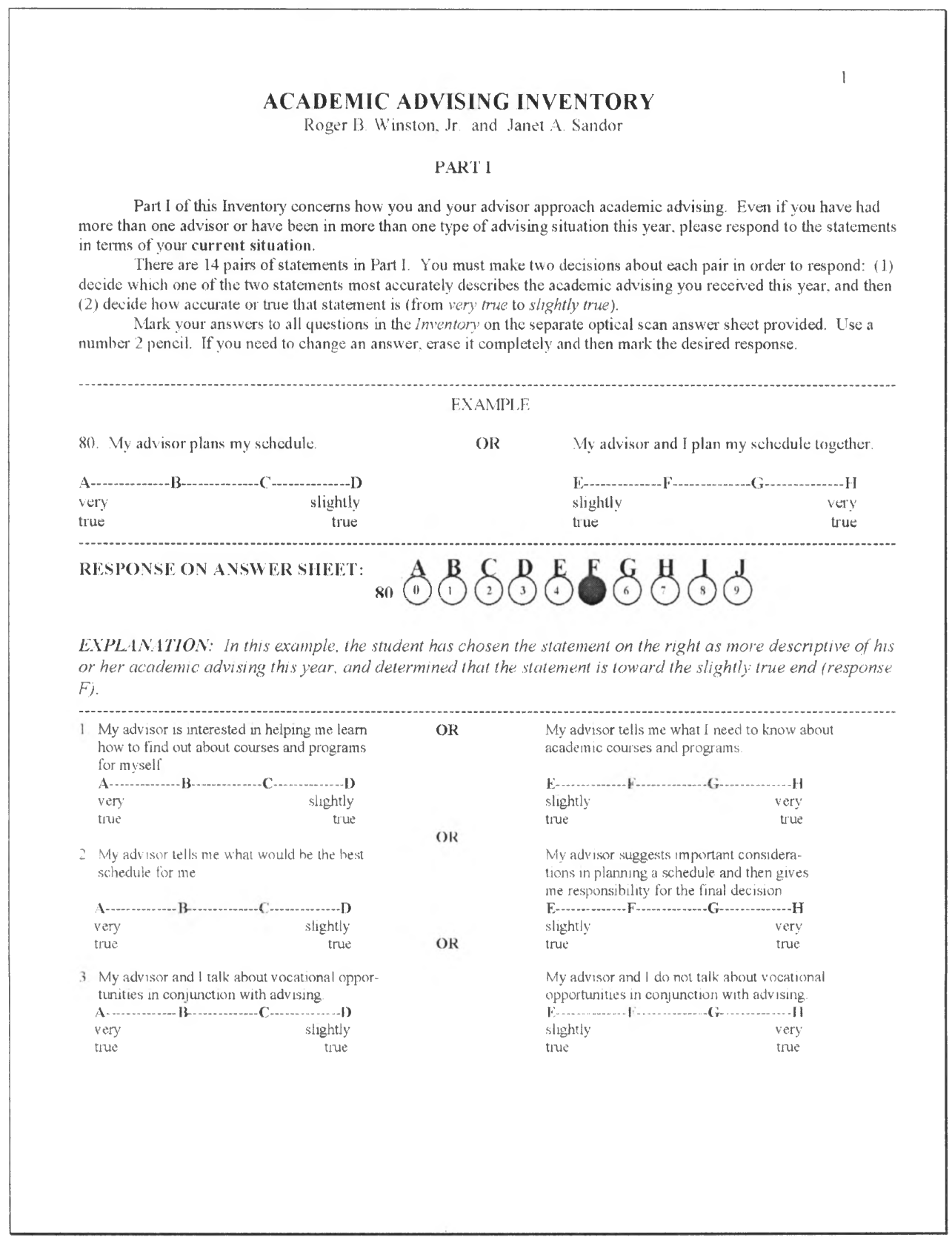




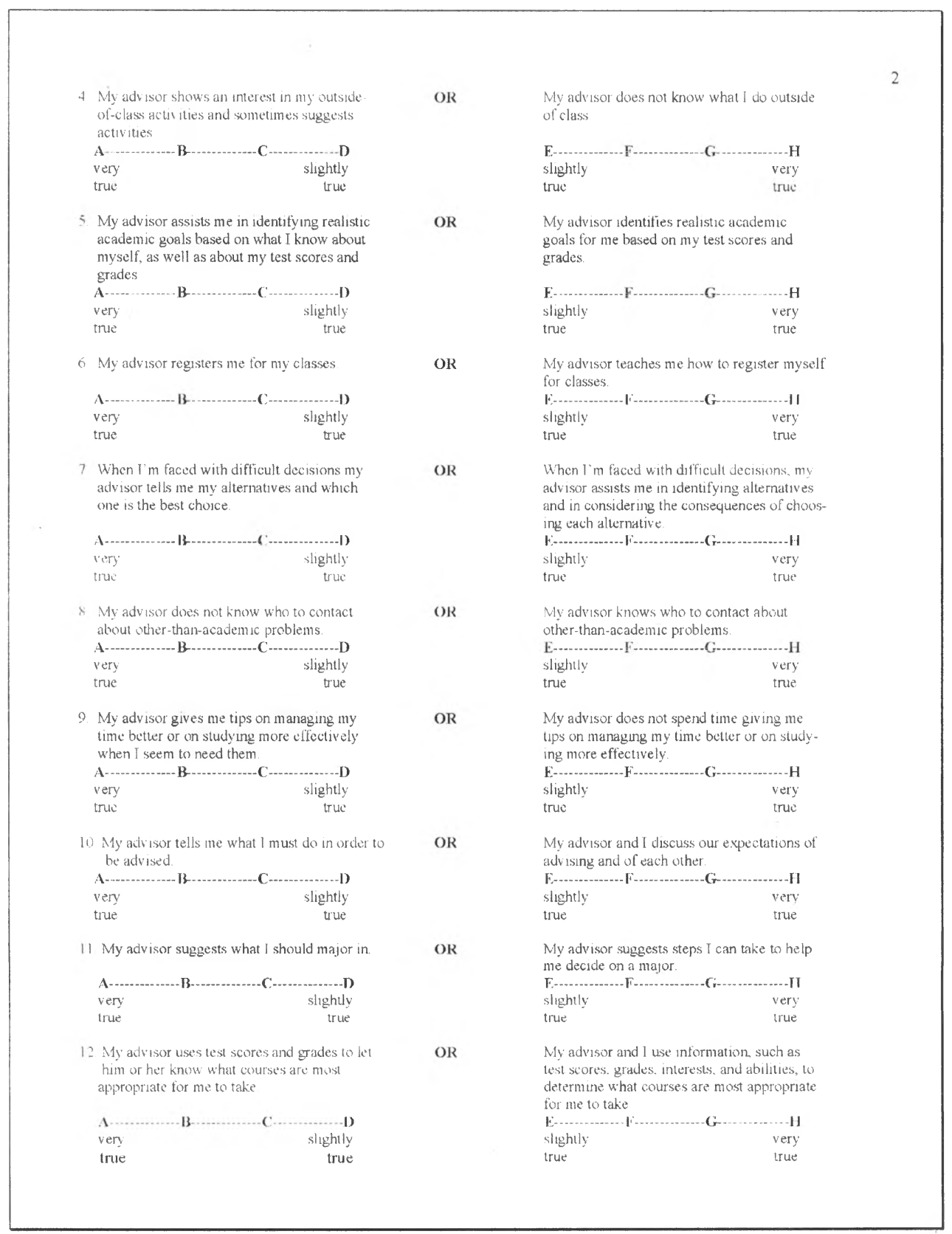


13. My advisor talks with me about my otherthan-academ ic interests and plans

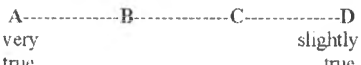

true

true

14. My advisor keeps me informed of my academic progress by examining my files and grades

only:

very

13.

$3-\ldots$

(

slightly
urue
OR

OR

My advisor does not talk with me about
interests and plans other than academic
ones
E-
slightly
true

true

true

My advisor keeps unformed of my academic progress by examining my files and grades and by talking to me about my classes E-a.t. G

PART II

Directions-Consider the following activities that often take place during academic advising. During this academic year, how many times have you been involved in each activity'? Use the code below to respond to questions $15-44$ on the separate answer sheet.
$A=$ None $(0$ times)
( $=2$ times
$\mathrm{D}=3$ times
$\mathrm{E}=4$ times
$\mathrm{F}=\mathbf{5}$ or more times

How lirequently have you and your advisor spent time.
15 Liscussing college policies
16. Signing registration forms
17 Lroppung and or adding course(s)
18. Discussing personal values 19. Discussing possible majors/academic con-
centrations
20) Discussing umportant social or polltical issues
21 Discussing content of courses
22 Selectung course's for the next term
23 Planning a class schedule for the next tern
24 Discussing transfer credit and policles
25 Discussing advanced placement or exempting courses
26 Discussing career altematives
27 Discussing probation and dismissal policies
28 Discussing financial and
29. Identify ing other campus offices that can provide dassistance
30 Discussing study skills or study tips 
PART III

Considering the academic advising you have participated in at this coilege this year. respond to the following five statements on the answer sheet using the code below

$$
\begin{array}{ll}
A=\text { Strongly Disagree } & C=\text { Agree } \\
B=\text { Disagree } & \text { D = Strongly Agree }
\end{array}
$$

45. I an satisfied in general with the academic advising I have recelved

46. I have received accurate information about courses, programs, and requirements through academic advising

47. Sufficient prior notice has been provided about deadlines related to institutional policies and procedures

48. Advising has been availatle when I needed it

49. Sufficient tume has been avalable during advising sessions

PART IV

Please respond to the following questions. Continue marking your responses on the same answer sheet

50. What is your sex?

$$
\text { (a) male }
$$

(b) female

51. What is your cultural/racial background?
(a) African American/3lack
c) Astan American or
(d) Native American
(e) White/Caucasian
(g) ()ther
(b) Hispanic American/Latuno/
$\begin{array}{ll}\text { f) Biracial/multiracial } & \text { (h) Decline to respond }\end{array}$

92 What was your age at your last burthday?
(a) 18 or younger
(c) 211
(c) 22
(g) 24
(1) 31 or older
(b) 19
(h) $25 \cdot 30$

(d) 21

(1)

53. What is your academic class standing"
(a) Freshman (first year)
(c) Junior (third year)
(e) IrregulariT ransient/Special Student
(b) Sophomore (second year)
(d) Senior (fourth or more years)
(f) Other than any of the above

54 Which of the following best describes the majority of the academic advising you have received this academic year"? Select only one.

(a) Advised individually by assigned advisor at an advising center

(b) Advised individually by any available advisor at an advising center

(c) Advised individually, not through an advising center

(d) Advised with a group of students

(c) Adviscel by a peer (student) adviser

(f) Advised in conjunction with a course in which i was enrolled

(g) Advised an a manner other than the altematives deseribed above

(h) Co advising recelved

54 Approxumately how much time was generally spent in each advising session?
(a) less than 15 minutes
(c) $31-45$ minutes
(e) more than 1 hour

(b) $15-30$ minutes

(d) $46-60 \mathrm{~m} \cdot \mathrm{nut}$

56. How many academic advising sessions have you had this academic year in your current situation
(a) non
(c) two
(e) four
(g) $s i x$
(i) eight

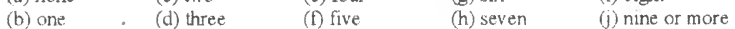

57 How many academic advising sessions in total have you had this year?
(a) non
(c) two
(e) four
(g) $\mathrm{six}$
(1) eight
(b) one
(d) three
(f) five
(h) seren
(j) nine or more 
Appendix 3: Modified Academic Advising Inventory (AAI) Instrument

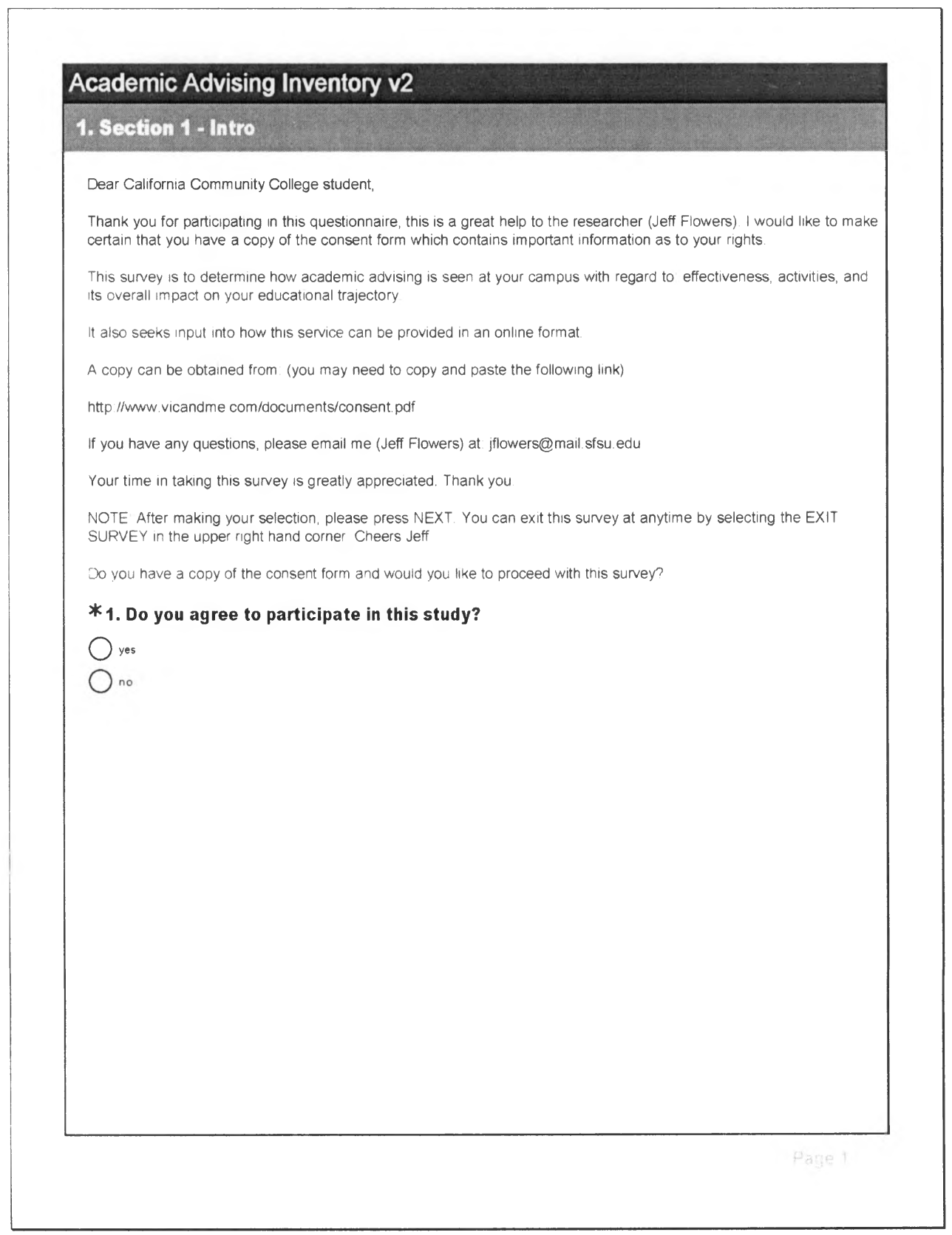


Academic Advising Inventory v2

\section{Part I}

Part I of this inventory concerns how you and your advisor approach academic advising. Even if you have had more than one advisor or have been in more than one type of advising situation, please respond to the statements in terms of your overall impression of academic advising

There are 14 statements

Please chose the statement that best describes the academic advising received. Then decide how accurate that statement is about your advising.

\section{*1. Statement 1}

Which statement best describes academic advising received?

My advisor tells me what I need to know about academic courses and programs

My advisor is interested in helping me learn now to find courses and programs for myself

*2. How accurate was statement 1 about your academic advising?

Accuracy of Statement
*3. Statement 2
Which statement best describes academic advising received?
My advisor tells me what would be the best schedule for me
My advisor suggest important considerations in planning a schedule and then gives me responsibility for the final decision.

* 4. How accurate was statement 2 about your academic advising?

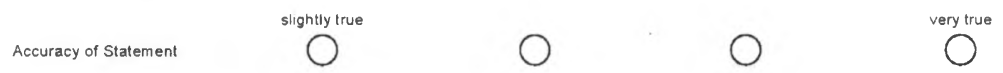

* 5. Statement 3

Which statement best describes academic advising received?

My advisor and I talk about vocational opportunities in conjunction with advising

My advisor and I do not talk about vocational opportunities in conjunction with advising

*6. How accurate statement 3 about your academic advising?

Accuracy of Statement $\bigcirc^{\text {slightly true }} \bigcirc \bigcirc$


Academic Advising Inventory v2

*7. statement 4

Which statement best describes academic advising received?

My advisor shows an interest in my outside-of-class activities and suggest activities

My advisor does not know what I do outside of class

* 8 . How accurate was statement 4 about your academic advising?

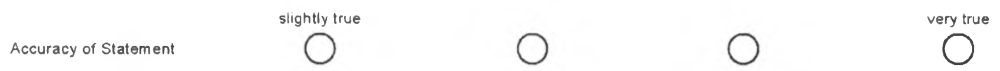

*9. Statement 5

Which statement best describes academic advising received?

My advisor assist me in identifying realistic academic goals based on what I know about myself. as well as about my test scores and grade My advisor identifies realist academic goals for me based on my test scores and grades.

*10. How accurate was statement 5 about your academic advising? sightly true

Accuracy of Statement
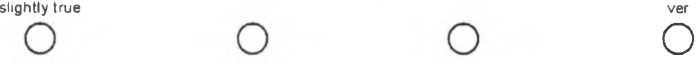

*11. Statement 6

Which statement best describes academic advising received?

My advisor registers me for my classes.

My advisor teaches me how 10 register myself in classes

* 12. How accurate was statement 6 about your academic advising?

Accuracy of Statement

0

very true

*13. Statement 7

Which statement best describes academic advising received?

When I'm faced with difficult decisions, my advisor tells me my alternatives and which one is the best choice

When I'm faced with difficult decisions. $m y$ advisor assist $m e$ in identifying alternatives and in considering the consequences of choosing each allemative

*14. How accurate was statement 7 about your academic advising?

Accuracy of Statement $\bigcirc^{\text {slightly true }}$

$\bigcirc$

$\bigcirc$ 
Academic Advising Inventory v2

*15. Statement 8

Which statement best describes academic advising received?

My advisor knows who to contact about other-than-academic problems.

My advisor does not know who to contact about other-than-academic problems

*16. How accurate was statement 8 about your academic advising?

Accuracy of Statement $\quad 0 \quad 0 \quad 0$

*17. Statement 9

Which statement best describes academic advising received?

My advisor gives me tips on managing my time better or on studying more effectively when I seem to need them.

My advisor does not spend time giving me tips on managing my time better or studying more effectively.

*18. How accurate was statement 9 about your academic advising?

Accuracy of Statement slightly true

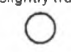

0

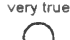

*19. Statement 10

Which statement best describes academic advising received?

My advisor tells me what I must do in order to be advised

My advisor and I discuss our expectations of advising and each other

*20. How accurate was statement 10 about your academic advising?

Accuracy of Statement slightly true

*21. Statement 11

Which statement best describes academic advising received?

My advisor suggest steps I can take to help decide my major

My advisor suggest what I should major in.

*22. How accurate was statement 11 about your academic advising?

Accuracy of Statement slightly true

O

0 
Academic Advising Inventory v2

*23. Statement 12

Which statement best describes academic advising received?

My advisor uses test scores and grades to let him or her know what courses are most appropriate for me to take.

My advisor and i use information, such as test scores, grades, interest. and abilities, to determine what courses are most appropriate for me to take.

*24. How accurate was statement 12 about your academic advising?

Accuracy of Statement $\quad O^{\text {sightly true }}$

*25. Statement 13

Which statement best describes academic advising received?

My advisor talks with me about my other-than-academic interest and plans.

My advisor does not talk with me about my interest and plans other than academic ones

*26. How accurate was statement 13 about your academic advising?

Accuracy of Statement

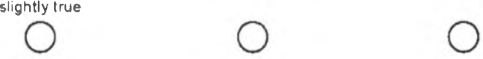

very true

*27. Statement 14

Which statement best describes academic advising received?

My advisor keeps me informed of $m y$ academic progress by examining my files and grades and by talking to me about my classes

My advisors keeps me informed of my academic progress by examining my files and grades only

*28. How accurate was statement 14 about your academic advising?

Accuracy of Statement slightly true

O

$\bigcirc$

O 
Academic Advising Inventory v2

3. Part III

Consider the academic advising you have participated in college. Please respond to the following five statements

*1. I am satisfied in general with the academic advising I have received.

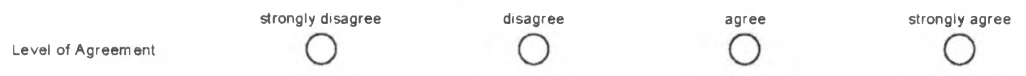

*2. I have received accurate information about the courses, programs, and requirements through academic advising
Level of Agreement
strongly disagree
$\bigcirc^{\text {disagree }}$
$\bigcirc^{\text {agree }}$
strongly agree

*3. Sufficient prior notice has been provided about deadlines related to institutional policies and procedures

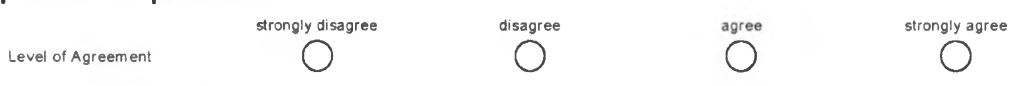

*4. Advising has been available when I needed it.

*evel of Agreement




\section{Academic Advising Inventory v2}

4. Domographic Information

Please respond to the following questions

1. What is your gender?

male

female

Other (please specify)

\section{What is your Ethnicity?}

African American

American Indian/Alaskan Native

$\mathrm{OAsian}$

Filipino

Hispanic

$\bigcirc$ Pactifi Istandes

$\bigcirc$ mite

Otner (please specify)

3. What was your age at your last birthday?
19 or Less
201024
251029
301034
351039
401049
${ }^{50+}$ 


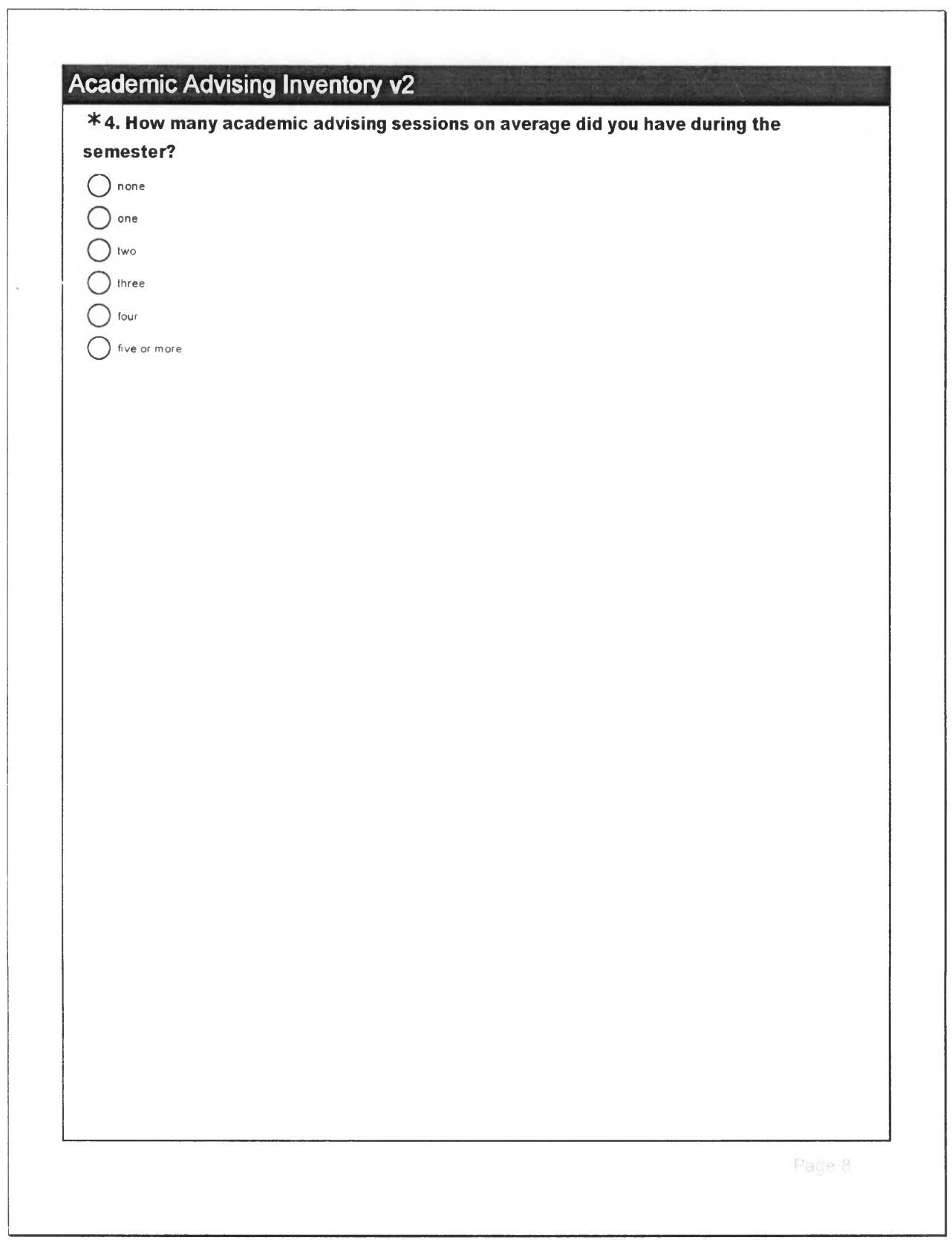


Academic Advising Inventory v2

5. Academic History

The Last Section - Please Answer the Following

1. Did you have a specific educational goal when you first came to college?

Yes

No

Other (please specify)

2. Do you believe academic advising has helped in educational goal creation/modification?

Ores

No

Other (please specify)

3. How would you characterize yourself.

Transfer Student

vocational Student

Lifetime Learner

Other (please specify)

4. If you would be interested in participating further, interviews and the like, please provide your email. This won't be shared and would help me out greatly. Thanks for considering. You DO NOT need to though, you can skip this one. 


\section{Academic Advising Inventory v2}

6. Thank Youl

THANK YOU for taking this survey first developed by

Roger B. Winston, Jr. and Janet A. Sandor

Modified for use by Jeff Flowers at

San Francisco State University

Your participation has been greatly appreciatedl 


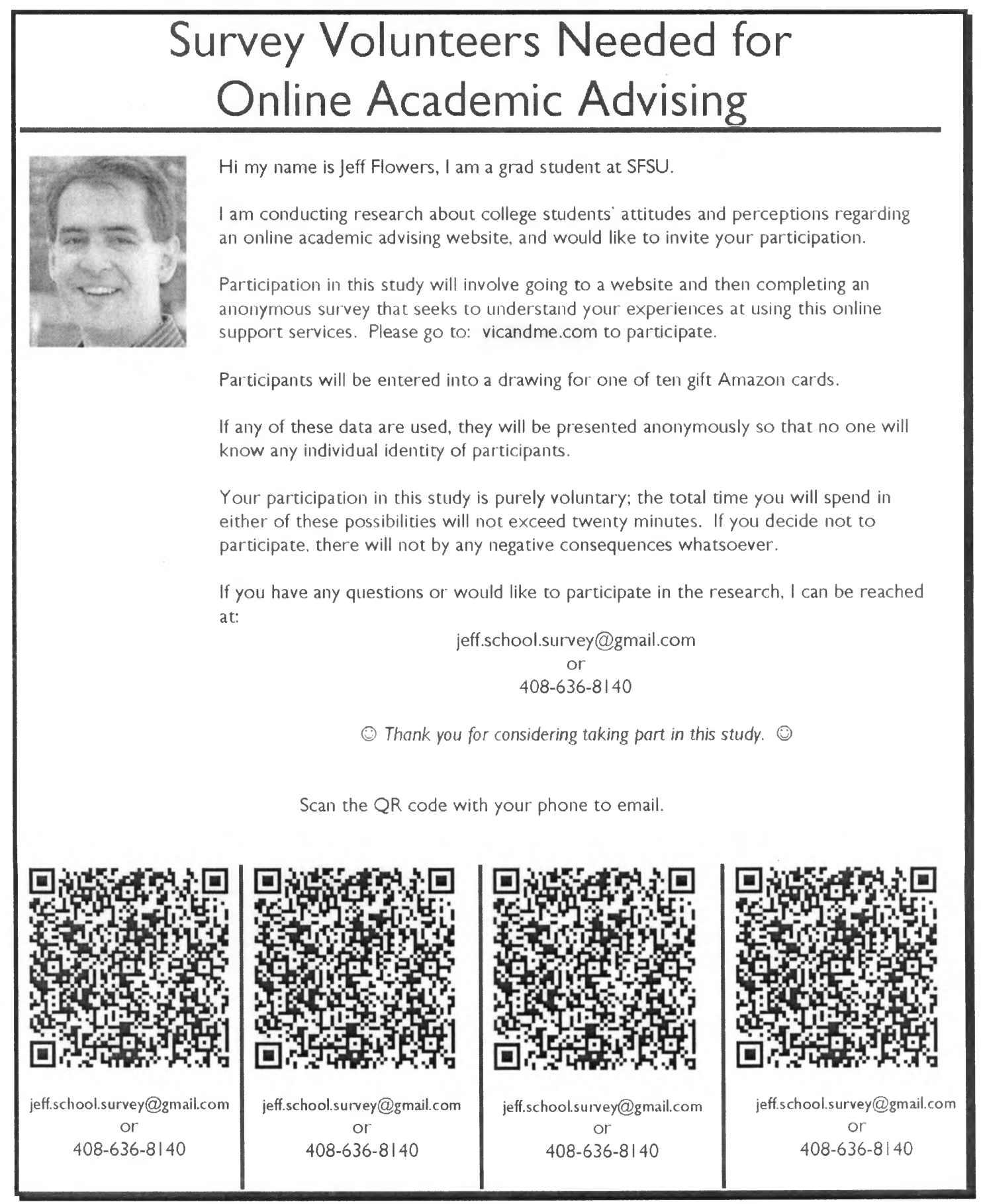


Appendix 5: IRB Approval Letter

\section{Human Protections Protocol Exemption}

11 messages

protocol@sfsu edu <protocol@sfsu.edu>

To: Jefferson L Flowers <jflowers@mail.sfsu.edu>

Tue, Feb 1, 2011 at 2:49 PM

Cc: JAMAL COOKS <jcooks@sfsu.edu>, Robert S Gabriner <gabriner@sfsu.edu>

$2 / 1 / 11$

Determ ination: Exemption from Hum an Protections Review

Dear Jefferson Flowers

ORSP - Human and Anımal Subjects has determined that your protocol, "A Study in the Scope and Role of Online Academic Advising". Is "Exempt" from regulatory oversight and does not need further ORSP-HAP review. Ple ase note that your protocol will not expire, but any future changes to your reseanch may requre review

Faculty advisors and reseanchers are responsible for ensuring that all publicly viewable documents are clear of grammar, spelling, readability and formatting errors

If you change your research or have ary questions, please contact us

Sylvie Kim

Human and Animal Protections

San Francisco State University

1600 Holloway Avenue

Physical Address 452 Administration Building

Malling Address: 250 Admunistration Building

Phone 415338109

Fax: $\frac{415.405 .2474}{10}$

Email biotacoliostsuedu

hitto /he search sfisu eduiprotocolis 
Appendix 6: Virtual Intelligent Counselor (VIC)

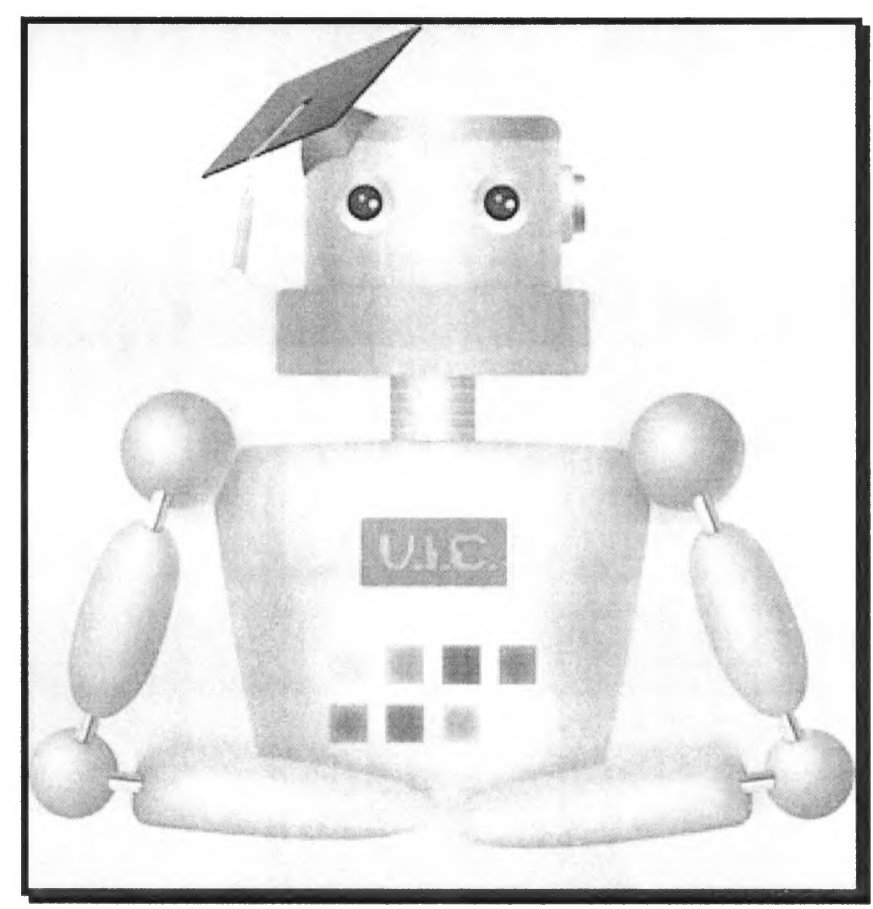


Appendix 7: Design Choices of VIC

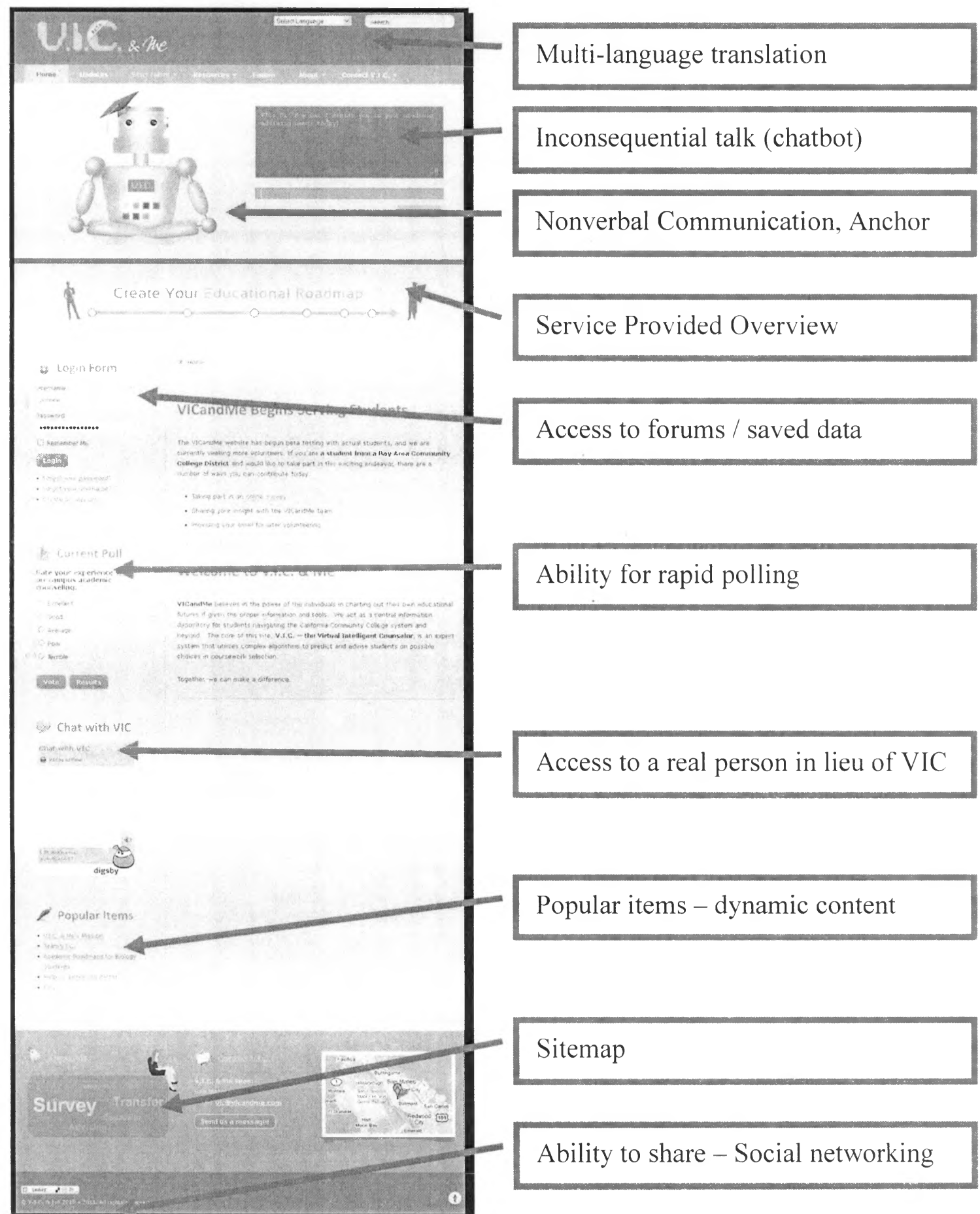


Appendix 8: Detailed Explanation of Design Choices for VIC

\begin{tabular}{|c|c|}
\hline Component & Supplemental Explanation \\
\hline Language Translation Module & $\begin{array}{l}\text { It was determined that the ability to have the site } \\
\text { dynamically translated in a dozen languages would } \\
\text { permit the widest possible audience to interface. }\end{array}$ \\
\hline Chatbot & $\begin{array}{l}\text { A natural language algorithm provides a space for } \\
\text { visitors to feel that they are being heard at all times. }\end{array}$ \\
\hline VIC & $\begin{array}{l}\text { A friendly face with which to build a level of trust } \\
\text { and begin a collaborative experience. }\end{array}$ \\
\hline "Create Your Educational Roadmap" & $\begin{array}{l}\text { A graphical representation of what the site hopes to } \\
\text { accomplish through a goals generation engine and } \\
\text { the resulting educational roadmaps that are } \\
\text { delivered. }\end{array}$ \\
\hline Login Functionality & $\begin{array}{l}\text { The ability to save data in the future and to have } \\
\text { access to real time forums. }\end{array}$ \\
\hline Survey Module & $\begin{array}{l}\text { The ability for rapid, low burden polling. These } \\
\text { would be used to create an ever expanding dataset } \\
\text { that could then be mined later. }\end{array}$ \\
\hline Chat Module & $\begin{array}{l}\text { The ability to interact with an actual human, if the } \\
\text { user did not wish to chat directly to VIC (i.e. the } \\
\text { Chatbot engine). }\end{array}$ \\
\hline Popular Items & $\begin{array}{l}\text { A dynamically created container of the most popular } \\
\text { items accessed by others. Allows for the most used } \\
\text { information by the community to bubble up. }\end{array}$ \\
\hline Sitemap & Navigation of the site. \\
\hline Social Networking Tools & $\begin{array}{l}\text { Ability to have this site promoted to the most } \\
\text { popular social networking sites. }\end{array}$ \\
\hline
\end{tabular}


Appendix 9: Select Demographics of Student Research Assistants Student Research Assistant Profiles

\begin{tabular}{llll}
\hline Name & Gender & Ethnicity & Notes \\
Fred & Male & Latino & $\begin{array}{l}\text { Newly arrived, first in family to go to college, } \\
\text { undocumented status }\end{array}$ \\
Liz & Female & Latina & Newly arrived \\
Al & Male & Latino & Newly arrived, first in family to go to college \\
\hline
\end{tabular}


Appendix 10: Document Control and Worksheets Used to Generate Roadmaps

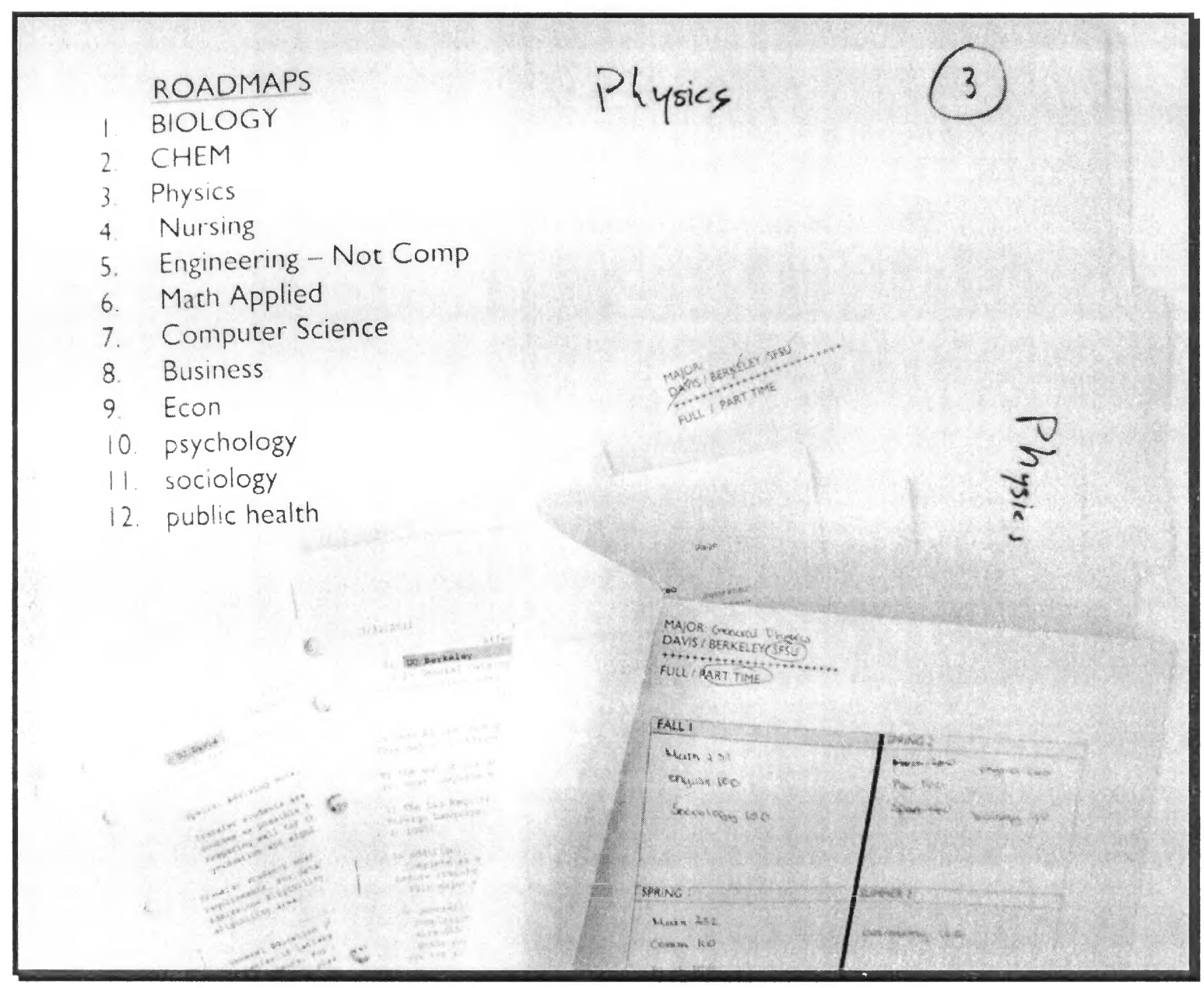


Appendix 11: Protocol Used for Roadmap Generation

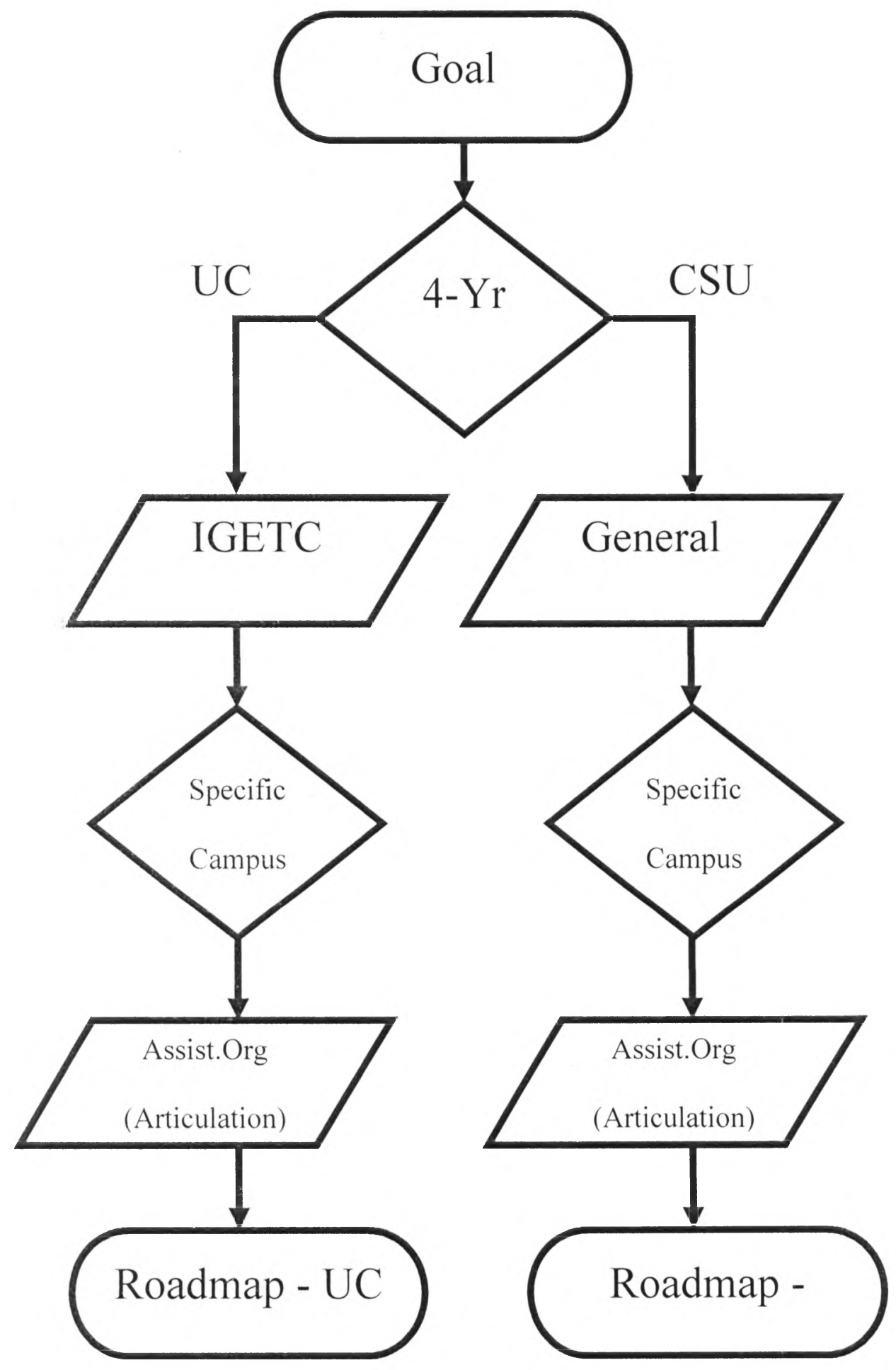


Appendix 12: Rapid Scanning System to Encode Peninsula College Course Catalogue

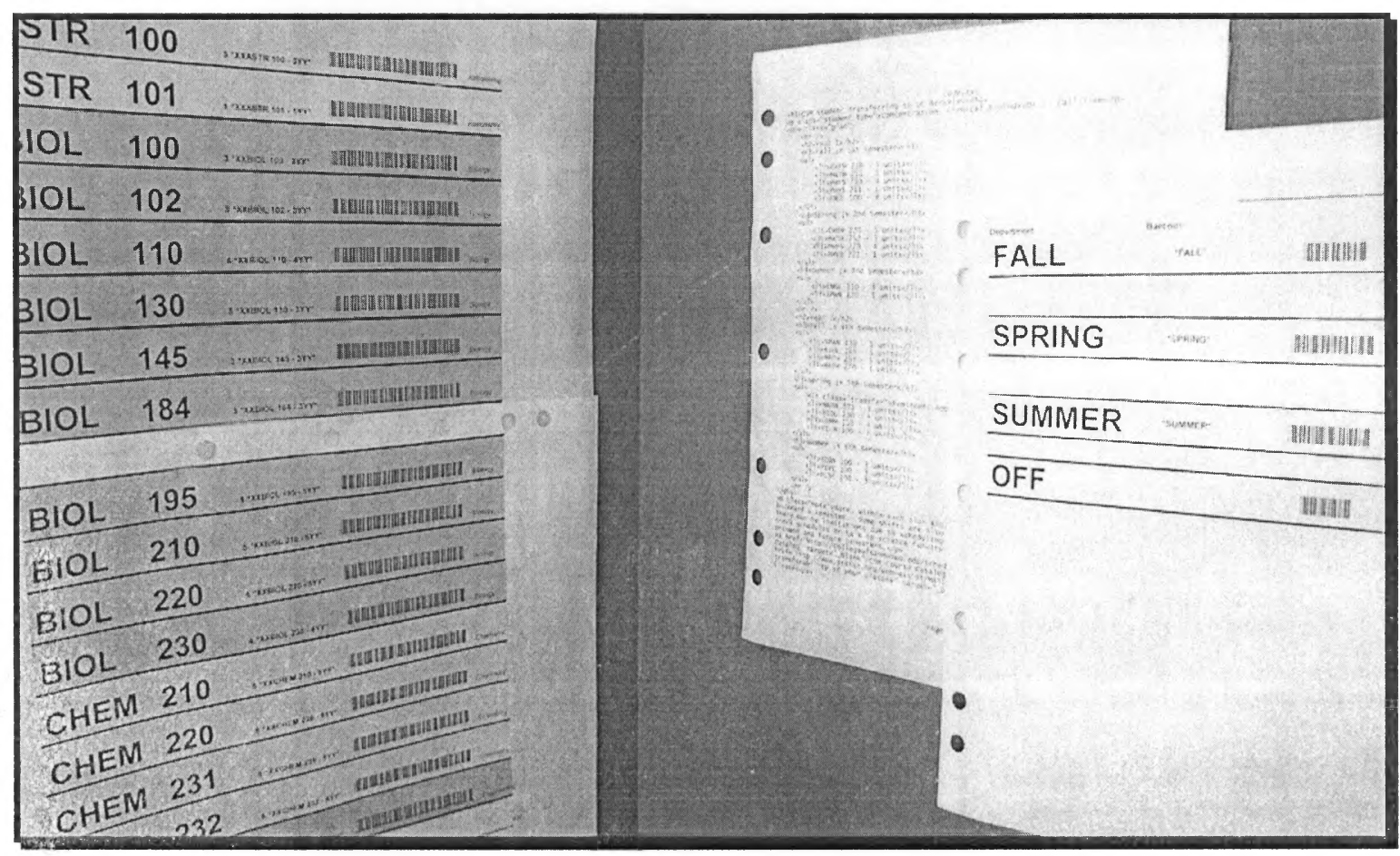


Appendix 13: Entering Data into VIC

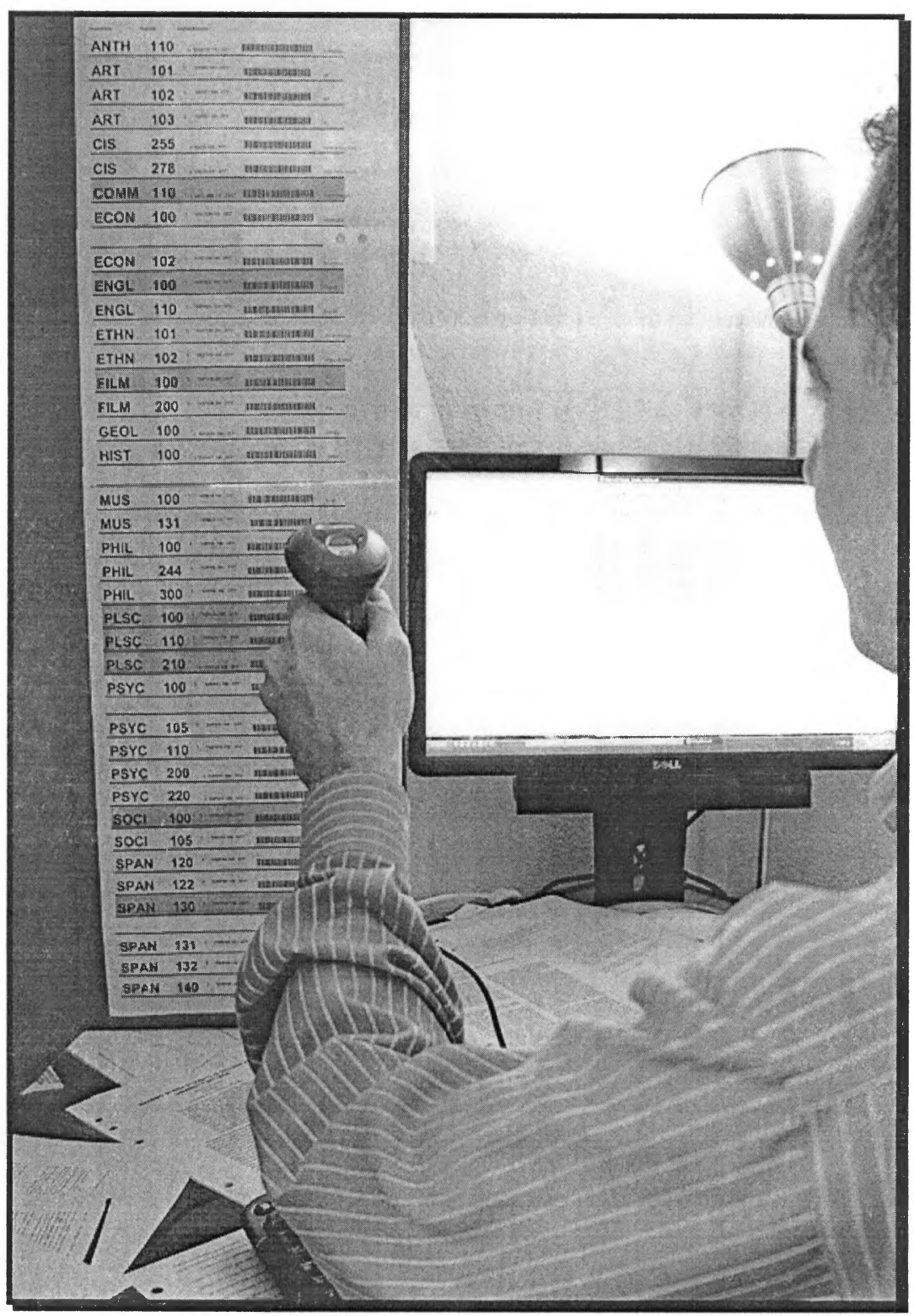


Appendix 14: Flowchart of Intended Use of VIC Roadmaps Towards a SEP

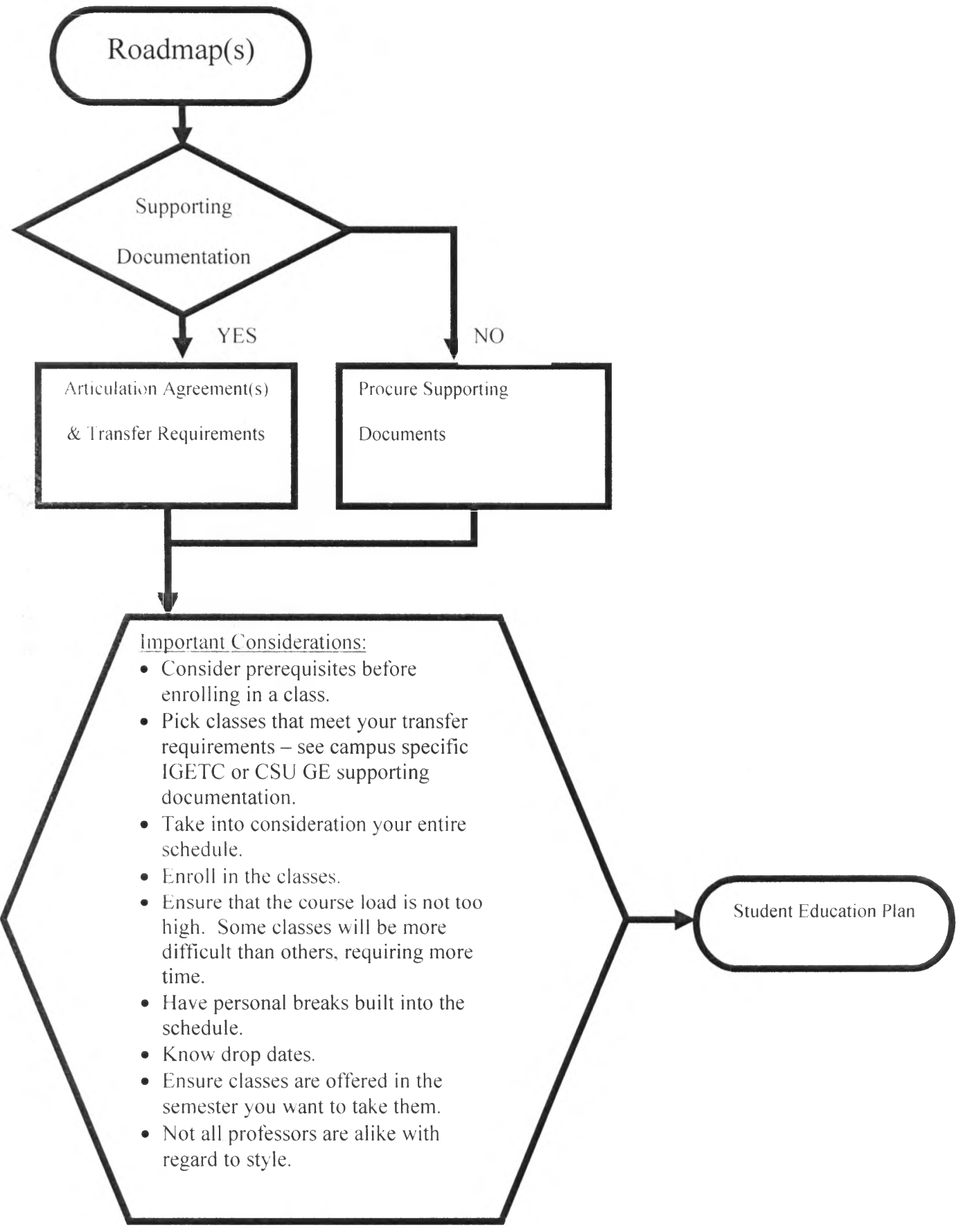


Appendix 15: Example Structure of a User Initiated Roadmap

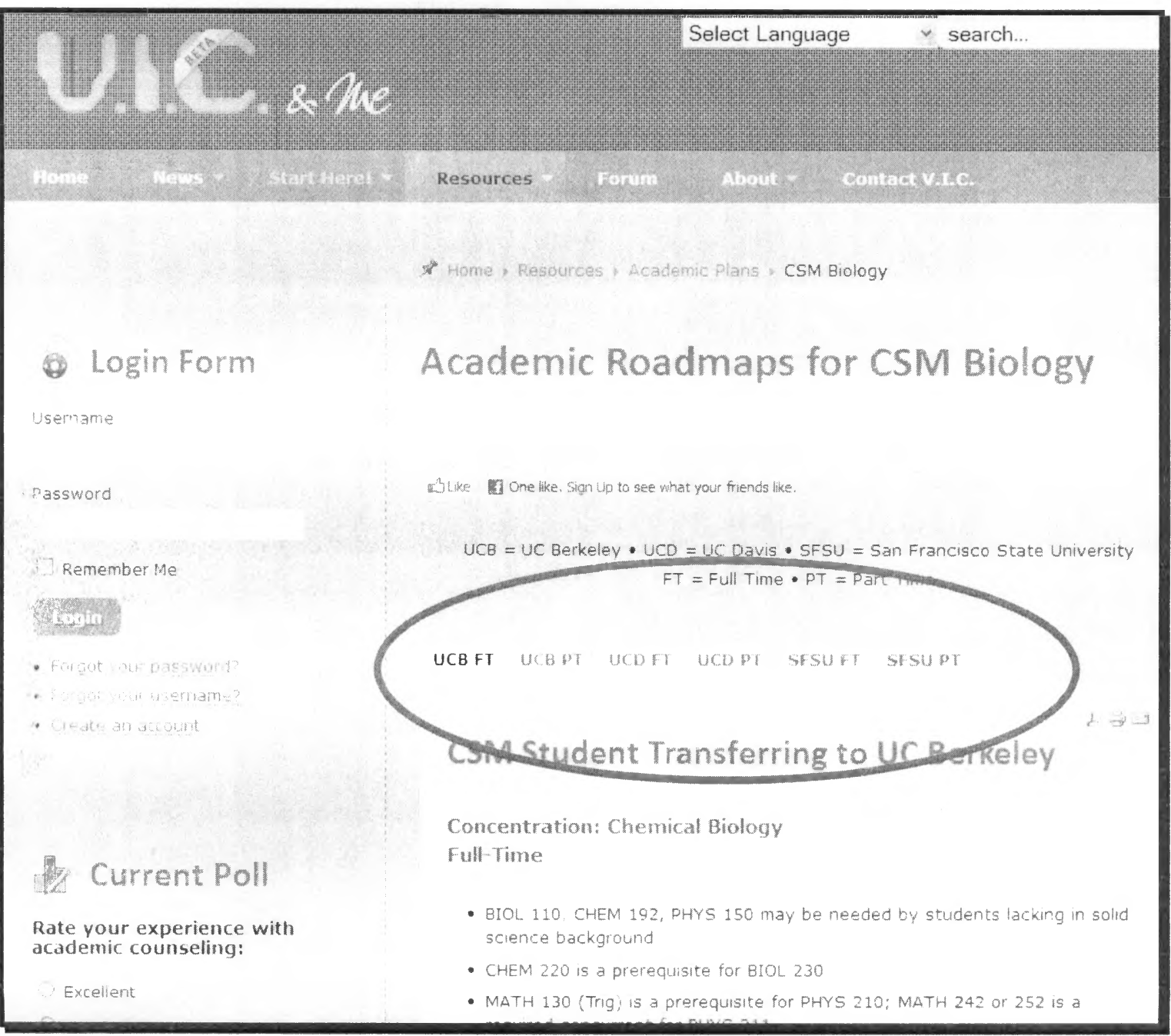


Appendix 16: Example of a User Initiated Roadmap

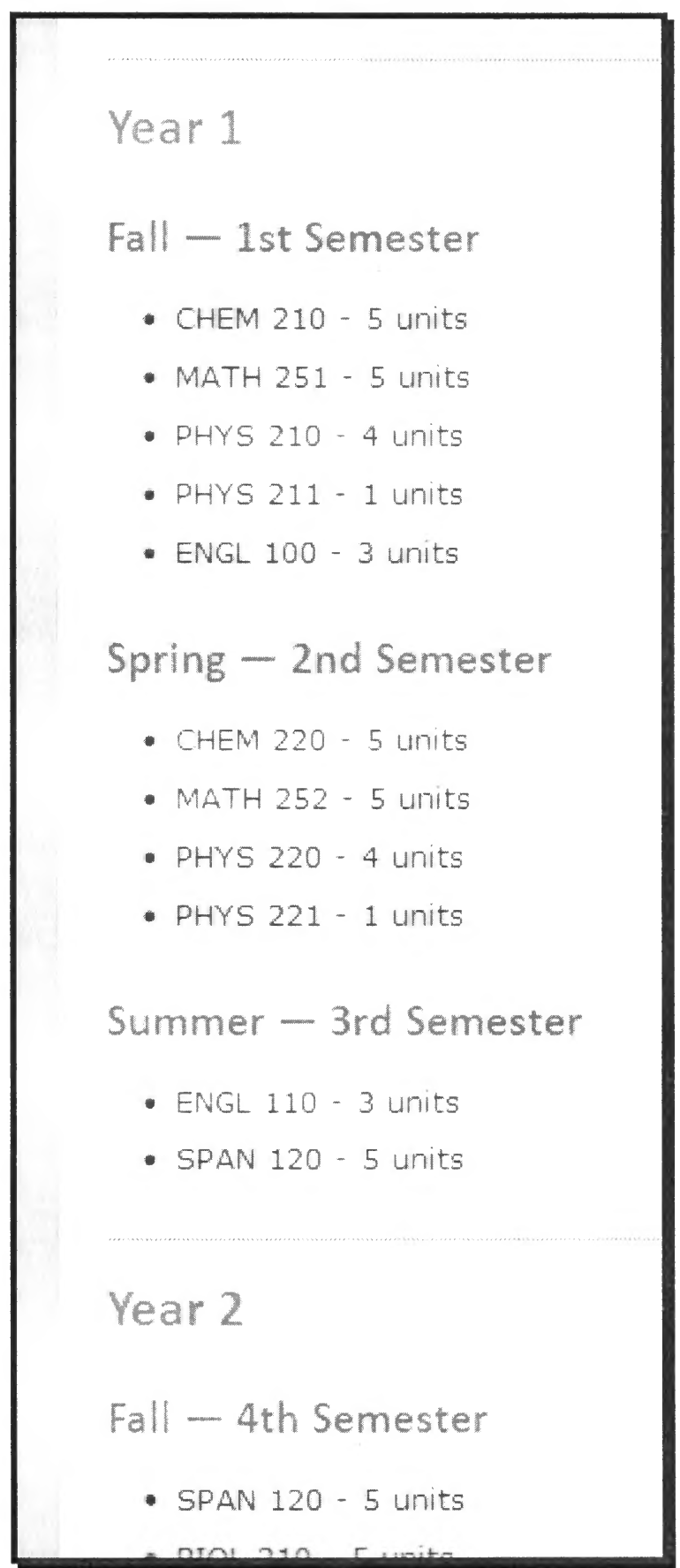


Appendix 17: Interview Guide I, Goals Interview

\author{
Interview I - Interview Guide
}

Goal: To learn how the interaction with vicandme, specifically the goals generation engine, differed from traditional advising experiences.

I. Did you have a set educational goal when you started your studies at college?

a. What was your process in developing this plan?

b. Are there trusted individuals to help you?

c. How firm do you believe your goal(s) is(are) to you?

2. Was the choice of this goal(s) based in some measure around your future aspirations? (as in a career choice)

a. Why?

b. How much do you know about this(these) particular career(s)?

c. Where did you obtain your information regarding this(these) career(s)?

3. What are your prior experiences around academic advising?

a. Do you believe that this service is best encapsulated within a set flowchart or

b. Do you believe that these types of decisions are best developed through the mutual dialogue between yourself and others?

4. Regarding your use of vicandme specifically, what did you think about this experience?

a. How did this experience differ from prior advising experiences?

b. Do you believe that the goal crafted during this experience was a product of co-development between yourself and the program?

5. Regarding the educational roadmaps provided, what is the perceived value of this plan to you? (Explain) 
Appendix 18: Interview Guide, VIC Specific Interview

Interview 2 - Interview Guide

Goal: To learn the extent that the model educational roadmaps had on the crafting of their student educational plan.

1. Did you use vicandme after the last interview?

a. If so, what can you say about that new experience?

b. Did you think that further exploration would be useful?

2. With regard to the educational roadmaps that were created through the use of vicandme, what can you say about

a. The ability to be understood by you - were they in a format that was readily accessible?

b. Did you think that they looked right regarding content contained within?

c. Did you have a trusted individual look over them for content?

3. Advising experiences afterwards:

a. Did you see an academic advisor any time afterwards?

i. Did you using the site prompt an interest to see this person?

ii. Was a SEP developed?

b. Was the roadmap brought into this experience?

i. Was it used as a starting point in your conversation with this person?

ii. Was it your perception that by having this roadmap alter this visit in any way?

4. Regarding a SEP:

a. Do you think that the roadmap helped with the creation of a matriculation plan?

b. Does having this planning tool make your goal more concrete for you? 


\title{
Appendix 19: Informed Consent Form
}

\author{
San Francisco State University \\ Informed Consent to Participate in a Research Study \\ "TITLE: Scope and Role of Online Academic Advising"
}

A. PURPOSE AND BACKGROUND

The purpose of this research study is to engage in an exploracory manner the scope and role of online instruments to provide academic advising services to community college students.

The researcher. Jeff Flowers, is a current graduate student in the Educational Leadership Program at San Francisco State University and will be the individual conducting this research.

You are being asked to participate in this study because you are a community college student.

\section{B. PROCEDURES}

If you agree to participate in this research scudy, the following will occur.

- You will be asked to complete an anonymous questionnaire regarding your attitudes and perceptions around academic advising

services. The estimated time for completing the questionnaire will be thirty minutes.

- You will allow to be observed during times in which you are procuring academic advising services. either in person or online.

- You will be asked to use an online academic advising services website and will be asked to provide feedback as to the usefulness of this website.

C. RISKS

There is a risk of loss of privacy. However. no names or identities will be used in any published reports of the research. Only the researcher will have access to the research data. Any names or identifying information of individual participants will be changed or omitred in the stt: dy.

D. CONFIDENTIALITY

The research data will be kept in a secure location, and only the researchers will have access to the data. For any student products used in the study, all identifying information will be removed and the data will be kept in a locked cabinet or office. At the conclusion of the study questionnaire data will be stored for one year following the completion of the study then destroyed.

E. DIRECT BENEFITS

There will be ro direct benefits to the participant.

r. COSTS

There will be no cost to you for participating in this research.

G. COMPENSATION

There will be no compensation for participating in this research.

H. ALTERNATIVES

The alternative is not to participate in the research.

I. QUESTIONS

You have spoken with che researcher about this study and have had your questions answered. If you have furcher questions about the study. you may contact the researcher (Jeff Flowers) by email at jflowers@mail.sfsu.edu or you may contact the researcher's thesis advisor, Dr.

Cooks. His email is: jcooks@sfsu.ed

Questions abouc your rights as a study participant. or comments or complaints about the study, may also be addressed to the Offlce for the Protection of Himar Subiects ac 415.338.1093 or protocol@sfsu.edu

J. CONSENT

You tave been given a copy of this consent form to keep

PARTICIPATION IN THIS RESEARCH IF VOLUNTARY. You are free to decline to participare in this research study, or to withdraw your parricipation at any point without penalty. Your decision whether or not to participate in this research will have no influence on your present or gure stawis ac San Francisco State University.

Signature

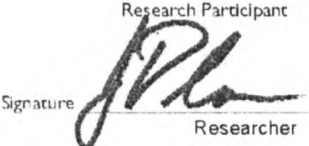

Date:

Date. Feb 282011 